\title{
Descoberta De Regras DE ClassificAÇÃo COM
}

Hierarquias Conceituais

Marco Eugênio Madeira Di Beneditto

Instituto de Matemática e Estatística

da

Universidade de São Paulo

como parte dos requisitos para a

obtenção do grau de

Mestre em Ciência da Computação

Área de Concentração: Inteligência Artificial Orientadora: Prof. Dr. Leliane Nunes de Barros

Universidade de São Paulo - São Paulo - SP 


\section{DESCOBERTA DE REgRAS \\ DE Classificação \\ $\mathrm{COM}$}

Hierarquias Conceituais

Este exemplar corresponde à redação final
da dissertação de Mestrado devidamente
corrigida e defendida por
Marco Eugênio Madeira Di Beneditto
e aprovada pela comissão julgadora.

São Paulo, 3 de fevereiro de 2004.

Banca examinadora:

- Profa. Dra. Leliane Nunes de Barros (Orientadora) - IME-USP

- Prof. Dr. Roberto Marcondes Cesar Junior - IME-USP

- Profa. Dra. Maria Carolina Monard - ICMC-USP 


\section{Agradecimentos}

À Profa. Leliane Nunes de Barros, pela confiança, dedicação e paciência com que me orientou no desenvolvimento deste trabalho.

Aos Profs. João Eduardo Ferreira e Roberto Marcondes Cesar Junior pelas sugestões apresentadas durante a qualificação e discussões nos seminários.

Ao CMG (EN) Ilson Soares, Diretor do Centro de Coordenação de Estudos da Marinha em São Paulo, e todos os demais oficiais e guarnição deste Centro, pelo apoio e convivência:

Ao colega de turma Waldyr Benits, pela constante troca de informações e ajuda mútua durante todo o período que estive no IME-USP.

Aos meus pais e irmã, pelo incentivo e preocupação.

À minha esposa Elizabeth, com apreço e consideração, pelo constante incentivo, apoio e sobretudo paciência nestes 23 meses de estudos em São Paulo. 


\section{Resumo}

A descoberta de conhecimento em bancos de dados (KDD - Knowledge Discovery in Databases) é um tópico de pesquisa que envolve diversas áreas de interesse como Reconhecimento de Padrões, Aprendizado de Máquina, Bancos de Dados e Inteligência Artificial. $K D D$ é definida como um processo não trivial de identificação de padrões válidos, novos, potencialmente úteis e compreensíveis incluídos nos dados.

$\mathrm{Na}$ mineração de dados, uma das etapas do processo de $K D D$, o uso de hierarquias de conceitos pode permitir a descoberta de conhecimento num nível de abstração mais elevado, compacto e muitas vezes mais interessante. A mineração de dados em múltiplos níveis conceituais é mais complexa do que a mineração num único nível, pois o espaço de busca é geralmente maior. Alguns trabalhos empregam a pré-generalização dos dados como forma de reduzir este espaço, dificultando a descoberta em níveis de abstração arbitrários. No entanto, para descobrir regras em diferentes níveis de generalidade de maneira eficiente, sem pré-generalizar os dados, é necessário um acesso rápido às hierarquias bem como métodos de avaliação de consultas velozes.

Nesta dissertação, é apresentado o sistema NETUNO-HC que realiza a indução de regras de classificação em diferentes níveis de generalidade, através do uso de hierarquias de conceitos. sobre os valores dos atributos de um banco de dados, sejam eles numéricos ou categóricos. É mostrado como o nível de generalidade das regras descobertas é afetado pela estratégia de busca empregada e pela variação das medidas de relevância. Além disso, como é demonstrado através de uma série de experimentos, o sistema NETUNO-HC implementa técnicas que resultam num aumento de eficiência significativo, a saber: (i) uso de uma primitiva em SQL para efetuar as consultas ao banco de dados; (ii) codificação numérica da hierarquia conceitual; (iii) estratégia de Busca em Feixe (Beam Search); (iv) codificação e indexação das regras descobertas numa tabela hash. 


\section{Abstract}

Knowledge Discovery in Databases $(K D D)$ is a research area that merges different areas like Pattern Recognition, Machine Learning, Databases and Artificial Intelligence. $K D D$ is the non-trivial process of identifying valid, novel, potentially useful, and ultimately understandable patterns in data.

In data mining, a step of the $K D D$ process, the use of background knowledge can allow express the knowledge discovered in a higher abstraction level, more concise and usually more interesting. The data mining for high level concepts is more complex because the search space is generally bigger. Some data mining systems require that databases be pre-generalized to reduce the space, what makes difficult the discovery at arbitrary levels of abstraction. To efficiently induce high-level rules at varying levels of generality, without pre-generalizing databases, fast access to concept hierarchies and fast query evaluation methods are needed.

In this work, it will be presented the NETUNO-HC system that performs induction of classification rules at different conceptual levels, using concept hierarchies for the atributes values of a database. It is showed how the abstraction level of the discovered rules is affected by the search strategy and by the relevance measures. Moreover, as it is demonstrated by a series of experiments, the NETUNO-HC system uses techniques that improves the efficiency of the data mining process: (i) a SQL primitive to execute the databases queries; (ii) the numerical encoding of the concept hierarchy; (iii) the Beam Searh strategy, and (iv) the indexing and encoding of the discovered rules in a hash table. 


\section{Sumário}

\section{Lista de Figuras}

\section{Lista de Tabelas}

1 Introdução $\quad$ p. 17

1.1 Descoberta de Conhecimento em Bancos de Dados: uma visão geral . . . . p. 17

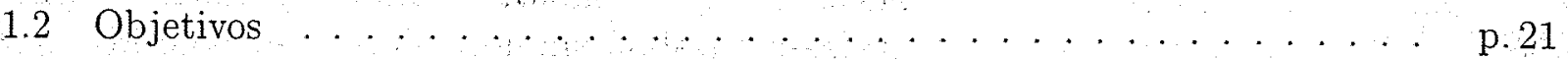

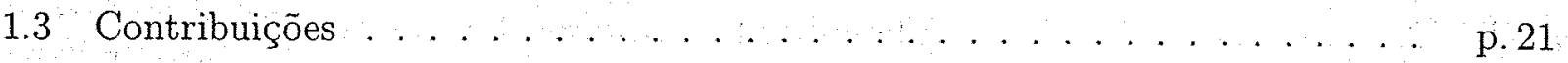

2 Fundamentos e trabalhos correlatos p. 23

2.1 Padrões descobertos em bancos de dados . . . . . . . . . . . p. 24

2.2 Hierarquia de conceitos . . . . . . . . . . . p. 26

2.2.1 Representação e armazenamento de hierarquias de conceitos . . . . p. 29

2.2.2 Codificação de hierarquias conceituais . . . . . . . . . p. 30

2.3 Regras de classificação . . . . . . . . . . . . . . . . . . p. 33

2.4 Medidas de relevância . . . . . . . . . . . . . . . . p. 36

2.4.1 Cálculo de medidas de relevância num BD . . . . . . . . . . p. 37

2.5 Definição do problema de descoberta de regras de classificação . . . . . . . p.39

2.5.1 Espaço de busca. . . . . . . . . . . . . . . . . p. 40

2.5.2 Geração das regras de classificação e suas propriedades . . . . . . p. 42

2.5 .3 Algoritmos de busca . . . . . . . . . . . . . . p. 45 
2.5.4 Geração de nós sucessores com o uso de hierarquias conceituais . . . p. 48

2.6 Realização de testes . . . . . . . . . . . . . . . . . . . . p. 49

2.7 Critérios de avaliação de regras de classificação . . . . . . . . . . . . p. 51

2.8 Trabalhos correlatos . . . . . . . . . . . . . . . p. . 51

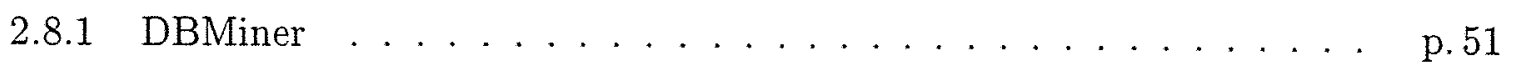

2.8.2 Algoritmo ParDRI . . . . . . . . . . . . . . . p. 52

2.8.2.1 Tabela de co-ocorrências . . . . . . . . . . . p. 52

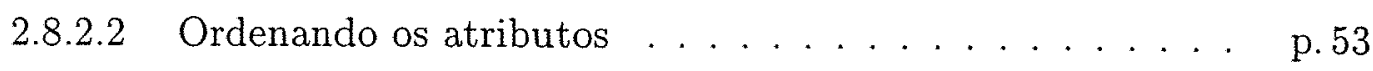

2.8.2.3 Cache dos resultados de pesquisa e dos valores de atributos

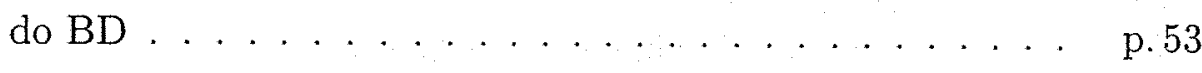

2.8 .3 Sistema CUPID . . . . . . . . . . . . . p. 54

2.8.4 Algoritmo BFMP-RL - Breadth-First Marker Propagation - Rule Le-

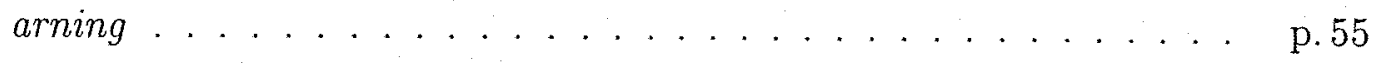

2.8 .5 Algoritmo AQ . . . . . . . . . . . . . . 55

3 O Algoritmo NETUNO P. p 57

3.1 Parâmetros da mineração . . . . . . . . . . . . . . . . p. 57

3.2 Especificação do algoritmo NETUNO $\ldots \ldots \ldots \ldots$ p. . . . . . . . . . . . . .

3.2.1 Critério de ordenação das hipóteses de regra . . . . . . . . . . p. 61

3.2.2 Redução do conjunto de regras descobertas . . . . . . . . . . . . p. 61

3.3 Estruturas de dados . . . . . . . . . . . . . . p. 62

3.4 Especializando hipóteses . . . . . . . . . . . . . . . p. 64

3.4.1 Especialização na hierarquia . . . . . . . . . . . . p. 64

3.4 .2 Geração de uma hipótese de regra . . . . . . . . . . . . . p. 65

3.4 .3 Inclusão entre regras . . . . . . . . . . . . . p. 66 
3.5 Cálculo das medidas de relevância $\ldots \ldots \ldots \ldots \ldots$ p.67 . . . . . . .

3.5.1 Primitiva de contagem para consultas em alto nível ao $\mathrm{BD} \ldots \ldots$ p. 68

3.5.2 Cálculo das medidas de alto nível ............ p. 70

3.6 Codificação de regras e hierarquias . . . . . . . . . . . p. . 71

3.6.1 Algoritmo de codificação de hierarquias . . . . . . . . . . . p.71

3.6 .2 Descrição do algoritmo . . . . . . . . . . . . . . p. 72

3.7 Uso de atributos com domínio de valores contínuo . . . . . . . . . p.74

3.8 Conjunto de teste . . . . . . . . . . . . . . . . . . . . . . .

3.9 Classificando um novo exemplo . . . . . . . . . . . . . p.75

3.10 Características funcionais . . . . . . . . . . . . . 77

4 Experimentos com o Algoritmo p. 79

4.1 Bancos de dados utilizados . . . . . . . . . . . . . p. 80

4.2 Experimentos preliminares . . . . . . . . . . . . . . . p. 81

4.2 .1 Eficiência nas consultas a $\mathrm{BD} \ldots \ldots \ldots \ldots$ p. . . . . . . . . . . .

4.2.2 Estratégia de busca: Eficiência da Busca em Feixe . . . . . . . p. p. 82

4.2 .3 Seleção de atributos . . . . . . . . . . . . . . p. 84

4.3 Experimentos sobre o uso de hierarquias conceituais . . . . . . . p. 84

4.3 .1 Taxa de acerto ...................... p. 85

4.3.2 Efeito da variação da largura do feixe na taxa de acerto e no número de exemplos não classificados . . . . . . . . . . . p. 87

4.3 .3 Complexidade do conjunto de regras $\ldots \ldots \ldots \ldots$ p. 89

4.3.3.1 Tamanho médio das regras descobertas . . . . . . . . p. 91

4.3.3.2 Valores de alto nível nas regras . . . . . . . . . p. 91

4.3 .4 Seleção de atributos . . . . . . . . . . . . . . p. 92 
4.3.5 Eficiência do Sistema NETUNO-HC ............ . . p. 93

4.3 .6 Avaliação semântica . . . . . . . . . . . . . . . . . . . p.94

4.4 Experimentos adicionais . . . . . . . . . . . . . . . 95

4.4.1 Redução do conjunto de regras descobertas . . . . . . . . . . . p.96

4.4.2 Critério de classificação do conjunto de teste . . . . . . . . . p. p7

4.4.3 Exemplos não classificados . . . . . . . . . . . . . p. 97

4.4.4 Critério de seleção das hipóteses de regra para o feixe da busca . . . p.98

4.5 Extensão na semântica da regra de classificação . . . . . . . . . . . . . p.99

\section{Conclusões}

\section{Trabalhos futuros}

6.1 Hierarquias conceituais para os valores da classe . . . . . . . . . . p. 106

6.2 Uso de outros tipos de conhecimento prévio . . . . . . . . . . . p. 107

6.3 Seleção de atributos . . . . . . . . . . . . . . . . . . p. 107

6.4 Linguagem de consulta para a mineração de BD relacionais . . . . . . . . p. 107

6.5 Outros bancos de dados . . . . . . . . . . . . . . . 108

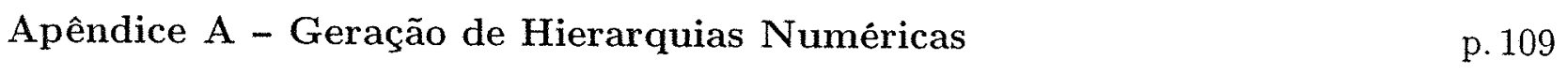

A.1 Introdução . . . . . . . . . . . . . . . . . . . . p. 109

A.2 Abordagens para criação dos intervalos . . . . . . . . . . . . . p. 109

A.3 Motivação . . . . . . . . . . . . . . . . . . . p. 110

A.4 Algoritmo para a geração de hierarquias numéricas . . . . . . . . . . . . p. 110

A.4.1 Algoritmo InfoMerge . . . . . . . . . . . . . . . p. 111

A.4.2 Algoritmo implementado para a criação de hierarquias numéricas . p.112

Apêndice B - Banco de dados utilizados $\quad$ p. 114 
B.1 Banco de dados sobre cogumelos ................. . . . 114

B.2 Banco de dados sobre censo demográfico . . . . . . . . . . . p. 117

Referências Bibliográficas

p. 120 


\section{Lista de Figuras}

1 Etapas do processo de Descoberta de Conhecimento . . . . . . . . . p. 18

2 Hierarquia de conceitos para alimentos ............. p. . 20

3 Exemplos de hierarquias de conceitos . . . . . . . . . . . p. 27

4 Hierarquia de conceitos para os atributos cujo domínio seja cor . . . . p. 28

5 Codificação pós-fixada de uma hierarquia . . . . . . . . . . . p. 31

6 Dois códigos diferentes em que o vértice com código 37463 é um descendente do vértice com código $18 \ldots \ldots \ldots \ldots \ldots \ldots$. . . . . . . . . . . . . . . . . .

7 Codificação de uma hierarquia $(L U, 1997) \ldots \ldots \ldots$ p. 33

8 Completude e consistência de diferentes regras nas classes - e $+\ldots$ p. 36

9 Espaço de busca de regras . . . . . . . . . . . . . . . . p.41

10 Representação dos conjuntos formados pelas regras $R^{\prime}$ e $R_{1}^{\prime} \ldots \ldots$ p. 42

11 Representação dos conjuntos formados pelas regras $R^{\prime}$ e $R_{2}^{\prime} \ldots \ldots$ p. 43

12 Algoritmo de busca por regras de classificação . . . . . . . . . . . p. 45

13 Busca em feixe com $k=3$ - apenas os três melhores nós são expandidos a cada nível do espaço de busca . . . . . . . . . . . . . . p. 46

14 Algoritmo de busca em feixe . . . . . . . . . . . . . . p. 47

15 Divisão de um conjunto de exemplos em cinco partes . . . . . . . . . p. 49

16 Algoritmo NETUNO . . . . . . . . . . . . . . . . . . p. . . . . . . .

17 Exemplo de uma hipótese de regra da lista_nós_abertos . . . . . . . p. 63

18 Estrutura de uma hierarquia conceitual . . . . . . . . . . . . p. 64 
19 Hierarquia dos valores de um ätributo com apenas um nível conceitual . p. 64

20 Hipótese de regra $\mathrm{H} 0$ e suas hipóteses sucessoras . . . . . . . . . . . p. 65

21 Verificação na hierarquia (os conceitos sombreados atingiram o critério de poda $\ldots \ldots \ldots \ldots \ldots \ldots$ p. 66

22 As linhas da matriz representam os conceitos no nivel folha da hierarquia . p.69

23 Exemplo de uma hipótese de regra especializada - nó_sucessor . . . . . . . p. 69

24 Algoritmo para calcular o número de bits necessários para codificar os vértices em determinada altura da hierarquia . . . . . . . . . . . p. 72

25 Algoritmo de codificação dos conceitos . . . . . . . . . . . . p. 73

26 Algoritmo Codificação . . . . . . . . . . . . . . . . p. 73

27 Codificação de uma hierarquia utilizada no Algoritmo NETUNO $\ldots \ldots$ p. 74

28 Procedimento para o cálculo da taxa de acerto . . . . . . . . . p. 76

29 Diagrama funcional envolvendo o algoritmo NETUNO e o conjunto de procedimentos de pré e pós-processamento que integram o Sistema NETUNO-HC . . . . . . . . . . . . . . p. 80

30 Execução de um algoritmo de Busca em Largura para a descoberta de regras de classificação no BD Cogumelo ( $\sup =20 \%$, conf $=90 \%) \ldots \ldots$ p. 83

31 BD Cogumelo - taxa de acerto versus valor de suporte e confiança com largura de feixe $=256 \ldots \ldots \ldots \ldots \ldots$ p. . . . . . . . . . . . . . .

32 BD Adulto - taxa de acerto versus valor de suporte e confiança com largura de feixe $=256 \ldots \ldots \ldots \ldots \ldots \ldots \ldots \ldots$ p. . . . . . . . . . . . . . . . . .

33 BD Cogumelo - Taxa de acerto versus valor de largura do feixe para $\sup =4 \%, \operatorname{conf}=98 \% \ldots \ldots \ldots \ldots \ldots$ p. 88

34 BD Adulto - Taxa de acerto versus valor de largura do feixe para sup $=4 \%$, $\mathrm{conf}=90 \% \ldots \ldots \ldots \ldots \ldots \ldots \ldots \ldots \ldots$

35 BD Cogumelo - Número de regras descobertas versus valor de suporte em diferentes níveis de confiança e com largura do feixe=256 . . . . . . p. 90 
36 BD Adulto - Número de regras descobertas versus valor de suporte em diferentes níveis de confiança e com largura do feixe=256 . . . . . . . p. 90

37 BD Cogumelo - Percentual de regras de alto nível no conjunto de regras descobertas versus valor de suporte para conf $=98 \%$ e largura do feixe $=256$

38 BD Adulto - Percentual de regras de alto nível no conjunto de regras descobertas versus valor de suporte para $\operatorname{conf}=90 \%$ e largura do feixe $=256$

39 BD Cogumelo - variação da taxa de acerto versus largura do feixe para diferentes percentuais na redução do conjunto de regras, COM hierarquias conceituais, $\sup =20 \%, \operatorname{conf}=90 \% \ldots \ldots \ldots \ldots$ p. 96

40 BD Cogumelo - variação do número de regras descobertas versus largura do feixe para diferentes percentuais na redução do conjunto de regras, COM hierarquias conceituais, $\sup =20 \%, \operatorname{conf}=90 \% \ldots \ldots \ldots$ p. 96

41 As colunas da matriz representam os conceitos no nível folha da hierarquia do atributo classe . . . . . . . . . . . . . . . p. 106

42 Geração de uma hierarquia numérica . . . . . . . . . . . . . . . p. 113

43 Hierarquia de conceitos para o atributo odor . . . . . . . . p. 115

44. Hierarquia de conceitos para o atributo population . . . . . . . p. 115

45 Hierarquia de conceitos para o atributo ring-type . . . . . . . . p. 115

46 Hierarquia de conceitos para os atributos cujo domínio seja cor . . . . . p. 116

47 Hierarquia de conceitos para os atributos cujo domínio seja surface . . . p. 116

48 Hierarquia de conceitos para o atributo capital_gain . . . . . . . p. 117

49 Hierarquia de conceitos para o atributo capital_loss . . . . . . . . p.118

50 Hierarquia de conceitos para o atributo hours_per_week ...... p. 118

51 Hierarquia de conceitos para o atributo education_num ....... p.118

52 Hierarquia de conceitos para o atributo age ............. . . . . 119

53 Hierarquia de conceitos para o atributo nationality . . . . . . . . . p.119 
54 Hierarquia de conceitos para o atributo marital . . . . . . . . . . p. 119 


\section{Lista de Tabelas}

1 Representação do BD através de uma tabela, em que cada linha representa uma tupla . . . . . . . . . . . . . . . . p. 24

2 Hierarquia de conceitos sobre cor codificada numa tabela relacional . . . . p. 30

3 Extrato da tabela relacional com atributos sobre cogumelos . . . . . . . p. 30

4 Representação do $\mathrm{BD}$ utilizado por um algoritmo supervisionado . . . . . p. 33

5 Estrutura geral da saída da primitiva de contagem, na qual $A v_{i}$ significa os valores do Atributo_Candidato $(1 \leq i \leq m), C_{j}$ representa os valores do Atributo_Classe $(1 \leq j \leq n), T_{i j}$ o número de tuplas que têm o valor $A v_{i}$, atendem à restrição de valor do Descritor_tuplas e pertencem a classe $C_{j}$, $T_{i+}$ o total de tuplas na linha $i, T_{+j}$ o total de tuplas na coluna $j$ e $T_{++}$o total de tuplas. . . . . . . . . . . . . . . p. 38

6 Variação das medidas de suporte e confiança de acordo com a operação de especialização. $\mathrm{O}$ valor de suporte de uma hipótese de regra só diminui com operações de especialização, enquanto que a confiança pode aumentar . . .

7 Definição do Espaço de Busca . . . . . . . . . . . . . . . p. 45

8 Tabela contendo as informações sobre as hierarquias de determinado BD . p.61

9 Número de regras descobertas pelo algoritmo NETUNO no BD sobre cogumelos, sem utilizar hierarquias conceituais e com $\sup =4 \%$, conf $=98 \%$ e largura do feixe $=64 \ldots \ldots \ldots \ldots \ldots \ldots \ldots \ldots \ldots$. . . . . . . . . . . 62

10

11 Taxas de acerto obtidas por outros algoritmos no BD Cogumelo . . . . p. 81

12 Taxas de acerto obtidas por outros algoritmos no BD Adulto . . . . . . p. p1 
13 Comparação do resultado da utilização da primitiva de contagem para o BD Cogumelo

14 Comparação do algoritmo de Busca em Largura e Busca em Feixe, para - BD Cogumelo utilizando hierarquias conceituais, e com $\sup =20 \%$, conf $=90 \%$ e largura do feixe $=256 \ldots \ldots \ldots \ldots$ p. 83

15 BD Cogumelo - Média e desvio padrão $(\sigma)$ da taxa de acerto para cada valor de suporte e confiança e com largura do feixe=256 . . . . . . . . p. 85

16 BD Adulto - Média e desvio padrão $(\sigma)$ da taxa de acerto para cada valor de suporte e confiança e com largura do feixe=256 . . . . . . . . p. 86

17 BD Cogumelo - Número de exemplos não classificados para cada largura

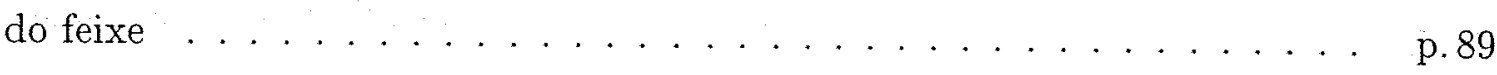

18 Tamanho médio das regras descobertas em cada $\mathrm{BD}$, com sup $=20 \%$, $\mathrm{conf}=90 \%$ e feixe $=256 \ldots \ldots \ldots \ldots \ldots$ p: $9 \ldots \ldots$

19 Atributos do BD Cogumelo . . . . . . . . . . . . . . . p: 93

20 BD Cogumelo - Taxa de acerto para a mineração com conjuntos selecionados de atributos, com $\sup =4 \%$, conf $=98 \%$ e largura do feixe $=16 \ldots$ p. 93

21 BD Cogumelo - conjunto de regras descobertas com $\sup =4 \%$, conf $=90 \%$, largura do feixe $=1$, COM hierarquias conceituais . . . . . . . . . . p.94

22 BD Cogumelo - conjunto de regras descobertas com $\sup =4 \%$, conf $=90 \%$, largura do feixe $=1$, SEM hierarquias conceituais . . . . . . . . . p.95

23 Comparação do resultado obtido por diferentes critérios de classificação do conjunto de teste para o BD Cogumelo, utilizando hierarquias conceituais, com suporte $=20 \%, 12 \%, 4 \%$ e confiança $=90 \%, 94 \%, 98 \%$, e largura do feixe $=256$.

24 BD Adulto - Número de exemplos não classificados para cada largura do

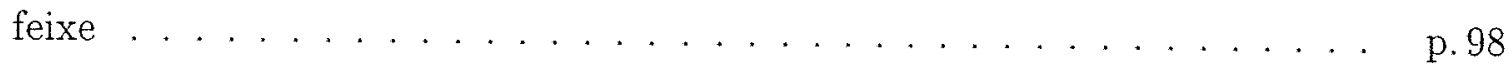

25 Comparação do resultado obtido pela utilização de uma classe padrão para exemplos não cobertos por regras utilizando hierarquias conceituais, com sup $=4 \%$, conf $=90 \%$ e largura do feixe $=256$. 
26 Comparação do resultado obtido por diferentes critérios de ordenação da lista_nós_abertos, utilizando hierarquias conceituais, com suporte $=20 \%$, $12 \%, 4 \%$ e confiança $=90 \%, 94 \%, 98 \%$, e largura do feixe $=256 \ldots$. . . . . 98

27 Estrutura geral da saída da primitiva de contagem - a condição de desigualdade é obtida pela diferença entre a linha Total e a linha onde se encontra o valor do atributo $A v_{i} \ldots \ldots \ldots$. . . . . . . . . . . . . . 100

28 Dados do BD MONK-3 . . . . . . . . . . . . . . . . . . p. 100

29 Taxa de acerto obtidas por outros algoritmos e pelo Sistema NETUNO-HC no BD Monk-3 . . . . . . . . . . . . . . . . . . . . p. 100

30 Conjunto de regras descobertas para a classe 1 com sup $=30 \%$, conf $=90 \%$ e largura do feixe $=16$, pelo Sistema NETUNO-HC . . . . . . . . . . . . p. 101

31 Conjunto de regras descobertas para a classe 0 com $\sup =30 \%$, conf $=90 \%$ e largura do feixe $=16$, pelo Sistema NETUNO-HC . . . . . . . . . . . . p. 101

32 Descrição dos valores dos atributos do BD Cogumelo . . . . . . . . . p. 114

33 Descrição dos valores dos atributos do BD Adulto . . . . . . . . . . p. 117 


\section{Introdução}

\subsection{Descoberta de Conhecimento em Bancos de Dados: uma visão geral}

Em inúmeras áreas de trabalho e pesquisa, a coleta e armazenamento de dados tem crescido num ritmo acelerado. Este aumento no volume de dados torna inexeqüivel uma análise destes dados na qual apenas o fator humano esteja presente, isto é, sem o auxílio de alguma ferramenta de apoio. Desta forma, são necessários métodos e técnicas computacionais que permitam ao usuário extrair informação útil desta grande massa de dados de forma automática ou semi-automática. O desenvolvimento destes métodos e técnicas definem a área denominada Descoberta de Conhecimento em Bancos de Dados.

Segundo (FAYYAD; PIATESKY-SHAPIRO; SMYTH, 1996), a descoberta de conhecimento em bancos de dados é um processo não trivial de identificação de padrões válidos, novos, potencialmente úteis e compreensiveis incluidos nos dados. Para compreender esta definição é necessário examinar outras definições, a saber:

- dados correspondem aos fatos, objetos ou tuplas em um banco de dados (BD), que poderão estar representados através de um conjunto de atributos ou características, por exemplo, os valores dos dados cadastrais de um cliente;

- padrão é uma expressão, em alguma linguagem matemática ou simbólica, que descreve um subconjunto dos dados ou um modelo aplicável a este subconjunto. Um exemplo de padrão é uma fórmula lógica que impõe restrições sobre um conjunto de valores.

- por processo, entende-se um conjunto de etapas, envolvendo preparação dos dados, busca, avaliação e refinamento dos padrões, todos repetidos em múltiplas iterações; 
- não trivial implica que o processo envolve algum tipo de busca ou inferência e não apenas o cálculo direto das ocorrências num BD;

- a validade decorre da necessidade de haver alguma medida de certeza ou relevância sobre os padrões descobertos;

- padrões novos são mais desejados;

- padrões potencialmente úteis conduzem a algum benefício ao usuário ou a um sistema, e finalmente,

- padrões devem ser compreensiveis, imediatamente ou após algum processamento por um especialista no domínio dos dados.

Os objetivos de um sistema de descoberta de conhecimento podem ser: (i) a predição, quando os padrões descobertos serão usados para prever o comportamento de novos dados, ou (ii) a descrição, que visa apresentar ao usuário uma síntese dos dados.

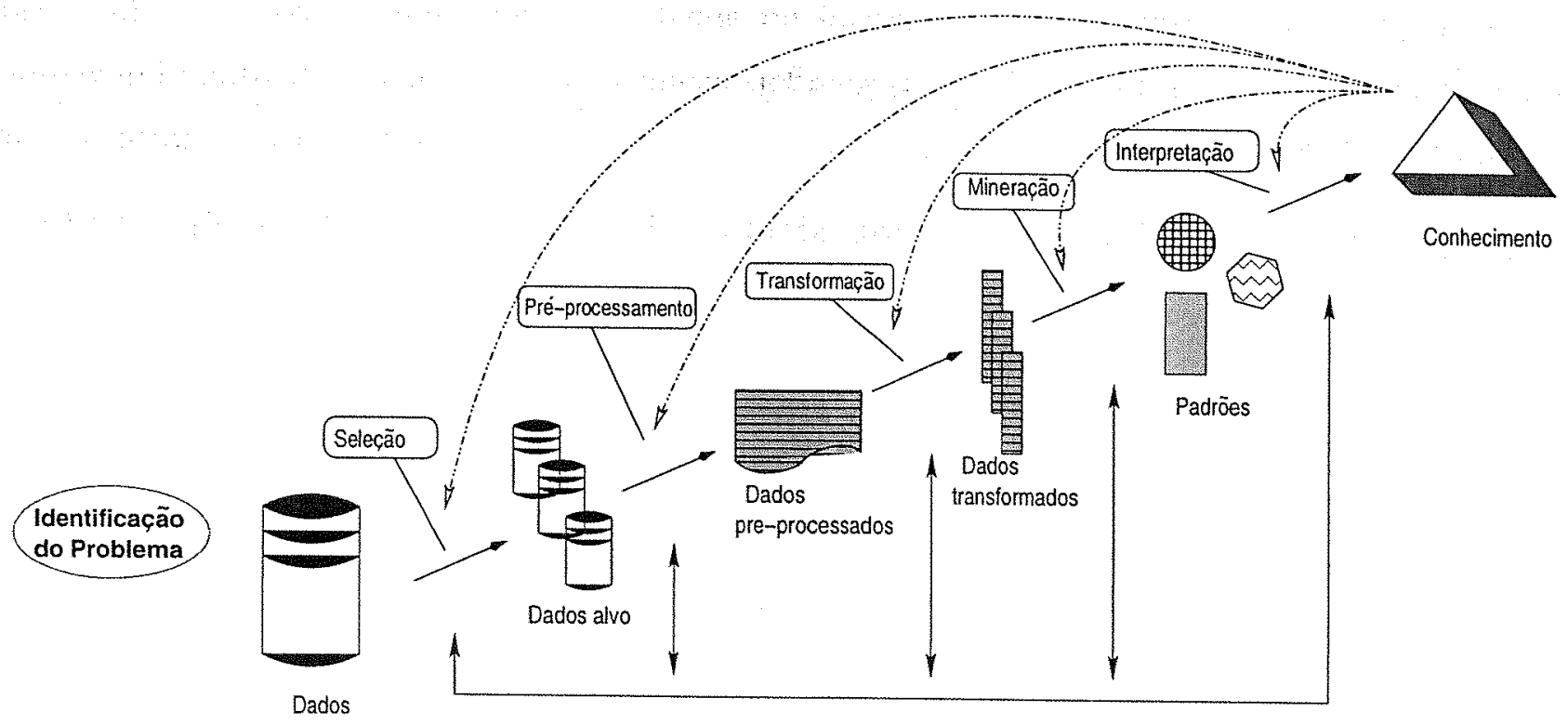

Figura 1: Etapas do processo de Descoberta de Conhecimento

Na Figura 1, o processo de descoberta de conhecimento é dividido em uma fase inicial e cinco etapas: identificação do problema, seleção, pré-processamento, transformação, mineração e interpretação. 
Na fase de identificação do problema é feito o estudo do domínio de aplicação, o levantamento do conhecimento prévio relevante (por exemplo, a identificação de hierarquias de conceitos como será abordado neste trabalho), a definição dos objetivos do sistema, bem como dos tipos de padrões desejados. A etapa de seleção visa obter os dados relevantes aos objetivos do sistema, que poderá consistir de um subconjunto das tuplas de todo o BD inicial (nesta etapa, pode-se reservar um conjunto de dados para testes). Nas etapas de pré-processamento e transformação, seleciona-se quais características ou atributos são mais relevantes para representar os dados de acordo com o padrão a ser descoberto (feature selection), bem como é decidido como serão tratados os valores ausentes. Na etapa de mineração é executado o algoritmo de descoberta propriamente dito, que fará a busca e extração dos padrões existentes. Finalmente, os padrões descobertos devem ser interpretados e só então poderão ser considerados como conhecimento descoberto. Na Figura 1, as linhas sólidas mostram que as etapas podem interagir entre si; as linhas pontilhas denotam que o conhecimento, prévio ou descoberto, pode fornecer subsídios a todas as etapas do processo.

$\mathrm{Na}$ mineração de dados, o uso de conhecimento prévio pode permitir a descoberta de conhecimento num nível de abstração mais elevado, compacto e muitas vezes mais interessante. Um exemplo de conhecimento prévio pode ser uma hierarquia de conceitos (Figura: 2), ou seja, uma estrutura em que conceitos de mais alto-nível de abstração (generalizações de conceitos de mais baixo nível) são organizados hierarquicamente por um especialista do: domínio dos dados ou por processos automáticos.

A mineração de dados, no nível conceitual do $\mathrm{BD}$, nem sempre corresponde ao nível de conhecimento que facilita a interpretação do padrão pelo especialista, ou mesmo o nível que possui o maior grau de interesse. Dados com grande regularidade, isto é, com grande ocorrência no $\mathrm{BD}$, normalmente não aparecem em padrões que envolvam níveis conceituais baixos pois, neste caso, os padrões tendem a ser dispersos e com pequeno número de ocorrências (TAYLOR, 1999). Por exemplo, os dados obtidos a partir de compras efetuadas num supermercado podem conter apenas os códigos de barra dos produtos (conceitos dp tipo cod da hierarquia apresentada na Figura 2). Neste caso, tudo o que poderá ser descoberto, a partir desses dados, será: pessoas que compram pão da marca $X$, também compram leite da marca $Y$. Por outro lado, deve-se observar que dados descritos num nível conceitual muito elevado, i.e., com grau de generalização grande, podem levar à descoberta de padrões que já são de conhecimento comum e não apresentam nada de novo, como: pessoas que compram 


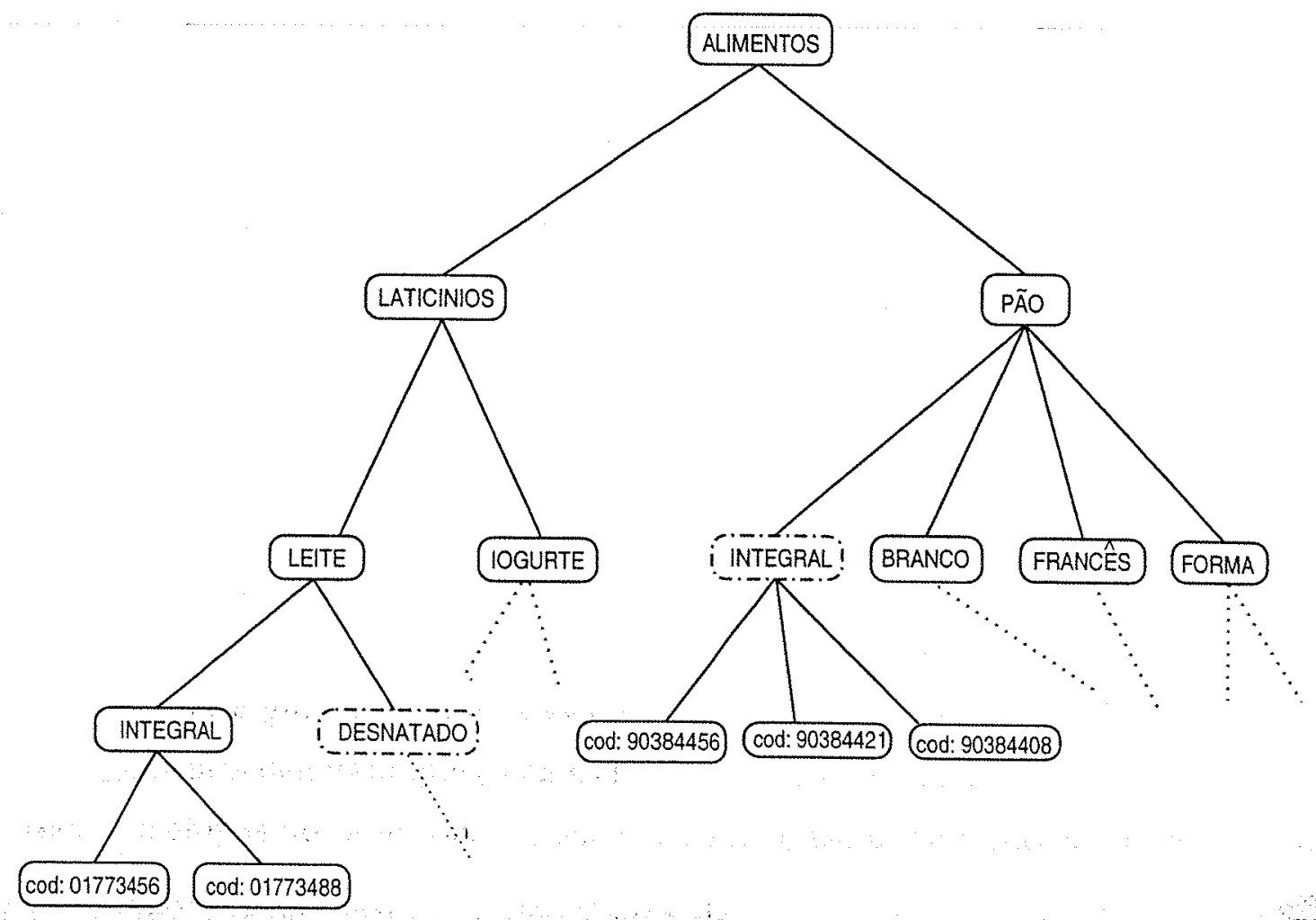

Figura 2: Hierarquia de conceitos para alimentos

pão também compram leite. Um padrão de maior interesse seria aquele que envolve conceitos num nivel intermediário de abstração, ou seja: pessoas que compram pão integral também compram leite desnatado (conceitos assinalados na Figura 2. O grande desafio dessa abordagem é determinar o melhor nível de abstração para cada conjunto de valores dos atributos de um BD.

Por outro lado, a redução de espaço causada pelo uso de hierarquias conceituais pode ser substancial, especialmente em hierarquias com diversos niveis. Por exemplo, considere hierarquias sobre regiões geográficas, variando do CEP até a região do estado. Trabalhandose apenas com o BD, todos os possíveis níveis da hierarquia deveriam ser incluídos no BD através da adição de atributos (i.e., CEP, rua, bairro, cidade, estado). Através da utilização de uma hierarquia conceitual é possível se obter uma representação mais econômica dos dados.

Estas observações motivaram a descoberta de conhecimento em múltiplos níveis conceituais, aumentando assim a diversidade dos padrões descobertos (TAYLOR, 1999; FU, 1996; HAN; CAI; CERCONE, 1992; PROVOST; ARONIS; BUCHANAN, 1999; AGRAWAL; SRIKANT, 
1995; MALLEN; BRAMER, 1995).

\subsection{Objetivos}

A mineração de dados em múltiplos níveis conceituais é mais complexa e exige uma busca maior do que a mineração num único nível, pois o espaço de busca é geralmente maior. Porém, como foi discutido na seção anterior, pode gerar padrões mais interessantes.

A descoberta de padrões pode ser feita de duas maneiras: (1) pré-generalizando o BD com base nas hierarquias conceituais e posteriormente realizando a mineração de dados, ou (2) utilizando concomitantemente o BD e as hierarquias, fazendo consultas ao BD em níveis conceituais mais elevados do que os conceitos existentes no BD. A primeira maneira, apesar de reduzir a complexidade da mineração dos dados, pode levar a exclusão de padrões interessantes, pois o critério de generalização dos dados é realizado antes da etapa de mineração propriamente dita sendo necessário fixar um nível de generalidade. A segunda maneira processa $\mathrm{O} \mathrm{BD}$ e as hierarquias durante toda a mineração, o que resulta num maior custo computacional, podendo assim tornar o problema intratável. Porém, esta maneira permite mostrar padrões em diferentes níveis da hierarquia.

Neste trabalho, são estudadas técnicas de descoberta de conhecimento em BD com uso de hierarquias conceituais, a fim de implementar um algoritmo para indução de regras de classificação em BD relacionais, cujos valores estão associados a hierarquias de conceitos, sem pré-generalizar os dados. O algoritmo proposto é independente de um SGBD particular ou mesmo de alguma ferramenta de representação de hierarquias conceituais, como por exemplo, uso de linguagens baseadas em lógica de descrição.

Serão realizados experimentos que comparam os resultados da mineração de um mesmo BD de teste utilizando ou não hierarquias conceituais. Além disso, serão avaliadas as técnicas de representação de hierarquias conceituais, as estratégias de busca e os métodos de acesso aos dados.

\subsection{Contribuições}

As principais contribuições são: 
1. Desenvolvimento de um algoritmo que pode ser utilizado em qualquer SGBD relacional que suporte consultas em SQL. O algoritmo é descrito no Capítulo 3.

2. Uso de uma estrutura de dados para representar e manipular as hierarquias conceituais, sem necessitar de qualquer outra ferramenta para isto, flexibilizando o uso do algoritmo. $\mathrm{Na}$ Seção 2.2 é definida a hierarquia conceitual utilizada neste trabalho e no Capítulo 3 é descrito seu uso no processo de descoberta.

3. Modificação da consulta em SQL proposta por Alex Freitas (FREITAS, 1997) a fim de permitir obter os dados necessários para o cálculo de medidas de relevância quando empregando hierarquias conceituais. Na Seção 3.5 é apresentada a consulta em SQL utilizada pelo algoritmo.

4. Proposta de um algoritmo de codificação de hierarquias conceituais com pequena complexidade a fim de permitir comparar dois conceitos de uma hierarquia de maneira eficiente. Na Seção 3.6 é descrito o algoritmo de codificação.

5. Avaliar o resultado da utilização de hierarquias conceituais na descoberta de regras de classificação e compará-los com trabalhos correlatos. No Capítulo 4, são apresentados os resultados do uso de hierarquias conceituais no processo de descoberta.

6. Extensão da representação das regras de classificação. No Capítulo 4 são apresentados os testes com a adição da negação, na relação entre um atributo e seu valor, às regras de classificação e apresentados os resultados e as modificações feitas nas consultas em SQL. 


\section{$2 \quad$ Fundamentos e trabalhos correlatos}

A habilidade do ser humano de fazer generalizações a partir de fatos ou de descobrir regularidades é denominada aprendizado indutivo (MICHALSKI, 1993). Durante a fase de aprendizado, um ser humano observa o ambiente e reconhece similaridades entre objetos e eventos. Ele pode agrupar os objetos similares em categorias, ou classes, e construir regras para prever o comportamento de outros objetos similares ou mesmo classificar um novo objeto numa das classes aprendidas. A área de aprendizado de máquina tem o objetivo de estudar e modelar computacionalmente o processo de aprendizado (MONARD et al., 1997).

Há duas técnicas principais de aprendizado indutivo. A primeira é o aprendizádo supervisionado, no qual as classes são definidas previamente, sendo o aprendizado realizado sobre exemplos pré-classificados. Nesse caso, o sistema deve descobrir propriedades comuns nos exemplos de cada classe, isto é, a descrição da classe. A segunda técnica é o aprendizado não supervisionado, no qual o sistema deve descobrir as próprias classes baseando-se em propriedades comuns dos exemplos.

Este capítulo irá tratar sobre tópicos relevantes à indução de regras em BD relacionais, hierarquias conceituais e trabalhos correlatos. Na Seção 2.1 são apresentados os principais tipos de padrões que podem ser descobertos. Na Seção 2.2 é apresentada a definição de hierarquia conceitual, seus diferentes tipos, métodos de representação e de armazenamento. $\mathrm{Na}$ Seção 2.3 é definido o formato da regra de classificação e são apresentadas as definições de cobertura e consistência de regras. Na Seção 2.4 são definidas algumas medidas de avaliação de regras e como calculá-las através de uma interface em SQL com um BD. Na Seção 2.5 é definido o problema de descoberta de regras como um problema de busca. Na Seção 2.6 é apresentada a metodologia para realização dos testes e na Seção 2.7 as medidas que serão feitas. Na Seção 2.8 são apresentados outros trabalhos da literatura que utilizam hierarquias conceituais para a descoberta de conhecimento. 


\subsection{Padrões descobertos em bancos de dados}

Uma forma de compreender um conceito é usar uma simplificação deste conceito, ou seja, um modelo ou padrão. Para os algoritmos de aprendizado, o BD representa a informação do ambiente. Em princípio, há vários possíveis formalismos de representação e de consulta aos dados, entretanto, a maioria é gerenciada por Sistemas Gerenciadores de Banco de Dados (SGBD) do tipo relacional com uma interface SQL, abordagem esse que será usada neste trabalho.

Dados armazenados em SGBD podem ser diretamente minerados, através de operações de manipulação de dados (funções e procedimentos) do SGBD. Entretanto, algumas funcionalidades são particulares de um SGBD, o que pode dificultar a migração de um algoritmo de mineração para outros SGBD. Em (ONODA; EBECKEN, 2001) foi feita uma implementação de um algoritmo de mineração (sem hierarquias conceituais) através de uma interface externa ao SGBD, e os resultados são comparados com uma implementação feita através de funções e procedimentos codificados no próprio SGBD. A comparação mostra que o tempo de execução das duas abordagens é equivalente, o que conduz a vantagem de utilizar uma interface externa ao BD devido a sua flexibilidade de uso em diferentes SGBD.

Num BD, todas as informações sobre um objeto devem ser descritas através de uma coleção de características, ou atributos, e seus respectivos valores. Cada um destes atributos possui um domínio de valores definido pelo seu tipo, isto é, valores categóricos ou discretos e valores contínuos ou numéricos. Sendo $\mathcal{A}=\left\{A_{1}, \ldots, A_{m}\right\}$, um conjunto de atributos, o $\mathrm{BD}$ será uma tabela sobre $\mathcal{A}$. A representação de um objeto nesta tabela, denominada de exemplo ou tupla $t_{k}=\left(a_{k 1}, \ldots, a_{k m}\right)$ tal que $a_{k j} \in \operatorname{Dom}\left(A_{j}\right)\left(\right.$ domínio do atributo $\left.A_{j}\right)$ com $1 \leq j \leq m$.

\begin{tabular}{|c|llll|}
\hline$t$ & $A_{1}$ & $A_{2}$ & $\ldots$ & $A_{m}$ \\
\hline \hline$t_{1}$ & $a_{11}$ & $a_{12}$ & $\ldots$ & $a_{1 m}$ \\
$t_{2}$ & $a_{21}$ & $a_{22}$ & $\ldots$ & $a_{2 m}$ \\
$t_{3}$ & $a_{31}$ & $a_{32}$ & $\ldots$ & $a_{3 m}$ \\
\hline
\end{tabular}

Tabela 1: Representação do BD através de uma tabela, em que cada linha representa uma tupla

Em cada tipo de aprendizado, diferentes padrões podem ser descobertos. No supervisionado destacam-se as regras de classificação e caracterização. Já no aprendizado nãosupervisionado tem-se as regras de associação, a sumariação e agrupamentos (HAN, 1995), 
detalhados a seguir.

Regras de Classificação A classificação pode ser vista como uma função que mapeia dados de entrada em um número finito de classes pré-definidas. Seja $C=\left\{c_{1}, \ldots, c_{n}\right\}$ um conjunto finito de classes. Dado um BD, no qual cada tupla pertence a uma classe, uma regra de classificação pode ser expressa da forma: se $P$ então $c_{n}$ na qual $P$ é a representação escolhida, que pode ser uma conjunção de pares atributo-valor da forma $\left(A_{1}, a_{1}\right) \wedge\left(A_{2}, a_{2}\right) \wedge \ldots \wedge\left(A_{i}, a_{i}\right)$.

Regras de Caracterização Descrevem os padrões que caracterizam uma determinada classe, sendo o conjunto de dados analisado pertencente a apenas uma classe. Uma regra de caracterização pode ser expressa da forma: se $c_{n}$ então $P$, na qual $c_{n}$ representa a classe à qual pertence o conjunto de dados, e $P$ é a representação escolhida.

Regras de Associação Caracterizam o quanto a presença de um conjunto de atributos nos objetos de um BD implica na presença de um outro conjunto distinto de atributos nos. mesmos objetos. São regras da forma $E \rightarrow D$, na qual $\mathrm{E}$ e $\mathrm{D}$ são conjuntos disjuntos de pares atributo-valor. Note que esta implicação difere da implicação apresentada nas regras anteriores. Aqui, o lado direito da regra pode conter um conjunto de atributos, não apenas um, e a implicação é comutativa, i.e., $E \Leftrightarrow D$.

Sumariação envolve a descoberta de formas compactas de descrição de um conjunto de dados. Apresentam as características gerais ou uma visão resumida dos dados organizados em dimensões, por exemplo, num Datawarehouse (ITALIANO; FERREIRA; TAKAI, 2001).

Agrupamentos ou Clustering Agrupam um conjunto de dados, não associados à uma classe pré-definida, com base no conceito de maximização da similaridade dentro de um agrupamento e minimização da similaridade entre os agrupamentos. Após um agrupamento ter sido descoberto, este pode ser definido como uma classe e então um conjunto de regras pode ser determinado para descrever os dados, ou prever o agrupamento (ou cluster) ao qual os dados pertencem. 


\subsection{Hierarquia de conceitos}

Para que o conhecimento descoberto esteja descrito num nível superior ao encontrado no $\mathrm{BD}$, os conceitos e dados nesta base podem estar organizados em diferentes níveis de abstração. Tal organização pode ser definida por meio de uma hierarquia de conceitos especificada por um especialista do domínio do BD. Uma hierarquia de conceitos define relações de generalização e especialização para valores de um atributo ou de um conjunto de atributos. Embora uma hierarquia de conceitos possa ser fornecida por um especialista de domínio, esta também pode ser construída ou refinada automaticamente (FU, 1996), especialmente quando se trata de atributos numéricos.

Seja $\mathcal{U}$ um conjunto e $a, b, c \in \mathcal{U}$ elementos deste conjunto. Uma ordem parcial em $\mathcal{U}$ é uma relação $R$ em $\mathcal{U}$ que é:

1. reflexiva - $(a, a) \in R, \forall a \in \mathcal{U}$;

2. anti-simétrica - se $(a, b) \in R$, e $(b, a) \in R$, então $a=b$; e

3. transitiva - se $(a, b) \in R$ e $(b, c) \in R$, então $(a, c) \in R$.

Além disso, se uma relação $R$ em $\mathcal{U}$ define uma ordem parcial em $\mathcal{U}$, então $(a, b) \in R$ é designado por:

$$
a \preceq b
$$

Neste trabalho a relação de ordem parcial será designada por $\preceq$.

Definição 1 Hierarquia de Conceitos Uma hierarquia de conceitos $\mathcal{H C}$ é um conjunto parcialmente ordenado $(\mathrm{HC}, \preceq)$, no qual $\mathrm{HC}$ é um conjunto finito de conceitos, e $\preceq$ uma relação de ordem parcial em $\mathrm{HC}$.

Definição 2 Ascendente Um conceito a é denominado ascendente de um outro conceito $\mathbf{b}$, se $\{\mathbf{a}, \mathbf{b}\} \in \mathbf{H C}, \mathbf{b} \preceq \mathbf{a} e \mathbf{a} \neq \mathbf{b}$.

Definição 3 Ascendente mais próximo Um conceito a é denominado ascendente mais próximo de um outro conceito $\mathbf{b}$, se $\mathbf{a}$ é um ascendente de $\mathbf{b}$, e não há outro conceito $\mathbf{c} \in \mathbf{H C}$ tal que, $\mathbf{b} \preceq \mathbf{c} e \mathbf{c} \preceq \mathbf{a}$. 
Definição 4 Maior elemento Um conceito a é o maior elemento de $\mathcal{H C}$ se $\forall \mathrm{c} \in \mathrm{HC}$, $\mathbf{c} \preceq \mathbf{a}$.

Definição 5 Hierarquia regular Uma hierarquia de conceitos $\mathcal{H C}$ é regular se existe um maior elemento em $\mathrm{HC}$ e há conjuntos $H_{i}, i=0,1, \ldots,(n-1)$, tal que

$$
\mathbf{H C}=\bigcup_{i=0}^{n-1} H_{i} \quad \text { e } H_{k} \bigcap H_{j}=\emptyset \text { para } k \neq l
$$

e, se um ascendente mais próximo de um conceito em $H_{k}$ está em $H_{j}$, então os ascendentes mais próximos dos outros conceitos em $\mathrm{H}_{k}$ estão todos em $\mathrm{H}_{j}$.

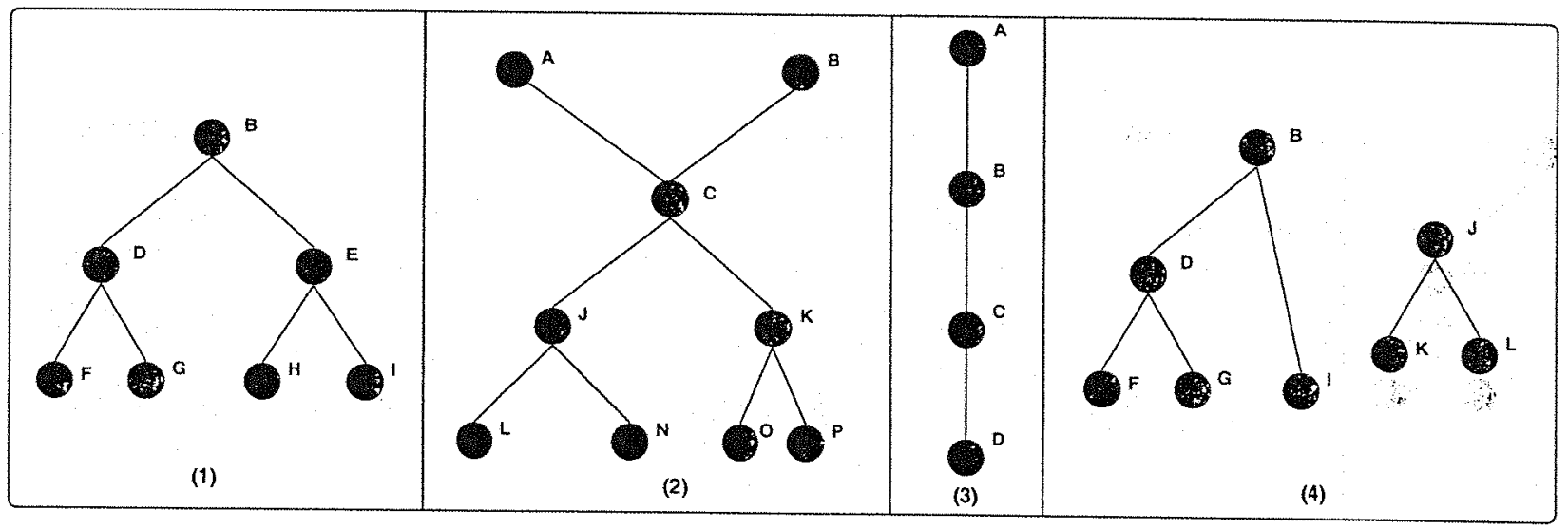

Figura 3: Exemplos de hierarquias de conceitos

Na Figura 3 são apresentados diferentes tipos de hierarquias conceituais. Dentre estas, apenas as hierarquias de número 1 e 3 são hierarquias regulares.

Neste trabalho, serão utilizadas apenas hierarquias regulares, nas quais o maior elemento será denominado de QUALQUER e uma hierarquia regular será chamada de hierarquia conceitual ou, simplesmente, hierarquia. Além disso, nas hierarquias utilizadas haverá apenas um ascendente mais próximo para cada conceito. Isto permitirá representar uma hierarquia como uma árvore e adotar a mesma terminologia empregada em estruturas de dados, ou seja, raiz, vértice, caminho, folha, filho, pai, etc.

Seguindo a Definição 5 , cada um dos conjuntos $H_{i}$ pode ser visto como um nível de generalidade. Deste modo, pode-se descrever o grau de generalidade de um conceito através do seu nível. O nível zero de uma hierarquia é o nivel do conceito mais geral, isto é, do maior 
elemento,-, e o nível de cada um dos outros conceitos da hieräquia é igual ao nível do seu ascendente mais próximo mais um.

A relação de generalização-especialização entre os conceitos de uma hierarquia é uma relação de ordem parcial. Nem todos os conceitos existentes em $\mathcal{H C}$ pertencem a esta relação. Por exemplo, se $\mathbf{a}$ e $\mathbf{b}$ estão num mesmo nível da hierarquia, a não é mais geral que $\mathbf{b}$ nem vice-versa. Se um conceito $\mathbf{x}$ é mais geral que um outro conceito $\mathbf{y}$ então $(\mathbf{y}, \mathbf{x}) \in \preceq$, e escreve-se $y \preceq x$. Outra maneira é dizer que $\mathbf{y}$ precede $\mathbf{x}$, ou que $\mathbf{y}$ é mais específico que $\mathbf{x}$.

Considerando um BD, uma hierarquia de conceitos pode ser estabelecida da seguinte maneira:

Hierarquia entre atributos Este tipo de hierarquia pode ser explicitamente representada no $\mathrm{BD}$ através da definição de níveis de generalidade entre os atributos como, por exemplo, o endereço residencial de um indivíduo representado pela seguinte relação de ordem parcial:

número da casa $\preceq$ rua $\preceq$ bairro $\preceq$ cidade $\preceq$ estado

Hierarquia entre valores de atributos Definida por um determinado conjunto de valores de um mesmo atributo, por exemplo, o atributo cor (Figura 4). Este tipo de hierarquia póde não estar explicitamente definida no BD mas em algum tipo de linguagem externa ao BD. No exemplo do atributo cor, conceitos de mais alto nível definem as tonalidades escura e clara. Aqui, pode-se notar que (clara, escura) $\notin \preceq$, mas branca $\preceq$ clara.

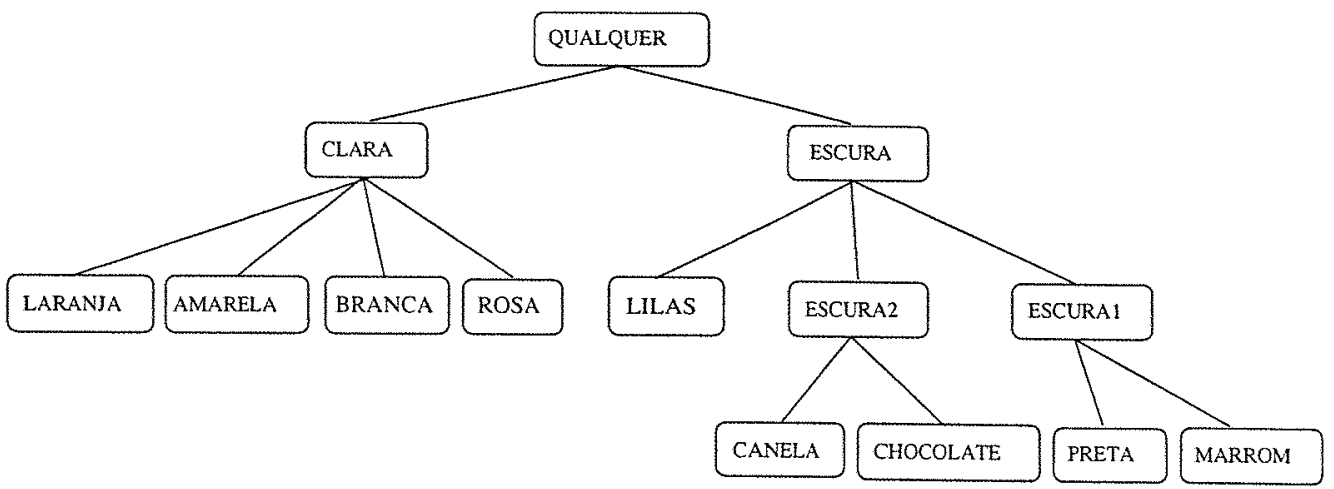

Figura 4: Hierarquia de conceitos para os atributos cujo domínio seja cor

Hierarquia entre valores de atributos também pode ser obtida através de operações sobre os valores de atributos como, por exemplo, no caso de atributos numéricos contínuos em que faixas de valores são estabelecidas, agrupando os valores contínuos em 
intervalos discretos. Por exemplo, as notas atribuídas aos alunos de pós-graduação numa universidade podem ser agrupadas nas seguintes faixas:

$\{0.0 \ldots 4.9\} \preceq$ Insuficiente, $\{5.0 \ldots 7.0\} \preceq$ Bom, $\{7.1 \ldots 8.5\} \preceq$ Muito Bom, $\{8.6$ ...10.0\} Excelente.

Hierarquia baseada em regras Definida por relações mais complexas. Em alguns casos, pode ser necessário representar uma generalização de conceitos que dependa não apenas do valor, mas também de alguma condição imposta sobre valores de outros atributos. No exemplo anterior, a nota 6.5 poderia ser generalizada como Muito Bom, caso o aluno fosse da graduação, que corresponderia a seguinte hierarquia:

$\{6.5 \ldots 8.5\} \wedge\{$ graduação $\} \preceq$ Muito Bom.

A construção de hierarquias sobre valores numéricos contínuos pode ser feita independentemente da tarefa de descoberta, por exemplo, no caso de regras de classificação, não considerando a distribuição dos valores do atributo classificador, como em (LU, 1997; TAYLOR, 1999). No apêndice A, é descrito um algoritmo de construção de hierarquia numérica, que considera a distribuição dos valores das classes, como foi utilizada neste trabalho.

\subsubsection{Representação e armazenamento de hierarquias de conceitos}

Como mencionado na seção anterior, uma hierarquia de conceitos pode ser descrita como uma árvore na qual cada vértice representa um conceito e cada aresta uma relação de especialização-generalização entre os conceitos de vértices adjacentes. Os vértices, cujos conceitos são valores de atributos no $\mathrm{BD}$, são denominados vértices folha e correspondem aos conceitos mais específicos.

Podemos armazenar uma hierarquia de conceitos numa tabela, na qual cada caminho entre o vértice raiz e um vértice folha é armazenado como uma tupla, e cada atributo desta tabela contém conceitos num mesmo nível da árvore, i.e., vértices que equiidistam da raiz. Através da Tabela 2, observa-se como a hierarquia da Figura 4 pode ser representada numa tabela relacional. Na Figura 4 os conceitos Marrom, Preta, Canela, Chocolate, Lilás, Branca, Amarela, Laranja e Rosa são valores de um atributo no BD que, na árvore, são vértices folha.

Por exemplo, na Tabela 3, são mostradas algumas tuplas de um BD sobre cogumelos. Observa-se que os atributos cor_esporo e cor_topo possuem valores dentro do domínio da 


\begin{tabular}{|l|l|l|l|}
\hline 0 & 1 & 2 & 3 \\
\hline \hline QUALQUER & Escura & Escura1 & Marrom \\
\hline QUALQUER & Escura & Escura1 & Preta \\
\hline QUALQUER & Escura & Escura2 & Canela \\
\hline QUALQUER & Escura & Escura2 & Chocolate \\
\hline QUALQUER & Escura & Lilás & \\
\hline QUALQUER & Clara & Branca & \\
\hline QUALQUER & Clara & Rosa & \\
\hline QUALQUER & Clara & Amarela & \\
\hline QUALQUER & Clara & Laranja & \\
\hline
\end{tabular}

Tabela 2: Hierarquia de conceitos sobre cor codificada numa tabela relacional

\begin{tabular}{|l|l|l|l|}
\hline cor_esporo & forma & cor_topo & classe \\
\hline \hline lilás & cônica & rosa & comestível \\
\hline preta & achatada & canela & venenoso \\
\hline amarela & convexa & branca & comestivel \\
\hline amarela & sino & rosa & venenoso \\
\hline mạrrom & achatada & canela & venenoso \\
\hline lilás & convexa & branca & comestível \\
\hline
\end{tabular}

Tabela 3: Extrato da tabela relacional com atributos sobre cogumelos

hierarquia da Figura 4 e portanto, a hierarquia de cores poderá ser utilizada para generalizar os conceitos contidos no $\mathrm{BD}$ sobre cogumelos relacionados a dois atributos diferentes.

O armazenamento de hierarquias de conceitos pode ser feito através de arquivos ou de tabelas relacionais. A vantagem das tabelas relacionais resulta das facilidades fornecidas pelo uso de um SGBD, como o acesso concorrente de uma mesma tabela e a segurança dos dados (LU, 1997). Neste trabalho, as hierarquias serão armazenadas em tabelas relacionais e lidas para a memória principal antes da etapa de mineração de dados.

\subsubsection{Codificação de hierarquias conceituais}

Para verificar se um conceito é mais geral que outro, pode-se consultar a hierarquia conceitual. Porém, como será visto mais adiante, o algoritmo de mineração necessita constantemente determinar quais conceitos são mais gerais que outros, e por isso deve-se procurar um método que torne esta verificação mais eficiente. Uma proposta para isto é codificar os conceitos da hierarquia, a fim de que este código represente a relação de ordem parcial entre os conceitos, evitando-se consultar a hierarquia. 
Um método de codificação de hierarquias proposto em (WANG; IYER, 1997) gera os códigos percorrendo-se a hierarquia de maneira pós-fixada. Essa codificação possui a seguinte propriedade: para qualquer vértice com código $j$, se o menor código dentre os seus descendentes for $i$, então $i<j$ e $j$ possui exatamente $j-i$ descendentes com códigos variando entre $i$ até $j-1$. Deste modo, o intervalo $[i, j-1]$ fornece os códigos de todos os descendentes. Na Figura 5, é mostrada uma codificação de uma hierarquia obtida através do percurso pós-fixado (WANG; IYER, 1997).

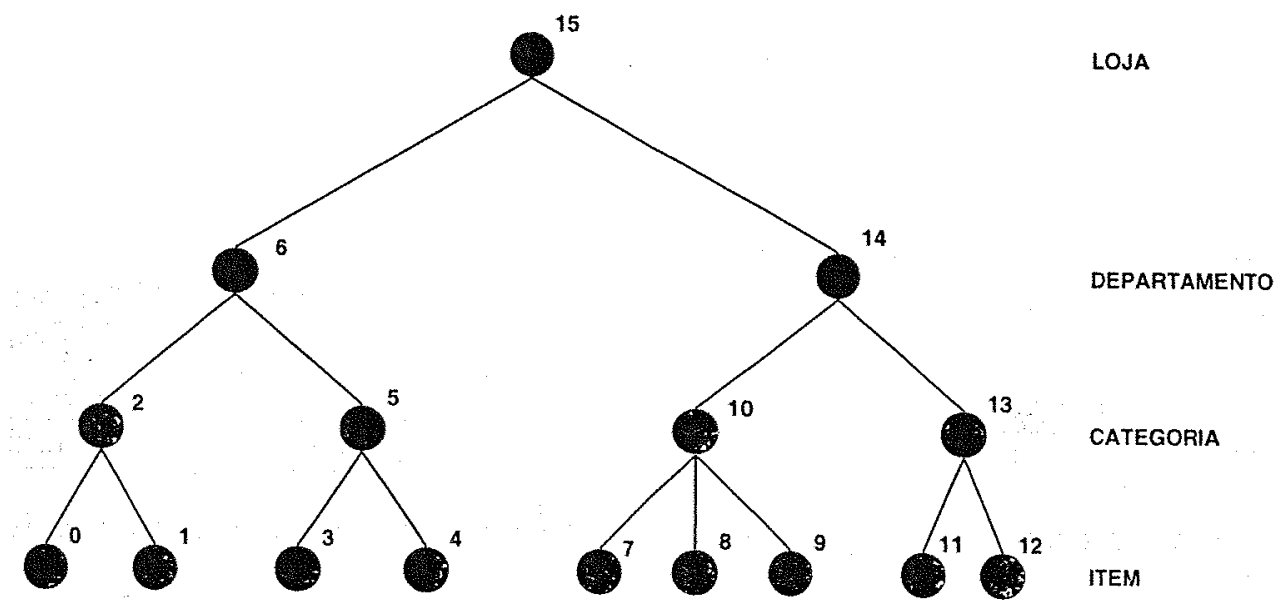

Figura 5: Codificação pós-fixada de uma hierarquia

Este método é utilizado para operações de drill-down em OLAP (ITALIANO; FERREIRA; TAKAI, 2001), e seu emprego usa características do SGBD DB2 v2, que permite definir a função que gera os códigos através de uma função definida pelo usuário, que é uma extensão fornecida pelo SGBD em questão. Entre dois conceitos pertencentes a uma mesma hierarquia de um mesmo atributo, para determinar se os mesmos pertencem à relação $\preceq$, o algoritmo deverá ter a função e verificar os valores do código gerado pela função. Este esquema de codificação, além de depender de um SGBD específico para sua implementação, pois utiliza uma funcionalidade própria do SGBD, necessita da informação do intervalo do código dos filhos de um vértice qualquer.

Um outro método de codificação é proposto em (LU, 1997), no qual cada vértice da hierarquia recebe um único código binário com $n$ campos, em que $n$ é o número do nível do vértice na hierarquia. Cada um dos campos deste código binário possui $k$ bits, no qual $k$ é o número de bits necessários para codificar os irmãos num mesmo nível da árvore. Este método é utilizado no sistema DBMiner que armazena, para cada caminho na hierarquia, o código correspondente numa tabela relacional, e o utiliza para gerar a tabela generalizada. Neste 
método, após a hierarquia ter sido codificada, para determinar se um vértice é filho de um outro, basta manipular o código dos vértices, não sendo necessário consultar a hierarquia. $\mathrm{Na}$ Figura 6, é mostrado como verificar se um vértice é descendente de outro. Após obter o número de bits correspondente a diferença entre os códigos, desloca-se para a direita o código de maior valor, e caso o valor resultante seja igual ao código do outro vértice (código de menor valor), então o vértice com o código maior é descendente do vértice de menor código.

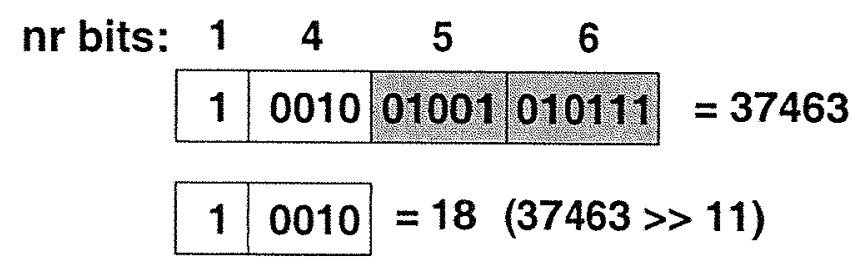

Figura 6: Dois códigos diferentes em que o vértice com código 37463 é um descendente do vértice com código 18

Isto épossível devido à seguinte propriedade:

Propriedade 1 Numa hierarquia, para quaisquer dois vértices $\mathbf{A}$ e $\mathbf{B}$ com códigos $c_{A 0} c_{A 1} \ldots c_{A i}$ e $c_{B 0} c_{B 1} \ldots c_{B j}$ respectivamente, $\mathbf{A}$ é filho de $\mathbf{B}$ se e somente se $i=j+1$ e $c_{A k}=c_{B k}$ para $k=0,1, \ldots j$

Esta propriedade é decorrente da formação dos códigos, cujos valores representam a relação $\preceq$. Na Figura 7, é mostrada uma hierarquia codificada pelo algoritmo de (LU, 1997). Este algoritmo recebe como entrada todos os caminhos entre o vértice raiz e uma folha da hierarquia, em ordem crescente, e o número máximo de irmãos em cada nível da hierarquia. Para cada caminho, o algoritmo percorre todos os vértices e gera seus códigos através da concatenação de números binários previamente gerados. A complexidade deste algoritmo é $\mathrm{O}(l m)$, em que $l$ é o número de níveis e $m$ é o número de vértices folha da hierarquia.

Conforme a propriedade citada anteriormente, através do código do vértice folha de uma hierarquia é possível obter o código de seus ascendentes. Por isso, para cada caminho, apenas o código do vértice folha deste caminho é armazenado, e a generalização é feita deslocando-se os códigos como mostrado na Figura 6. 


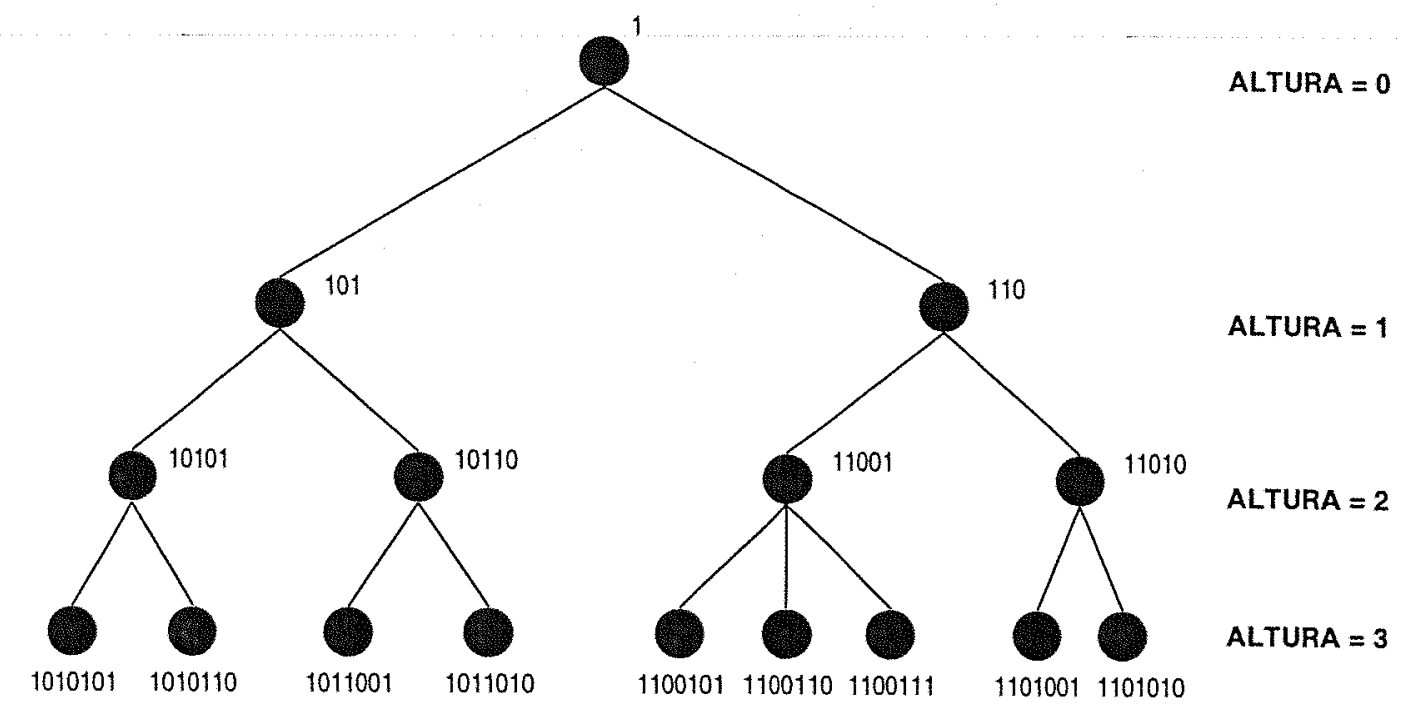

Figura 7: Codificação de uma hierarquia (LU, 1997)

\subsection{Regras de classificação}

Um das principais tarefas da descoberta de conhecimento é a classificação. No aprendizado supervisionado, o conjunto de itens do BD, para os quais são definidas classes, será denominado de conjunto de exemplos, que neste trabalho será representado por $E$ : A classe de um exemplo será indicada por $c$, em que $c \in C$ e $C$ é um conjunto de classes.

Seja $\mathcal{A}=\left\{A_{1}, \ldots, A_{m}, C\right\}$ um conjunto de atributos, tal que um exemplo $e \in E$, está descrito através dos valores dos atributos $\left\{A_{1}, \ldots, A_{m}\right\}$, isto é, $e=\left(a_{1}, \ldots, a_{m}\right)$ tal que $a_{j} \in \operatorname{Dom}\left(A_{j}\right)$ e $1 \leq j \leq m$, e sua classe está rotulada pelo atributo $C$, ou seja, classe $(e)=c$. O BD utilizado pelo algoritmo de aprendizado supervisionado será uma tabela sobre $\mathcal{A}$, no qual cada tupla desta tabela pode ser vista como um par ordenado $t=(e, c)$, ou seja, um exemplo e a classe à qual pertence.

\begin{tabular}{|c|lllll|}
\hline$t$ & $A_{1}$ & $A_{2}$ & $\ldots$ & $A_{m}$ & $C$ \\
\hline \hline$t_{1}$ & $a_{11}$ & $a_{12}$ & $\ldots$ & $a_{1 m}$ & $c_{1 n}$ \\
$t_{2}$ & $a_{21}$ & $a_{22}$ & $\ldots$ & $a_{2 m}$ & $c_{2 n}$ \\
$t_{3}$ & $a_{31}$ & $a_{32}$ & $\ldots$ & $a_{3 m}$ & $c_{3 n}$ \\
\hline
\end{tabular}

Tabela 4: Representação do BD utilizado por um algoritmo supervisionado

Em geral classe, pode ser qualquer função de classificação $f$ com domínio em $E$, e cujo conjunto imagem são as classes existentes, isto é: 


$$
f: E \rightarrow C
$$

Dado um $\mathrm{BD}$, o problema tratado pelo algoritmo de indução de regras é gerar uma regra de classificação que estime $f$.

Escolhida uma representação para a regra de classificação $r$, o conjunto $\mathcal{R}$ será o conjunto de todas as regras descobertas pelo algoritmo. Deste modo, o conjunto $\mathcal{R}$ representa uma função sobre $E$, ou seja:

$$
\mathcal{R}: E \rightarrow C
$$

O objetivo do algoritmo de aprendizado é achar um conjunto de regras $r$, denominado $\mathcal{R}$ tal que, $\exists r \in \mathcal{R} \mid r(e)=$ classe $(e)$ para toda tupla $t \in B D$.

Neste trabalho, a função de classificação será representada como um conjunto de regras da forma:

SE antecedente ENTÃo conseqüente.

O conseqüente é a classe predita. O antecedente é uma expressão na forma normal conjuntiva, isto é, uma conjunção de pares atributo-valor. Um par atributo-valor é uma condição envolvendo um atributo que descreve um exemplo, e um valor dentro de seu domínio. Por exemplo, utilizando a Tabela 4 , um atributo poderá ser qualquer um entre $\left\{A_{1}, A_{2}, \ldots, A_{m}\right\}$. Para atributos categóricos, esta condição é um simples teste de igualdade (e.g., $A_{1}=v$ ), e para atributos numéricos é uma inclusão num determinado intervalo fechado em um dos extremos (e.g., $1 \leq A_{2}<4$ ). Um mesmo atributo não poderá compor o antecedente de uma regra mais de uma vez, mesmo com um valor diferente.

Definição 6 Uma tupla de um BD satisfaz ou é coberto por uma regra $r$, se os atributos desta tupla possuem os mesmos valores que os atributos pertencentes ao antecedente de $r$.

A definição acima pode ser formalizada da seguinte maneira:

Seja $A$ o conjunto dos atributos do antecedente da regra $r$ e $v\left(a_{i}\right)$ o valor do atributo $a_{i} \in A$. Seja $B$ o conjunto dos atributos de uma tupla $t$ e $v\left(b_{j}\right)$ o valor do atributo $b_{j} \in B$. 
Define-se que uma tupla $t$ satisfaz ou é coberta pela regra $r$ se:

$$
\forall i, \exists j \mid a_{i}=b_{j} \rightarrow v\left(a_{i}\right)=v\left(b_{j}\right)
$$

Definição 7 uma regra é consistente com um conjunto de tuplas do BD se cada tupla for coberta pela regra e pertencer à classe (o conseqüente) da mesma.

Formalmente temos:

Seja $C$ o atributo classificador do BD. Seja $v_{r}(C)$ o valor do atributo $C$ do conseqüente da regra $r$. Uma regra $r$ é consistente com a tupla $t$ se:

$$
\forall i, \exists j \mid\left(a_{i}=b_{j} \rightarrow v\left(a_{i}\right)=v\left(b_{j}\right)\right) \wedge v_{r}(C)=c
$$

Considerando a indução de regras de classificação utilizando-se hierarquias conceituais, as definições anteriores serão modificadas do seguinte modo:

Definição 8 uma tupla de um BD satisfaz ou é coberto por uma regra $r$ de alto nivel; se os atributos da tupla possuem valores que precedem os valores dos atributos do antecedente de $r$.

A definição acima pode ser escrita da seguinte forma:

Seja $A$ o conjunto dos atributos do antecedente de $r, \mathcal{H C}_{i}$ uma hierarquia de conceitos do atributo $A_{i}$ e $v\left(a_{i}\right)$ o valor do atributo $a_{i}$, tal que $v\left(a_{i}\right) \in \mathcal{H C}_{i}$. Seja $B$ o conjunto dos atributos de uma tupla $t$ e $v\left(b_{j}\right)$ o valor do atributo $b_{j} \in B$. Define-se que uma tupla satisfaz ou é coberta por uma regra $r$ de alto nivel se:

$$
\forall i, \exists j \mid a_{i}=b_{j} \rightarrow v\left(b_{j}\right) \preceq v\left(a_{i}\right)
$$

Definição 9 uma regra de alto nivel $r$ é consistente com um conjunto de tuplas do BD se cada tupla for coberta por $r$ e pertencer à classe (o conseqüente) da mesma. Caso contrário a regra é inconsistente com o conjunto de tuplas. 
Formalmente temos:

Seja $C$ o atributo classificador do BD. Seja $v_{r}(C)$ o valor do atributo $C$ do conseqüente de $r$. Uma regra $r$ é consistente com uma tupla $t$ se:

$$
\forall i, \exists j \mid\left(a_{i}=b_{j} \rightarrow v\left(b_{j}\right) \preceq v\left(a_{i}\right)\right) \wedge v_{r}(C)=c
$$

As hierarquias conceituais serão utilizadas apenas para os valores dos atributos que descrevem um exemplo e não para os valores da sua classe.

\subsection{Medidas de relevância}

A relevância de uma regra descoberta ou induzida necessita que duas condições sejam satisfeitas: (i) condição de completude e (ii) condição de consistência, (MICHALSKI, 1983).

Uma regra é completa, em relação a um $\mathrm{BD}$, se ela cobre todos as tuplas pertencentes à classe do conseqüente. Uma regra é consistente, em relação a um $\mathrm{BD}$, se ela não cobre qualquer tupla pertencente à uma classe diferente do conseqüente da regra.

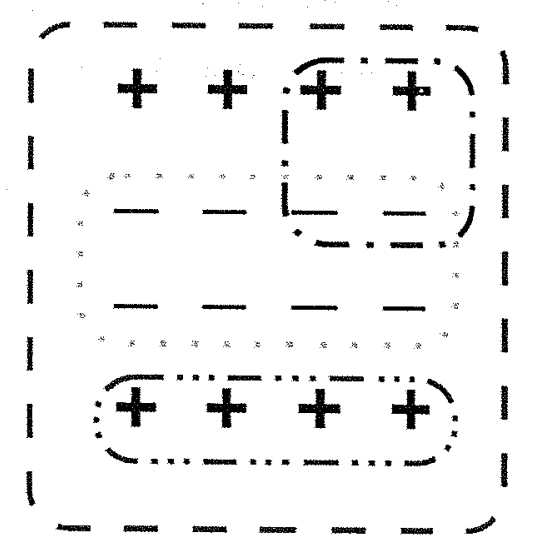

Figura 8: Completude e consistência de diferentes regras nas classes - e +

Na Figura 8 estão delimitados por linhas os exemplos cobertos por quatro regras. Apenas a regra de linha pontilhada é completa e consistente na classe -.

As diferentes medidas de relevância existentes para avaliação de regras de classificação, por exemplo, (HILDERMAN; HAMILTON, 1999) e (KODRATOFF, 2001), quantificam as duas condições anteriormente citadas. Dentre as medidas mais utilizadas estão a confiança e 
o suporte relativo (MICHALSKI; KAUFMAN, 2001) (este último é tämbém denominado de cobertura positiva (PROVOST; ARONIS; BUCHANAN, 1999)), normalmente usadas na descoberta de regras de classificação. O suporte relativo, ou simplesmente suporte (como será denominado neste trabalho), de uma regra $A \rightarrow C$ é a razão entre o número de exemplos que são consistentes com a regra e o número de exemplos que pertencem à classe $C$. A confiança é a razão entre o número de exemplos consistentes com a regra e o número de exemplos cobertos pela regra, isto é, a probabilidade condicional do conseqüente de uma regra dado que ocorre o antecedente: $P(C \mid A)$. Por exemplo, uma regra em que $p$ exemplos são consistentes e $p+n$ exemplos são cobertos, e há $P$ exemplos que pertencem à classe $C$, terá os seguintes valores de suporte e confiança:

$$
\sup =\frac{p}{P} \quad \text { e } \quad \operatorname{conf}=\frac{p}{n+p}
$$

Dadas as expressões acima, observa-se que os valores de suporte e confiança variam entre $[0,1]$. Se sup $=1$, então a regra é completa pois todas os exemplos que pertencem à classe são cobertas pela regra. Se conf $=1$, então a regra é consistente e classifica corretamente os exemplos na classe $C$ e não classifica nenhuma incorretamente. Regras com valores elevados de suporte e confiança são denominadas regras fortes.

\subsubsection{Cálculo de medidas de relevância num BD}

Num sistema de descoberta envolvendo grandes BD, não é possível trabalhar com os dados diretamente na memória principal. Assim, para que sejam obtidos os valores necessários para o cálculo das medidas de relevância, o algoritmo de descoberta deverá enviar requisições ao $\mathrm{BD}$, por exemplo, através de expressões em SQL, definindo assim uma arquitetura clienteservidor. Em (FREITAS, 1997) é apresentada uma expressão em SQL para avaliação de uma hipótese de regra, que corresponde a uma requisição básica traduzida na seguinte expressão em SQL:

SELECT Atributo_Candidato, Atributo_Classe, COUNT(*)

FROM Tabela_Dados

WHERE Descritor_Tuplas

GROUP BY Atributo_Candidato, Atributo_Classe;

sendo: 
- Atributo_Candidato, o último atributo adicionado ao antecedente da hipótese de regra;

- Atributo_Classe, o atributo que contém a classe a que pertence a tupla no BD;

- Tabela_Dados, a tabela do BD onde estão armazenados os dados e

- Descritor_Tuplas os atributos pertencentes ao antecedente da regra e seus respectivos valores, excetuando-se o Atributo_Candidato.

Dado o antecedente da regra $R:$ COR_ESPORO = PRETA, a expressão básica em SQL de uma nova hipótese de regra obtida pela adição de mais um atributo a $R$, por exemplo, $R^{\prime}$ : COR_ESPORO $=$ PRETA $\wedge$ FORMA $=$ ACHATADA, num BD no qual a tabela com os dados denomina-se Tabela_Cogumelos e $C$ é o atributo classe será:

SELECT forma, C, COUNT(*)

FROM Tabela_Cogumelos

WHERE cor_esporo = 'preta'

GROUP BY forma, C;

A saída desta expressão em SQL pode ser resumida pela matriz da Tabela 5 , que contém as quantidades de: tuplas que satisfazem à restrição de valor do Descritor_Tuplas (ou seja, da regra $R$ antes de se adicionar o Atributo__Candidato).

\begin{tabular}{l|lll|l} 
& $C_{1} \ldots C_{j} \ldots C_{n}$ & Total \\
\hline$A v_{1}$ & $T_{11} \ldots \ldots$ & $\ldots$ & $T_{1 n}$ & $T_{1+}$ \\
. & $\ldots \ldots$ & $\ldots$ & $\cdot$ \\
$A v_{i}$ & $\ldots \ldots T_{i j}$ & $\ldots$ & $T_{i+}$ \\
. & $\ldots \ldots$ & $\ldots$ & $\cdot$ \\
$A v_{m}$ & $T_{m 1} \ldots \ldots$ & $\ldots$ & $T_{m n}$ & $T_{m+}$ \\
\hline Total & $T_{+1} \ldots T_{+j} \ldots T_{+n}$ & $T_{++}$
\end{tabular}

Tabela 5: Estrutura geral da saída da primitiva de contagem, na qual $A v_{i}$ significa os valores do Atributo_Candidato $(1 \leq i \leq m), C_{j}$ representa os valores do Atributo Classe $(1 \leq j \leq n)$, $T_{i j}$ o número de tuplas que têm o valor $A v_{i}$, atendem à restrição de valor do Descritor Tuplas e pertencem a classe $C_{j}, T_{i+}$ o total de tuplas na linha $i, T_{+j}$ o total de tuplas na coluna $j$ e $T_{++}$ o total de tuplas.

Através desta expressão básica, denominada primitiva de contagem, Alex Freitas (FREITAS, 1997) apresenta diversas medidas que podem ser obtidas na avaliação de regras de classificação. Na Seção 3.5.1 será mostrado como a primitiva de contagem pode ser modificada quando utilizadas hierarquias conceituais. 


\subsection{Definição do problema de descoberta de regras de classificação}

Dado um conjunto de exemplos e as respectivas classes, um sistema de mineração de dados pode gerar inúmeras hipóteses de regras candidatas a serem um padrão descoberto. Algumas destas hipóteses são mais corretas do que outras, ou seja, têm mais chance de classificar corretamente um exemplo futuro.

Dado um BD no qual as tuplas são representadas como na Seção 2.3, o problema de descoberta de regras de classificação pode ser definidos de duas formas:

Problema 1: Descoberta de regras de classificação sem o uso de hierarquias conceituais. Dado um BD, um conjunto de medidas de relevância com seus valores mínimos desejados, descobrir um conjunto de regras de classificação que atendem aos valores mínimos desejados das medidas de relevância.

Problema 2: Descoberta de regras de classificação com o uso de hierarquias conceituais. Dado um BD, um conjunto de medidas de relevância com seus valores mínimos desejados e um conjunto de hierarquias conceituais, descobrir um conjunto de regras de classificação em relação à um conjunto de hierarquias conceituais, que atendem aos valores mínimòs desejados das medidas de relevância.

No problema 2, o uso de hierarquias conceituais irá aumentar o domínio dos valores de um atributo, ou seja, os valores de determinado atributo são acrescidos dos conceitos em níveis não folha da hierarquia correspondente.

Para se calcular o tamanho do conjunto de todas as hipóteses de regra, considere a Tabela 3. Dado que os atributos cor_esporo e forma possuem quatro valores possíveis e o atributo cor_topo possui três valores, um BD composto por esses três atributos pode possuir $48(4 \times 4 \times 3)$ diferentes tuplas, não considerando um valor nulo em qualquer dos atributos. A partir desse $\mathrm{BD}$, podemos investigar regras cujo tamanho varie entre zero e três atributos, e desta forma podem ser geradas $100(5 \times 5 \times 4)$ hipóteses de regras, ou seja:

$$
\prod_{\mathcal{A}}\left(\left|\operatorname{Dom}\left(A_{i}\right)\right|+1\right)
$$

Nota-se que o número de possíveis descrições elementares (regras) de uma classe depende do tamanho do domínio dos atributos e do próprio número destes, e não do número de tuplas do BD. Como uma classe pode ser descrita através de um conjunto de regras, o número de 
possíveis descrições de uma classè é qualquer subconjunto das possíveis regras. No exemplo anterior, $2^{100}-1$ e a fórmula geral obtida é:

$$
2^{\prod_{\mathcal{A}}\left(\left|\operatorname{Dom}\left(A_{i}\right)\right|+1\right)}-1
$$

Entre as descrições de classe, uma regra na qual o atributo $A_{i}$ não esteja presente, equivale às regras em que $A_{i}$ assume qualquer valor no seu domínio. Então, o valor em 2.5 será:

$$
\prod_{\mathcal{A}}\left(\left|\operatorname{Dom}\left(A_{i}\right)\right|\right)
$$

e agora, o número de descrições distintas é:

$$
2^{\Pi_{\mathcal{A}}\left(\left|\operatorname{Dom}\left(A_{i}\right)\right|\right)}-1
$$

Portanto, o número de possíveis regras cresce exponencialmente com o número de valores do domínio de cada atributo.

\subsubsection{Espaço de busca}

Como visto na seção 2.5 , tanto para a mineração com ou sem hierarquias conceituais, o espaço de hipóteses de regras é geralmente muito grande para ser percorrido por uma busca exaustiva. Por isso, definindo-se uma medida de qualidade, os algoritmos de mineração escolhem uma hipótese, ou um conjunto de hipóteses inicial e iterativamente o modifica melhorando a sua qualidade. Estas modificações são operações sobre as hipóteses de regras. O conjunto de hipóteses juntamente com as operações e a função de qualidade é chamado de espaço de busca.

Deste modo, para definir o problema de descoberta de regras de classificação num BD (Problema 1 e 2) como um problema de busca num espaço de hipóteses de regras, temos que especificar: o Estado Inicial, as Operações que geram nós sucessores neste espaço e o Teste para verificar se um nó é uma solução.

O conjunto de operações pode ser dividido em operações de generalização e operações de especialização.

- Generalização Aplicando-se a operação de generalização a uma hipótese de regra 
$H$ resulta numa nova hipótese de regra $H^{\prime}$ que cobre mais objetos, ou seja, se um objeto representado pelo exemplo e for coberto por $H$, então e também é coberto por $H^{\prime}$, porém o contrário não é verdadeiro. Deste modo, se uma regra classifica corretamente os objetos, a generalização desta regra não irá, necessariamente, classificálos corretamente. Entretanto, a generalização de regras preserva o falso: se um objeto é classificado incorretamente por uma regra (o objeto torna a regra falsa), então este objeto também o será pela regra generalizada.

- Especialização A especialização é a operação inversa da generalização. A especialização de uma hipótese de regra $h$ gera uma nova hipótese de regra $h^{\prime}$ que cobre um número menor ou igual de objetos que sua antecessora.

Assim, a criação do espaço de hipóteses de regras, pode ser feita através da especialização progressiva (abordagem de cima para baixo), ou da generalização progressiva (abordagem de baixo para cima).

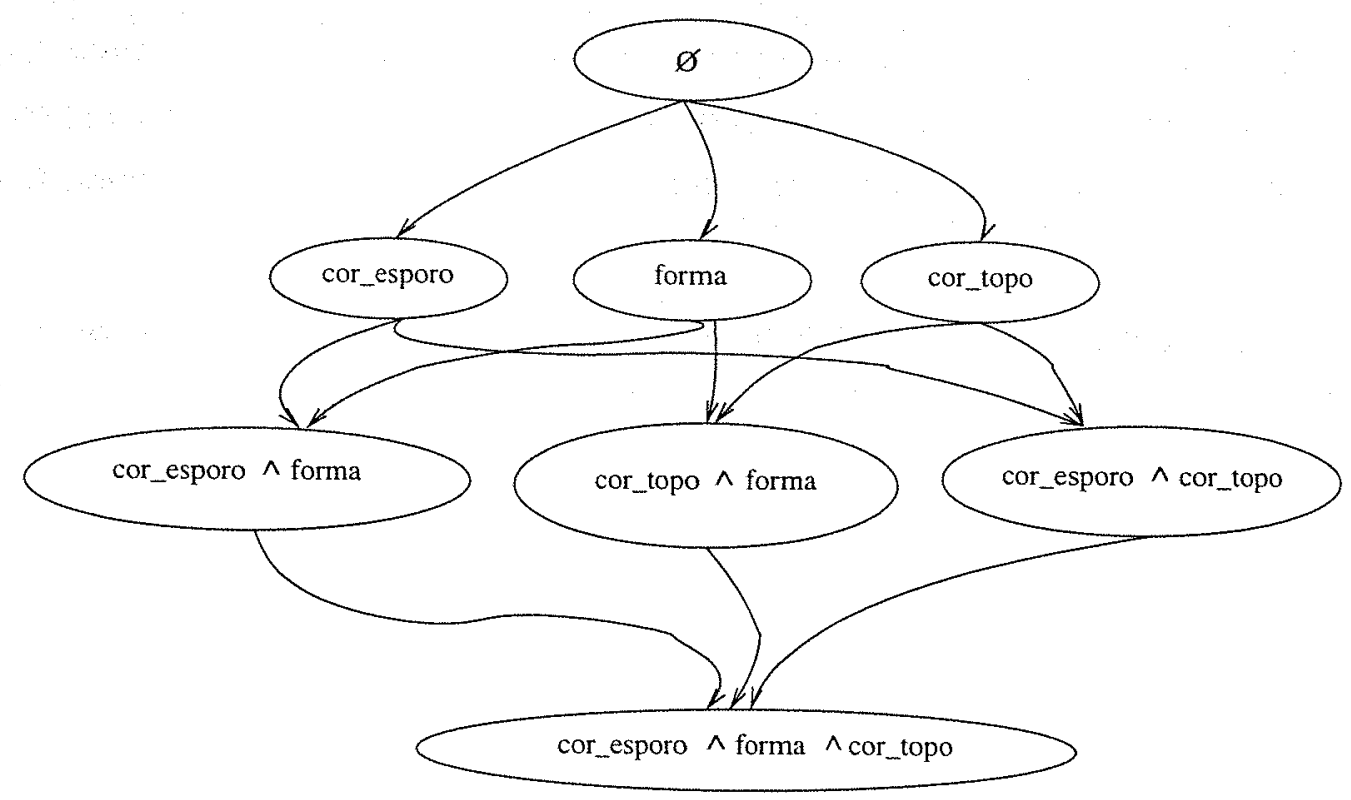

Figura 9: Espaço de busca de regras

Pode-se estruturar o espaço de hipóteses como uma árvore cuja raiz é a hipótese de regra mais geral (a regra nula) que, por não possuir nenhuma restrição sobre os atributos do $\mathrm{BD}$, cobre todos os exemplos. Os nós folha desta árvore representam as hipóteses mais específicas e as arestas as operações. O desenho da Figura 9 ilustra um espaço de hipóteses gerado pela combinação dos atributos da Tabela 3 (não são indicados os valores dos atributos por motivo de espaço), no qual a orientação das arestas representam as operações de especialização. 


\subsubsection{Geração das regras de classificação e suas propriedades}

Em KDD, sem a disponibilidade de uma hierarquia de conceitos, uma hipótese de regra de classificação pode ser especializada através da adição de um par atributo-valor. Esta operação será denominada de especialização pela adição de atributo. Por exemplo, dado o BD da Tabela 3 , uma determinada regra $R$ pode ser especializada gerando a regra $R_{1}$, a saber:

$R:$ COR_ESPORO $=$ PRETA $\rightarrow$ CLASSE $=$ VENENOSO

$R_{1}:$ COR_ESPORO $=$ PRETA $\wedge$ FORMA $=$ ACHATADA $\rightarrow$ CLASSE $=$ VENENOSO

No caso de existir hierarquias de conceitos para um determinado conjunto de atributos do BD, pode-se ainda realizar a especialização da hipótese de regra através da substituição do valor de um atributo por um outro que esteja num nível de abstração inferior na hierarquia conceitual. Esta operação será denominada de especialização na hierarquia. Neste caso, a regra a ser especializada contém um atributo com valor correspondente a um vértice não folha da hierarquia. Por exemplo, utilizando-se o BD da Tabela 3 (página 30) e a hierarquia da Figura 4, uma dada regra $R^{\prime}$ pode ser especializada utilizando as duas operações mencionadas acima, gerando as regras $R_{1}^{\prime}$ e $R_{2}^{\prime}$, a saber:

$$
\begin{aligned}
& R^{\prime}: \text { COR_ESPORO }=\text { ESCURA } \rightarrow \text { CLASSE }=\text { VENENOSO } \\
& R_{1}^{\prime}: \text { COR_ESPORO }=\text { ESCURA } \wedge \text { FORMA }=\text { ACHATADA } \rightarrow \text { CLASSE }=\text { VENENOSO } \\
& R_{2}^{\prime}: \text { COR_ESPORO }=\text { PRETA } \rightarrow \text { CLASSE }=\text { VENENOSO }
\end{aligned}
$$

Por possuir um valor não-folha da hierarquia conceitual, a regra $R^{\prime}$ é uma regra mais geral do que a regra $R$ : cor_esporo $=$ preta, pois $R^{\prime}$ cobre as tuplas que possuem todos os valores de nós folha desta hierarquia, i.e., preta, marrom, chocolate e canela.

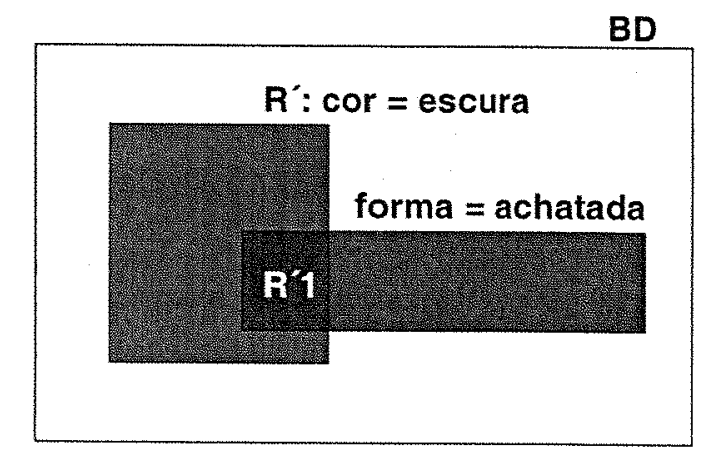

Figura 10: Representação dos conjuntos formados pelas regras $R^{\prime}$ e $R_{1}^{\prime}$

A regra $R_{1}^{\prime}$ é uma especialização da regra $R^{\prime}$ obtida pela adição de atributo. Esta regra 
é mais específica que $R^{\prime}$ pois ela cobre, no máximo, tantos exemplos quanto a regra $R^{\prime}$. A Figura 10 representa o diagrama de Venn dos conjuntos de tuplas de um BD. O conjunto de exemplos que satisfazem a regra $R_{1}^{\prime}$ é a interseç̧ão do conjunto de $R^{\prime}$ com o conjunto dos exemplos que possuem o valor achatada no atributo forma, o que leva a seguinte propriedade:

Propriedade 2 O número de exemplos que satisfazem a regra especializada pela adição de atributo é menor ou igual ao número de exemplos da regra mais geral.

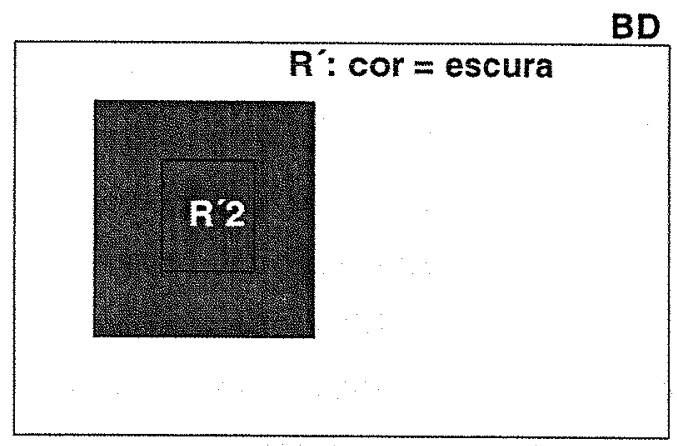

Figura 11: Representação dos conjuntos formados pelas regras $R^{\prime}$ e $R_{2}^{\prime}$

A regra $R_{2}^{\prime}$ é uma especialização da regra $R^{\prime}$ obtida pela especialização na hierarquia. Esta regra é mais específica que $R^{\prime}$ pois ela se aplica a um subconjunto dos exemplos que pertencem ao conceito escura, como mostrado na Figura 11. Aqui também o número de exemplos que satisfazem a nova regra nunca será maior do que o número de exemplos da regra mais geral, o que leva a segunda propriedade:

Propriedade 3 O número de exemplos que satisfazem a regra especializada na hierarquia é menor ou igual ao número de exemplos da regra mais geral.

Utilizando-se as medidas de suporte e confiança mencionadas na Seção 2.4 (página 36), seus valores irão variar conforme mostrado na Tabela 6. Uma hipótese mais específica nunca terá seu valor de suporte maior que o da hipótese que lhe deu origem, segundo as proriedades 1 e 2, pois, agora, o valor de $p$ não será maior que o valor da hipótese mais geral. Em relação à confiança, o valor de $n$, na hipótese mais específica poderá ter menos exemplos classificados incorretamente do que a hipótese mais geral (o que reduzirá o valor de $n$ da hipótese especializada), e o mesmo número de exemplos classificados corretamente, mantendo o valor $p$. Isto aumentará a razão $\frac{p}{p+n}$. Porém, este aumento poderá não ocorrer caso a distribuição do número de exemplos que são classificadas corretamente e incorretamente 


\begin{tabular}{|l|l|l|}
\hline OPERADORES DE ESPECIALIZAÇÃO & SUPORTE & CONFIANÇA \\
\hline \hline especialização pela adição de atributo & $\leq$ & $\leq$ ou $>$ \\
\hline especialização na hierarquia & $\leq$ & $\leq$ ou $>$ \\
\hline
\end{tabular}

Tabela 6: Variação das medidas de suporte e confiança de acordo com a operação de especialização. O valor de suporte de uma hipótese de regra só diminui com operações de especialização, enquanto que a confiança pode aumentar

entre as hipóteses especializadas seja igual, fazendo com que a razão anterior permaneça inalterada. Neste caso, deverão ser investigadas hipóteses mais específicas ainda.

A princípio, o uso de hierarquias de conceitos implica um aumento dos possíveis valores que um atributo pode assumir uma vez que, o conjunto de todos os valores de um atributo é acrescido dos valores dos vértices não-folha da hierarquia de conceitos. No entanto, empregando-se a especialização progressiva é possível realizar a descoberta de regras de classificação analisando regiões do espaço de busca com um número menor de hipóteses antes de analisar regiões mais povoadas. Por exemplo, utilizando a Tabela 3 (página 30) e a hierarquia da Figura 4 (página 28), são quatro as hipóteses de regra que contêm apenas um atributo, a saber:

$R 1:$ COR_ESPORO $=$ ESCURA $\rightarrow$ VENENOSO

$R 2: \mathrm{COR}_{\text {ESSPORO }}=\mathrm{CLARA} \rightarrow \mathrm{VENENOSO}$

$R 3: \mathrm{COR}_{\text {_TOPO }}=\mathrm{CLARA} \rightarrow \mathrm{VENENOSO}$

$R 4:$ COR_TOPO $=$ ESCURA $\rightarrow$ VENENOSO

Caso não houvesse a hierarquia conceitual, o número de regras inicialmente analisadas seria igual a sete, pois o atributo só poderia ter o valor existente no BD. As hierarquias de conceitos permitem que um menor número de regras sejam examinadas a cada iteração do problema e utilizando-se critérios de poda, pode-se reduzir o número total de regras que serão examinadas pelo algoritmo.

O algoritmo proposto neste trabalho empregará a especialização progressiva a partir do nó raiz contendo a hipótese nula. Esta escolha foi feita pois regras com nível de abstração mais elevado são mais informativas e geralmente mais interessantes. Além disso, essa estratégia pode reduzir a complexidade do espaço de busca, como será descrito a seguir. 


\subsubsection{Algoritmos de busca}

O problema de descoberta de regras pode ser formulado como um problema de busca segundo a Tabela 7. Essa formulação corresponde à especialização progressiva, sendo o Estado Inicial a regra vazia. O algoritmo apresentado na Figura 12 é um algoritmo geral de busca aplicado à tarefa de descobrir regras que atendam aos valores mínimos das medidas de relevância.

\begin{tabular}{|l|l|}
\hline Estado Inicial & a regra vazia \\
\hline Operadores & $\begin{array}{l}\text { aplicação das operações de especialização de regras } \\
\text { a) adição de atributo. } \\
\text { b) especialização na hierarquia. }\end{array}$ \\
\hline Teste do estado meta & $\begin{array}{l}\text { cálculo das medidas de relevância da hipótese de regra } \\
\text { para comparação com os valores mínimos estipulados } \\
\text { pelo usuário }\end{array}$ \\
\hline
\end{tabular}

Tabela 7: Definição do Espaço de Busca

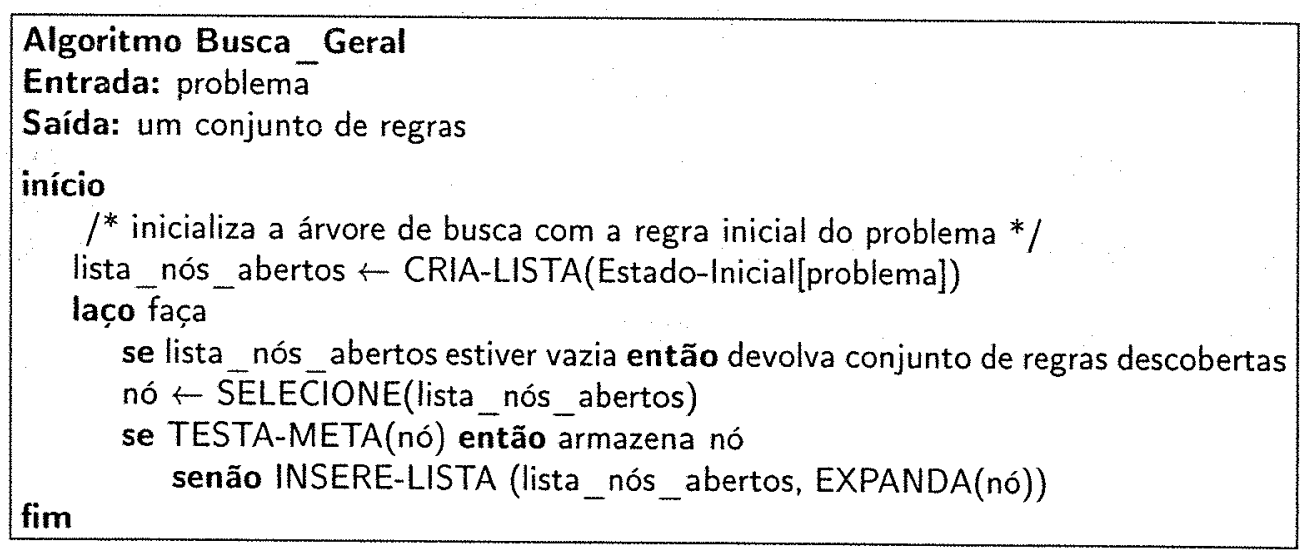

Figura 12: Algoritmo de busca por regras de classificação

A função CRIA-LISTA() cria a lista_nós_abertos que, inicialmente, contém apenas a regra vazia. A lista_nós_abertos é processada enquanto possuir elementos. Um nó é selecionado da lista_nós_abertos de acordo com algum critério que define a estratégia de busca (largura, profundidade, etc). A função TESTA-META() verifica se a hipótese de regra, representada pela variável nó, atende aos valores mínimos das medidas de relevância. Se isso for verdade, então esta hipótese será armazenada como uma regra descoberta senão, o nó será expandido. Deste modo, uma hipótese de regra, que atenda aos valores mínimos das medidas de relevância, será uma regra descoberta e o nó associado à regra não será mais expandido. Se o nó não gerar uma regra descoberta, ele será expandido pela função EXPANDA(), que gera seus nós sucessores, através das operações de especialização. A função 
INSERE-LISTA() irá inserir na lista_nós_abertos os sucessores de nó. As diferentes políticas de inserção e retirada de nós na lista, definem as diferentes estratégias de busca (busca em largura, busca em profundidade).

As soluções para o problema de busca descrito na Tabela 7, serão os nós (hipóteses de regras) que satisfazem os valores mínimos das medidas de relevância dados como entrada pelo usuário.

Dentre os diferentes algoritmos propostos para percorrer o espaço de estados, serão descritos aqueles mais importantes para esta dissertação.

\section{Busca em largura}

A busca em largura percorre o espaço de estados visitando os nós que estão mais próximos do estado inicial antes de visitar aqueles mais distantes. Na Figura 12, a lista_nós_abertos será administrada como uma fila. A complexidade da busca em largura é $\mathrm{O}\left(b^{d}\right)$ no tempo da execução e espaço de memória necessários para armazenar a lista de nós abertos, em que $b$ é o número de nós sucessores que podem ser gerados a partir de um nó e $d$ é a profundidade da árvore.

\section{Busca em feixe - Beam search}

$\mathrm{Na}$ busca em feixe, o espaço de busca é percorrido da mesma forma que na busca em largura. A cada nível da árvore de busca a quantidade de nós a serem expandidos é fixada num número constante $k$, sendo $k$ a largura do feixe. Consequentemente, a árvore de busca irá crescer linearmente em profundidade. Os nós do feixe podem ser selecionados de acordo com alguma medida de qualidade.

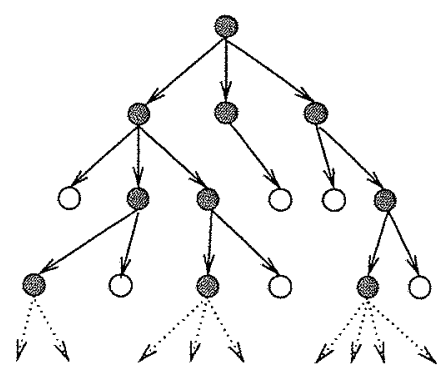

Figura 13: Busca em feixe com $k=3$ - apenas os três melhores nós são expandidos a cada nível do espaço de busca

A definição da largura do feixe que garante encontrar uma solução e da função heurística usada para selecionar os nós do feixe são pontos cruciais para o sucesso desta busca. Na Figura 14 é apresentado o algoritmo de busca em feixe em pseudo-código. A lista feixe 
irá armazenar os $k$ nós retirados da lista_nós_abertos que serão expandidos. A expansão de cada um destes nós será armazenada na lista_nós_sucessores para serem testados e, caso o nó sucessor não atinja o valor mínimo das medidas de relevância, ele será inserido na lista_nós_abertos.

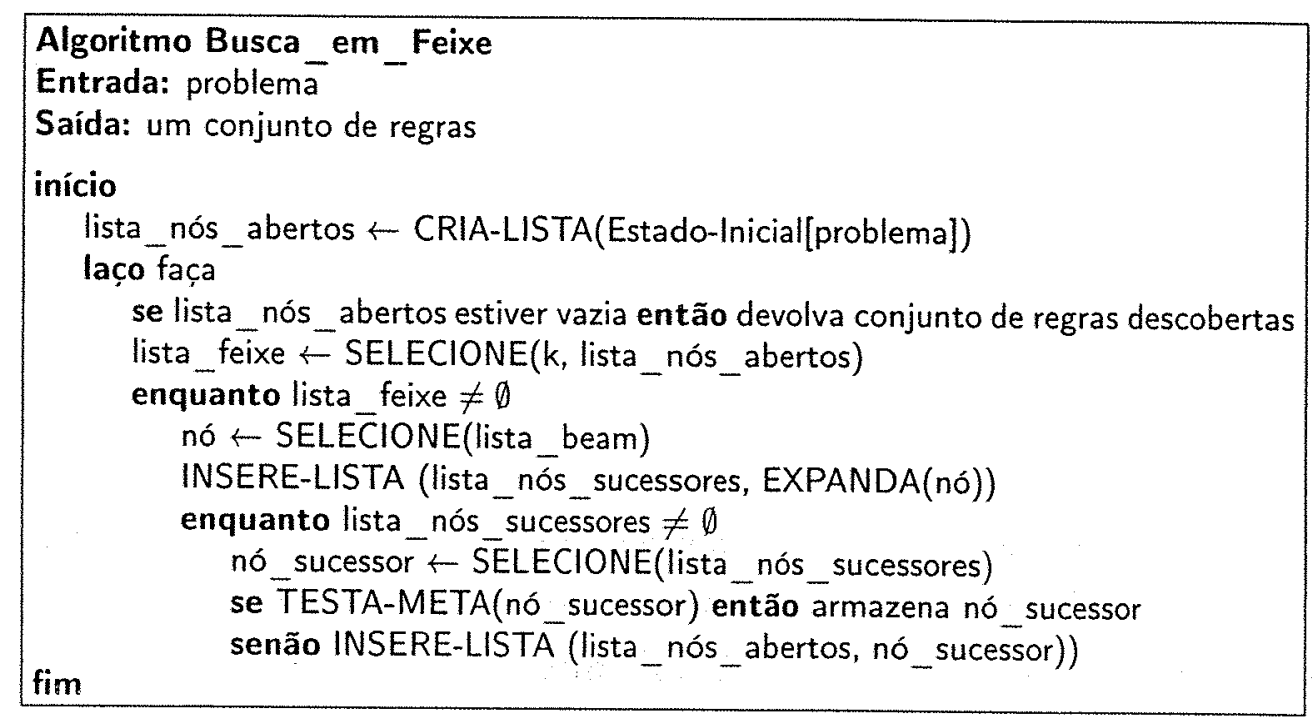

Figura 14: Algoritmo de busca em feixe

Uma regra de classificação possui um antecedente e um conseqüente, sendo este último uma das classes existentes no BD. Escolhida uma representação da regra, a geração do espaço de busca deverá representar todas as possíveis hipóteses de regras. No algoritmo proposto, cada estado do espaço de busca representa apenas o antecedente da regra definido assim um conjunto de hipóteses de regra. Por exemplo, seja $C=\left\{c_{a}, c_{b}, c_{c}, c_{d}\right\}$ as classes existentes no $\mathrm{BD}$. Um estado da busca é representado pelas quatro hipóteses de regra abaixo, que possuem o mesmo antecedente mas conseqüentes diferentes (classes).

$$
\begin{aligned}
& h_{1}: \text { ANTECEDENTE } \rightarrow c_{a} \\
& h_{2}: \text { ANTECEDENTE } \rightarrow c_{b} \\
& h_{3}: \text { ANTECEDENTE } \rightarrow c_{c} \\
& h_{4}: \text { ANTECEDENTE } \rightarrow c_{d}
\end{aligned}
$$

Estas hipóteses de regra podem ser representadas por apenas um nó do espaço de busca, que possui como valor o ANTECEDENTE. Isto facilita o uso da primitiva de contagem (Seção 2.4.1), permitindo assim obter os dados para o cálculo das medidas de suporte e confiança, em todas as possíveis classes, com apenas uma consulta. Observe que, apesar de existir mais de uma classe, um valor de confiança maior que $50 \%$ somente ocorrerá em apenas uma delas, 
ou seja, não é necessário utilizar um nó para cada classe e sim um nó para cada antecedente da hipótese de regra.

\subsubsection{Geração de nós sucessores com o uso de hierarquias conceitu- ais}

A estratégia de escolha das operações de especialização pode ser realizada da seguinte forma:

1. Especialização na hierarquia (critério de $O c c a m)^{1}$.

2. Se a especialização anterior não resultar numa regra, a hipótese será especializada pela adição de atributo.

A decisão de especializar descrita em 2, pode ser feita de duas formas, sendo $R:(A, a)$, uma hipótese de regra contendo um atributo $A$ com valor $a$ :

(i) adicionar à regra $R$ um novo atributo $B$, mantendo o atributo $A$ com o valor $a$, e.g., $R^{\prime}:(A, a) \wedge(B, b)$ ou

(ii) substituir o valor $a$ do atributo $A$ por um outro valor $a^{\prime}$ existente na hierarquia, e então adicionar um novo atributo, e.g., $R^{\prime}:\left(A, a^{\prime}\right) \wedge(B, b)$.

A forma descrita em (i) pode levar a uma redução muito grande no número de tuplas que satisfazem a nova regra especializada pois, no caso do valor a ser um conceito de baixo nível, o número de tuplas que satisfazem o valor a para o atributo $A$ nunca seria maior que um valor de mais alto nível, o que diminuiria a chance desta hipótese se tornar uma regra descoberta usando o suporte como medida de relevância. Em (TAYLOR, 1999), que utiliza a medida de suporte, é proposta a forma em (ii), onde a será substituído por um valor mais alto na hierarquia de conceitos do atributo $A$.

\section{Critérios de poda na geração do espaço de busca}

A decisão de expandir um nó pode, por exemplo, se basear no cálculo do suporte. Como foi descrito na Seção 2.5.2, uma hipótese que não possui o valor mínimo de suporte, implica que hipóteses especializadas a partir dela também não terão o valor mínimo (Tabela 6). Assim, esta hipótese pode ser descartada reduzindo-se assim o espaço de busca a ser explorado.

\footnotetext{
${ }^{1}$ De acordo com o princípio da Navalha de Occam, para duas hipóteses com a mesma relevância, a hipótese menor é melhor que a maior. Sendo assim, como a adição de mais um atributo aumenta o tamanho da regra, é melhor especializá-la na hierarquia antes de adicionar mais um atributo
} 
Um outro critério de poda pode ser feito excluindo-se hipóteses que, depois de especializadas, não resultaram em melhora no valor de confiança.

\subsection{Realização de testes}

As regras descobertas deverão ser testadas num conjunto de exemplos não utilizado para a mineração das regras, estimando-se, assim, o erro de predição do conjunto de regras descobertas.

O conjunto de exemplos no qual o algoritmo irá efetuar a mineração, é denominado conjunto de treinamento, e o conjunto no qual será aplicado o conjunto de regras é denominado conjunto de teste.

Idealmente, se houver dados suficientes, pode-se retirar uma parte dos exemplos e formar um conjunto de teste. Entretanto, se o número de exemplos disponíveis for escasso a divisão do conjunto de exemplos reduzirá ainda mais este número. Para minimizar este problema, utiliza-se a $K$-partes validação cruzada, em inglês $K$-fold cross validation (HASTIE; TIBSHIRANI; FRIEDMAN, 2001), na qual parte dos dados são utilizados como treinamentito, e uma parte diferente como teste.

Os dados são divididos em $K$ partes de mesmo tamanho. Por exemplo, com $K=5$, o cenário seria o mostrado na Figura 15.

\begin{tabular}{|c|c|c|c|c|}
\hline 1 & 2 & 3 & 4 & 5 \\
\hline TREINO & TREINO & TREINO & TESTE & TREINO \\
\hline
\end{tabular}

Figura 15: Divisão de um conjunto de exemplos em cinco partes

Dividindo-se o conjunto de exemplos em cinco partes e extraindo-se a $i$-ésima parte (a quarta parte na Figura 15), o algoritmo utiliza as outras $K-1$ partes como conjunto de treinamento, e a $i$-ésima parte é utilizada como conjunto de teste. Isto é feito para $i=1,2, \ldots, K$ sendo a média das $K$ medidas o valor desejado.

Seja $\operatorname{Med}\left(R_{i}\right)$ uma medida calculada para um conjunto de regras $R_{i}$, o qual foi obtido removendo-se do conjunto de exemplos a $i$-ésima parte. A estimativa desta medida obtida pela validação cruzada será: 


$$
\operatorname{Med}_{V C}=\frac{1}{K} \sum_{i}^{K} \operatorname{Med}\left(R_{i}\right)
$$

O caso em que $K=N$, no qual $N$ é o total de exemplos no BD, é denominado deixa um fora (leave-one-out), quando o algoritmo utiliza todos os exemplos menos um para descobrir o conjunto de regras, deixando apenas um exemplo para teste.

Neste trabalho, será empregado o método de validação cruzada estratificada, em que o conjunto de dados foi dividido em dez partes, sendo que cada parte possui a mesma distribuição de classes que o conjunto total.

Para realizar a classificação de um exemplo do conjunto de teste, o conjunto de regras descobertas pode ser aplicado como uma lista ordenada segundo algum critério (e.g., valor de confiança), que deverá ser percorrido na ordem. Caso uma regra cubra o exemplo, este será rotulado com a classe desta regra. Uma outra maneira seria não estabelecer uma ordem entre as regras. Neste caso, todas as regras são verificadas para cada exemplo. Se mais de uma regra cobrir um mesmo exemplo envolvendo classes diferentes, deverá ser adotado um critério de desempate. Se este exemplo não for coberto por nenhuma das regras, ou ele deixa de ser classificado, ou ele é rotulado na classe que possuir maior ocorrência no conjunto de treinamento.

Após o exemplo de teste ter sido rotulado, este valor é comparado com a sua classe real. Caso sejam iguais, o algoritmo incrementa um contador de exemplos classificados corretamente. Dividindo-se este valor pelo total de exemplos no conjunto de teste, obtém-se a taxa de acerto do conjunto de regras, isto é, do classificador obtido.

O método descrito acima pode levar a conclusões erradas caso a distribuição de exemplos em cada classe seja desbalanceada. Por exemplo, se no conjunto de teste houver 100 exemplos, e dentre estes 95 pertencem a uma classe $C_{1}$ e o restante a uma outra classe $C_{2}$, se nenhum exemplo desta última classe for corretamente classificado, mas todos os exemplos da classe $C_{1}$ o forem, a taxa de acerto, como descrita no parágrafo acima, será de $95 \%$, mesmo que o classificador não acerte nenhum exemplo da classe $C_{2}$. Deste modo, uma informação melhor sobre o desempenho de um classificador será a taxa de acerto para cada classe, e não para todo o conjunto de teste. 


\subsection{Critérios de avaliação de regras de classificação}

Em (BRAMER, 2000) são propostos dois critérios de avaliação de um classificador, a saber:

1. Precisão de Classificação. Visa determinar o percentual de acerto ou erro de classificação do conjunto de regras descobertas. Esta medida pode ser dividida em duas partes: (a) percentual de exemplos corretamente classificados; (b) número de exemplos nãoclassificados.

2. Complexidade do conjunto das regras. A complexidade de um conjunto de regras pode ser medida em termos de dois parâmetros: (a) o número de regras; (b) o número médio de termos por regras (tamanho da regra). Regras menos complexas são mais fáceis de interpretar do que regras maiores, sendo preferiveis quando o sistema se destina a apresentar uma descrição do conjunto de dados a um especialista de domínio, ou a algum usuário que precisa tomar uma decisão.

Um dos objetivos do sistema que será implementado é avaliar o conjunto de regras descobertas de acordo com os critérios acima.

\subsection{Trabalhos correlatos}

Nesta seção, serão apresentados os principais sistemas que empregam hierarquias conceituais na indução de regras.

\subsubsection{DBMiner}

Em (HAN; CAI; CERCONE, 1992), é proposto o método de Indução Orientada a Atributo - IOA (Attribute-Oriented Induction) para extração de tabelas generalizadas a partir de um BD utilizando hierarquias conceituais. Neste trabalho, uma tabela do BD é generalizada substituindo-se valores dos vértices folha da hierarquia por valores de nível mais alto, sendo o limite do nível de generalidade determinado pelo usuário. Após isto, são agrupadas as tuplas que contêm atributos com os mesmos valores substituíndo-as por uma única tupla na tabela generalizada e sendo incluído um atributo, denominado vote, que indica a quantidade de tuplas agrupadas para um determinado valor.

O DBMiner (HAN et al., 1996a), que evoluiu do DBLearn (HAN et al., 1994), é um sistema 
de mineração de dados que utiliza hierarquias de conceitos para generalizar as tabelas do BD, empregando a abordagem IOA. O sistema pode ser empregado sobre diversos tipos de SGBD relacionais, pois ele funciona como um cliente do servidor de BD. Após gerar as tabelas generalizadas através da $I O A$, pode-se buscar por uma diversidade de padrões como regras de classificação, regras de caracterização, regras de discriminação e regras de associação em múltiplos níveis conceituais. $\mathrm{O}$ armazenamento das hierarquias conceituais é feito através de tabelas relacionais existentes no próprio $\mathrm{BD}$, e o usuário interage através de uma linguagem denominada $D M Q L$ - Data Mining Query Language, que é uma extensão do SQL, contento expressões específicas para emprego na mineração de dados, bem como a escolha do tipo de padrão que se deseja descobrir.

\subsubsection{Algoritmo ParDRI}

O sistema ParDRI criado por Merwyn Taylor et al. e proposto em (TAYLOR, 1999), é um sistema de descoberta de regras de classificação que utiliza um ferramenta: de lógica descritiva $^{2}$ com processamento paralelo, denominada ParkaDB, para armazenar e raciocinar sobre as hierarquias conceituais, bem como armazenar os dados. Neste sistema, o algoritmo executa uma busca para percorrer o espaço de hipóteses de regras adotando a estratégia de especialização progressiva. O grau de generalidade das regras descobertas é estabelecido automaticamente pelo algoritmo de busca e o usuário apenas determina os valores mínimos de suporte e confiança, assim como no algoritmo descrito na seção 2.5.2.

\subsubsection{Tabela de co-ocorrências}

Como mostrado na Figura 9 (página 41), uma possível hipótese de regra pode ser qualquer um dos vértices. Entretanto, as tuplas existentes no BD limitam este espaço de busca, pois apenas os valores dos atributos em cada tupla podem gerar uma regra válida no $\mathrm{BD}$, ou seja, uma determinada combinação de atributos e valores pode não existir no BD e portanto regras que contêm esta combinação não serão regras válidas. Para evitar procurar por regras inexistentes no BD e deste modo reduzir o espaço de busca, antes de iniciar o algoritmo de mineração é gerada uma tabela de co-ocorrências.

Seja $C T(A, v)$ o conjunto de tuplas que possuem o atributo $A$ com valor $v$. Dois pares atributo-valor $\left(A, v_{1}\right)$ e $\left(A, v_{2}\right)$, em que $A \neq A^{\prime}$, co-ocorrem se $C T\left(A, v_{1}\right) \cap C T\left(A, v_{2}\right) \neq \emptyset$. Para cada par atributo-valor $(A, v)$ no $\mathrm{BD}$ o conjunto dos atributos com os valores no nível raiz

\footnotetext{
${ }^{2}$ Uma linguagem formal para descrever categorias de objetos e algoritmos eficientes para decidir relacionamentos de superconjuntos e subconjuntos entre categorias (RUSSELL; NORVIG, 2002)
} 
da hierarquia que co-ocorrem com $(A, v)$ são armazenados em memória persistente, através de tabelas de co-ocorência. Estes dados são consultados para serem utilizados durante a especialização de uma hipótese de regra pela adição de atributo, evitando que hipóteses de regras inexistentes sejam geradas. Como o algoritmo utiliza a especialização progressiva, todo par adicionado estará, inicialmente, com valor do nível raiz da hierarquia. Logo, somente os valores raiz dos pares atributo-valor que co-ocorrem $\operatorname{com}(A, v)$ são armazenados nas tabelas de co-ocorrência.

Esta informação é necessária pois o algoritmo adiciona um atributo com o valor imediatamente abaixo da raiz da hierarquia, o qual poderá não co-ocorrer com os valores dos outros atributos.

\subsubsection{Ordenando os atributos}

A adição de um atributo a uma hipótese de regra é feita obedecendo uma ordem entre os atributos. Esta ordem é estabelecida através de uma função, denominada Desvio Padrão Normalizado, que calcula o quanto um atributo discrimina os exemplos de um BD entre as classes. Quanto maior o seu valor, maior a capacidade de discriminação do atributo. Deste modo, uma hipótese de regra que contenha atributos com grande capacidade de discriminação, necessitará de um menor número de especializações para se tornar uma regra válida.

Após a ordenação dos atributos, uma hipótese de regra será especializada pela adição de um atributo cuja ordem for inferior a ordem dos atributos já existentes no antecedente da regra. Esta abordagem não gera todas as possíveis hipóteses de regra, reduzindo consideravelmente o espaço de busca.

\subsubsection{Cache dos resultados de pesquisa e dos valores de atributos do $\mathrm{BD}$}

A especialização de uma hipótese de regra pela adição de um atributo resultará num subconjunto das tuplas cobertas pela hipótese mais geral, como visto na seção 2.5.2. No ParDRI, para reduzir o número de tuplas que deverão ser consultadas para o cálculo das medidas de relevância de uma hipótese de regra, as tuplas que pertencem a esta hipótese são armazenadas em tabelas separadas, como um cache do resultado da pesquisa de uma regra. Deste modo, o algoritmo, ao acrescentar mais um atributo a esta regra, irá utilizar o cache da regra mais geral, ao invés de consultar toda a tabela de dados, reduzindo o número de tuplas que devem ser visitadas. Além deste tipo de cache o algoritmo também gera uma tabela para cada valor raiz do atributo. Nestas tabelas, são armazenadas o atributo identificador 
das tuplas, o valor folha do conceito-de alto nível e a classe. Assim, ao acrescentar mais um atributo, a avaliação das medidas de relevância desta nova hipótese de regra será feita pelo algoritmo através de um JOIN entre a tabela de cache da regra e a tabela de cache do atributo adicionado, não necessitando consultar todo o BD para cada regra.

\subsubsection{Sistema CUPID}

O sistema CUPID (MALLEN; BRAMER, 1995) realiza a indução generalizada de regras, isto é, o conseqüente da regra pode ser qualquer atributo do $\mathrm{BD}$, utilizando como medida de relevância a medida-J (HILDERMAN; HAMILTON, 1999), que fornece uma base para avaliar o grau de interesse de uma hipótese de regra em relação a um BD.

As regras são representadas da forma se $X$ então $Y$ em que $X$ pode ser uma conjunção de um ou mais literais, e $Y$ pode ser um único literal ou sua negação. Um literal é uma equivalência entre um atributo e um valor extensional ou um atributo intensional. Atributos extensionais são os atributos utilizados para descrever as tuplas num BD, enquanto que atributos intensionais são definidos em termos de outros atributos extensionais ou intensionais. Os atributos intensionais são definidos previamente pelo usuário. Outra forma de conhecimento prévio utilizado pelo sistema são as hierarquias de generalizações, i.e., uma hierarquia de conceitos. Para cada atributo extensional pode ser definida uma hierarquia conceitual.

O sistema emprega a especialização progressiva. A ordem de especialização de uma regra é primeiro adicionar um atributo extensional ou um atributo intensional, dando preferência para atributos intensionais. Caso o atributo extensional possua uma hierarquia conceitual, este atributo poderá ser especializado na hierarquia. A estratégia de preferência por atributos intensionais é justificada pelo maior grau de interesse deste tipo de atributo sobre o extensional. A especialização na hierarquia somente é realizada após a regra não poder mais ser especializada pela adição de um atributo, pois um dos parâmetros da busca é o tamanho máximo da regra, ou seja, o número de atributo existentes no antecedente da regra.

O sistema é interativo e os ciclos de especialização ficam sob controle do usuário, que pode determinar quando parar a execução do sistema. 


\subsubsection{Algoritmo BFMP-RL - Breadth-First Marker Propagation - Rule Learning}

Ao invés de gerar um hipótese e então testá-la no BD, (ARONIS; PROVOST, 1997), (PROVOST; ARONIS; BUCHANAN, 1999) propõem a substituição desta operação baseado no $B F M P$.

A cada especialização de uma hipótese de regra, os algoritmos de aprendizado devem verificar, no $\mathrm{BD}$, se esta nova hipótese é valida. No $B F M P$, o método de gerar-e-testar é substiuído por uma única operação para gerar contagens de todas as especializações de uma regra, realizando apenas uma leitura do BD. Este abordagem é aplicável a atributos que possuem seus valores organizados em hierarquias ou não.

Em vez de considerar as tuplas do BD como vetores de pares atributo-valor, elas são consideradas vetores de ponteiros bidirecionais dentro do espaço de valores. Por exemplo, um atributo de uma tupla possui um ponteiro para o seu valor, e a partir deste valor, já que ele é bidirecional, pode-se chegar a tupla. Deste modo, iniciando-se com uma hipótese contendo apenas um atributo-valor, podem ser obtidas as tuplas cobertas por esta hipótese através dos ponteiros. Partindo-se dessas tuplas, percorrem-se os ponteiros para outros atributos e seus respectivos valores, o que irá representar a hipótese original especializada pela adição destes novos atributos. Propagando-se os valores de contagem para cada valor de um atributo, ou pela hierarquia (caso exista) pode-se calcular as medidas de relevância das regras especializadas pela adição de pares atributo-valor.

A complexidade de tempo para a especialização de uma hipótese é $\mathrm{O}(a e)$, em que $a$ é o número de atributos e e é o número de exemplos ou tuplas no $\mathrm{BD}$.

\subsubsection{Algoritmo AQ}

O Algoritmo AQ (MICHALSKI; KAUFMAN, 2001; MICHALSKI; KAUFMAN; WNEK, 1991) se baseia na idéia da cobertura progressiva dos dados através da geração consecutiva de regras de decisão. O algoritmo busca por um conjunto de regras (conjunção de pares atributo-valor) que cubram todos os exemplos positivos, isto é, exemplos pertencentes ao conceito desejado, e nenhum exemplo negativo. Ao invés de particionar o conjunto de exemplos, o algoritmo generaliza, passo a passo, a descrição de exemplos positivos selecionados denominados de semente.

O procedimento de generalizar a semente, é denominado de estrela. Uma estrela não 
cobre exemplos de outras classes, isto é, exemplos negativos.

$\mathrm{O}$ algoritmo $\mathrm{AQ}$ pode utilizar valores de atributos organizados em hierarquias, denominado de atributo estruturado e induzir regras nas quais os valores dos atributos estarão expressos num maior nível de abstração. Neste caso, a generalização de uma semente também poderá ser feita aumentando o nível de abstração na hierarquia de valores do atributo considerado. 


\section{O Algoritmo NETUNO}

Como foi dito anteriormente, a indução de regras de classificação em BD precisa executar uma busca por um espaço de hipóteses de regras, o que muitas vezes pode ser intratável. Para minimizar este problema, é desejável reduzir o número de hipóteses geradas bem como aumentar a eficiência das consultas geradas para testar as hipóteses.

No algoritmo NETUNO, a redução das consultas geradas é obtida através da primitiva de contagem, das estruturas de dados utilizadas para representar os valores de um atributo qualquer, da representação de um conjunto de regra em cada nó da busca e do emprego da estratégia de Busca em Feixe.

Este capítulo descreve o algoritmo NETUNO, e está organizado da seguinte forma. Nas duas primeiras seções, serão descritos o algoritmo e seus requisitos. Na Seção 3.3 são abordadas as principais estruturas de dados utilizadas pelo algoritmo. Na Seção 3.4 trata sobre a especialização das hipóteses de regras e define a relação de igualdade entre as mesmas. $\mathrm{Na}$ Seção 3.5 será descrito o cálculo das medidas de relevância de hipóteses de alto nível. $\mathrm{Na}$ Seção 3.6 será discutida a codificação dos conceitos da hierarquia e apresentado o algoritmo de codificação. Na Seção 3.7 é feita uma breve discussão sobre o emprego de atributos com valores contínuos no algoritmo. Nas Seções 3.8 e 3.9 serão descritos o conjunto de teste e o procedimento para classificação dos exemplos no conjunto de testes, e na Seção 3.10 são apresentadas as características funcionais e de implementação.

\subsection{Parâmetros da mineração}

As hipóteses de regra geradas pelo algoritmo devem satisfazer um conjunto de requisitos do processo de mineração, que serão descritos nesta seção.

Dado um BD com os atributos $A_{1}, A_{2}, \ldots, A_{n}$, e o atributo $C$ que contém as classes, o algoritmo descobre um conjunto de regras de classificação $R$, tal que cada regra $r_{i} \in R$ 
satisfaz os seguintes critérios.

1. Atributos de interesse $\Delta: \forall A_{i}, \operatorname{SE} A_{i} \in$ antecedente $\left(r_{i}\right)$ ENTÃo $A_{i} \in \Delta$

2. Atributo classificador $C: \forall c_{j}, \operatorname{SE} c_{j} \in$ conseqüente $\left(r_{i}\right)$ ENTÃo $c_{j} \in C$

3. Sintaxe da regra: $r_{i}=\operatorname{SE} A$ ENTÃO $c_{j}$, em que A é uma conjunção de pares atributo-valor.

4. Suporte mínimo $s_{\min }$ : Seja $s$ o suporte de $r_{i} . s \geq s_{\min }$, tal que $0 \leq s_{\min } \leq 1$.

5. Confiança mínima $c_{\min }$ : Seja $c$ a confiança de $r_{i}, c \geq c_{\min }$, tal que $0 \leq c_{\min } \leq 1$

Atributos de interesse é o conjunto de atributos utilizados para geração das hipóteses de regra durante a etapa de mineração, que podem ser especificados pelo usuário ou selecionados através de algoritmos específicos de seleção de características. O antecedente de cada regra irá conter um ou mais atributos deste conjunto, sem conter atributos repetidos. A seleção dos atributos de interesse afeta diretamente o tempo de execução do algoritmo, sendo este um assunto de grande importância na área de mineração de dados, e que será melhor discutido no capítulo 4.

Sintaxe da regra define como a regra de classificação será representada. Cömo visto na seção 2.3 (página 33), o antecedente da regra é uma conjunção de pares atributo-valor, em que cada par representa uma condição entre o atributo e um valor de seu domínio, aqui incluídos os conceitos pertencentes a uma hierarquia. A condição poderá ser a igualdade ou inclusão. No capítulo 4 , a sintaxe da regra será extendida com a negação de cada uma das duas condições anteriores e será feita uma análise de como essa extensão afeta o espaço de busca e o conjunto de regras descobertas.

Suporte mínimo impõe um nível mínimo de completude da regra. Este requisito afeta a execução do algoritmo com relação ao número de regras que são geradas, e ao tempo de execução para a geração das regras e a qualidade do classificador. Regras com conceitos de mais alto nível possuem um valor de suporte maior ou igual a de regras com conceitos de nível inferior (vide seção 2.5.2). Por isso, fixar o suporte mínimo num valor mais alto tem o efeito de podar ainda mais o espaço de busca. Além disso, o suporte mínimo pode ser empregado para controlar o nível de generalidade das regras, pelo mesmo motivo anterior.

Confiança mínima controla a consistência de uma regra. Valores altos de confiança implicam um maior tempo de execução, pois o algoritmo deverá especializar uma hipótese até que ela atinja o valor mínimo. Quanto maior for este valor mínimo, menor será o número de 
tuplas inconsistentes com a hipótese verificada. Embora regras com alto valor de confiança possuam pequena taxa de erro no conjunto de treinamento, elas tendem a apresentar maior taxa de erro num conjunto de teste não utilizado na geração das regras. Este fenômeno é denominado super ajustamento ou overfitting, em inglês (MITCHELL, 1997).

O algoritmo NETUNO permite que o usuário escolha o valor de suporte e confiança mínimos, bem como fazer uma escolha de atributos de maior interesse, com base em métodos de seleção de atributos. Com isto, poderão ser testadas as combinações destes valores e obtidas, para um determinado $\mathrm{BD}$, quais são os melhores valores considerando o tempo de execução, taxa de acerto e generalidade das regras.

\subsection{Especificação do algoritmo NETUNO}

O algoritmo de regras de classificação em múltiplos níveis proposto neste trabalho é um algoritmo de busca em feixe com critérios de poda, no qual hipóteses de regras são geradas e testadas. Na Figura 16 é apresentado o algoritmo NETUNO.

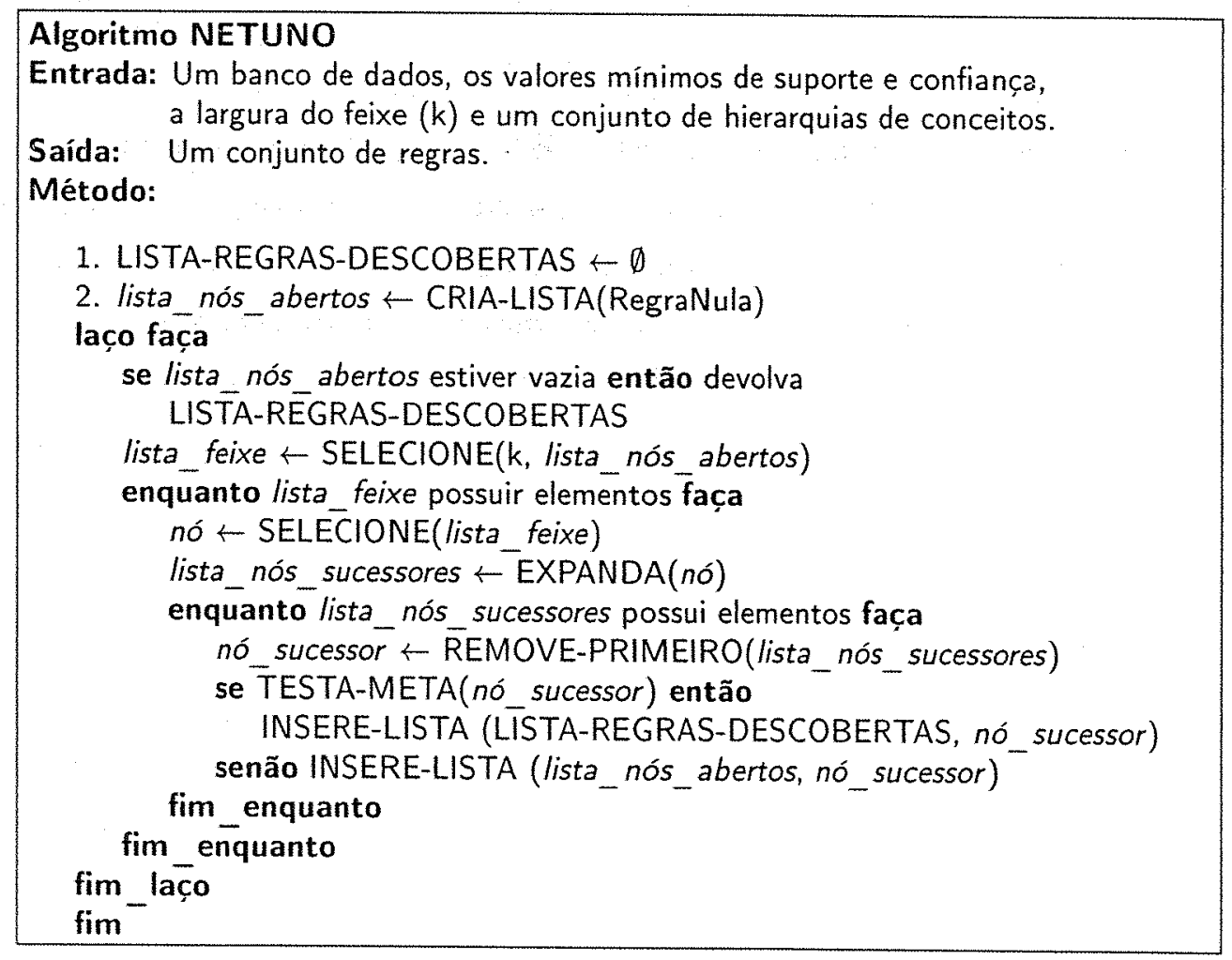

Figura 16: Algoritmo NETUNO

Após o algoritmo inicializar a lista_nós_abertos com a regra nula, a função SELE- 
CIONE() irá retirar $\mathbf{k}$ hipóteses desta lista e armazená-las na lista lista feixe. Enquanto houver hipóteses a serem expandidas nesta lista, elas serão expandidas pela função EXPANDA(), que realiza a especialização da hipótese em nó pela adição de mais um atributo, gerando a lista_nós_sucessores. Enquanto houver elementos na lista_nós_sucessores, a função REMOVE-PRIMEIRO() retira o primeiro elemento, o qual será testado pela função TESTA-META(). A função TESTA-META() irá verificar quais os valores do atributo adicionado que geram regras válidas. Caso haja uma hierarquia conceitual para este atributo, esta verificação será feita percorrendo-se a hierarquia do conceito mais geral ao mais específico.

Cada valor do atributo que gera uma regra válida, será armazenado no último par da hipótese gerando uma nova regra descoberta que será inserida na LISTA-REGRASDESCOBERTAS. Cada valor que não gera uma regra descoberta, mas que não atende ao critério de poda, será armazenado no último par da hipótese gerando uma nova hipótese de regra que será inserida no final da lista_nós_abertos para ser especializada numa próxima interação.

A hipótese de regra verificada pela função TESTA-META() não possui um valor determinado para o atributo do último par. Isto é feito para evitar gerar uma consulta ao BD para cada valor do atributo, pois, como será mostrado na seção 3.5 , o uso da primitiva de contagem permite obter os dados necessários para avaliar uma hipótese de regra utilizando. uma única consulta ao $\mathrm{BD}$, sem necessitar que o último atributo possua um valor. Deste. modo, o operador que gera os nós sucessores do espaço de busca realiza as duas operações de especialização: adiciona um atributo e verifica seus valores na hierarquia.

Para cada $\mathrm{BD}$, há uma tabela que armazena os dados das hierarquias (Tabela 8). Cada tupla desta tabela contém quatro atributos:

- Tabela_Dados - nome da tabela do BD.

- Atributo - atributo da tabela citada no item acima.

- Hierarquia - nome da tabela que armazena a hierarquia.

- qtd_nós - quantidade de vértices existentes na hiearquia.

Note que pode haver mais de uma hierarquia para um mesmo atributo de uma tabela, bem como uma mesma hierarquia poderá ser utilizada para vários atributos, desde que o domínio de valores do atributo esteja contido nos conceitos folha da hierarquia.

Numa etapa de pré-processamento, atributos que possuem valores numéricos, e não possuem uma hierarquia conceitual já codificada, terão o atributo Hierarquia com valor numé- 


\begin{tabular}{|l|l|l|l|}
\hline Tabela_Dados & Atributo & Hierarquia & qtd_nós \\
\hline \hline COGUMELO & cor_esporo & hiercor1 & 14 \\
\hline COGUMELO & forma & hierforma & 8 \\
\hline COGUMELO & cor_esporo & hiercor2 & 8 \\
\hline COGUMELO & cor_topo & hiercor1 & 14 \\
\hline COGUMELO & odor & hierodor & 10 \\
\hline COGUMELO & população & hierpop & 4 \\
\hline COGUMELO & tamanho & numerica & 3 \\
\hline
\end{tabular}

Tabela 8: Tabela contendo as informações sobre as hierarquias de determinado BD

rica, indicando para o algoritmo que deverá ser criada uma hierarquia numérica para este atributo. No caso da construção deste tipo de hierarquia, o atributo qtd_nós representa a altura que a hierarquia construída deverá possuir.

\subsubsection{Critério de ordenação das hipóteses de regra}

As hipóteses de regras serão ordenadas na lista_nós_abertos segundo o seguinte critério:

$$
\sup \times \operatorname{conf}
$$

Em cada hipótese de regra, para cada classe na qual o valor de suporte é maior que - mínimo, é calculado o produto do valor de confiança pelo valor de suporte (sup $\times$ conf). O maior valor encontrado será utilizado para ordenar as hipóteses de regra na lista_nós_abertos, e os $k$ melhores nós serão selecionados para compor a lista_feixe. No Capítulo 4 será verificado outro critério de ordenação e o reflexo na taxa de acerto.

\subsubsection{Redução do conjunto de regras descobertas}

Ao contrário de outros algoritmos de indução de regras de classificação, (CLARK; NIBLETT, 1989; AN; CERCONE, 1998; MICHALSKI; KAUFMAN; WNEK, 1991), o algoritmo NETUNO não remove do $\mathrm{BD}$ as tuplas cobertas por uma regra descoberta. Como conseqüência, o algoritmo irá gerar regras que cobrem as mesmas tuplas, bem como irá gerar um grande número de regras, pois se houvesse a remoção, hipóteses de regras que fossem geradas posteriormente poderiam não atingir o valor mínimo de suporte, e então seriam descartadas.

Após a geração do conjunto de regras descobertas, o algoritmo NETUNO compara, para cada par de regras, o número de tuplas consistentes com o par, isto é, a intersecção do par. 
Caso este número seja igual ao número de tuplas consistentes com uma das regras, isto é, $100 \%$, esta regra será retirada do conjunto. Na Tabela 9 é mostrado que o efeito da poda é relevante na redução do tamanho do conjunto de regras, sem afetar a taxa de acerto.

\begin{tabular}{|l|l|l|}
\hline Critério adotado & Número de regras descobertas & Taxa de acerto \\
\hline \hline Sem poda do conjunto de regras & 306 & $97,2 \%$ \\
\hline Com poda do conjunto de regras & 80 & $98,8 \%$ \\
\hline
\end{tabular}

Tabela 9: Número de regras descobertas pelo algoritmo NETUNO no BD sobre cogumelos, sem utilizar hierarquias conceituais e com $\sup =4 \%$, conf $=98 \%$ e largura do feixe $=64$

No Capítulo 4 serão apresentados os efeitos da redução do conjunto de regras descobertas no total de regras descobertas e taxa de acerto.

\subsection{Estruturas de dados}

Na Figura 17, é mostrada a estrutura de dados utilizada para representar uma hipótese de regra armazenada na lista_nós_abertos. O antecedente de uma hipótese de regra é formado pela conjunção de pares atributo-valor e é armazenado como uma lista ligada que deverá ser percorrida para se construir a consulta da hipótese em SQL (Seção 3.5.1). As informações armazenadas na estrutura da regra são:

- regraID.

- classe: terá o valor nulo enquanto a regra pertencer a lista_nós_abertos.

- tamanho: número de pares atributo-valor.

- primeiroPar: ponteiro para o primeiro elemento da lista ligada do antecedente da regra.

- ultimoPar: ponteiro para o último elemento da lista ligada do antecedente da regra.

- mapClasse_Confianca: o valor da medida de confiança é calculado para cada classe e será utilizado para verificar se a adição de um atributo aumenta a confiança de uma regra, como será descrito na Seção 3.4.2.

- mapMedida_ValorMedida: guarda os valores de suporte e confiança após a regra ser descoberta.

- mapCódigoPar_Par: mapeamento entre o código de um par e o próprio par do antecedente da regra, para efetuar a comparação de regras repetidas. 


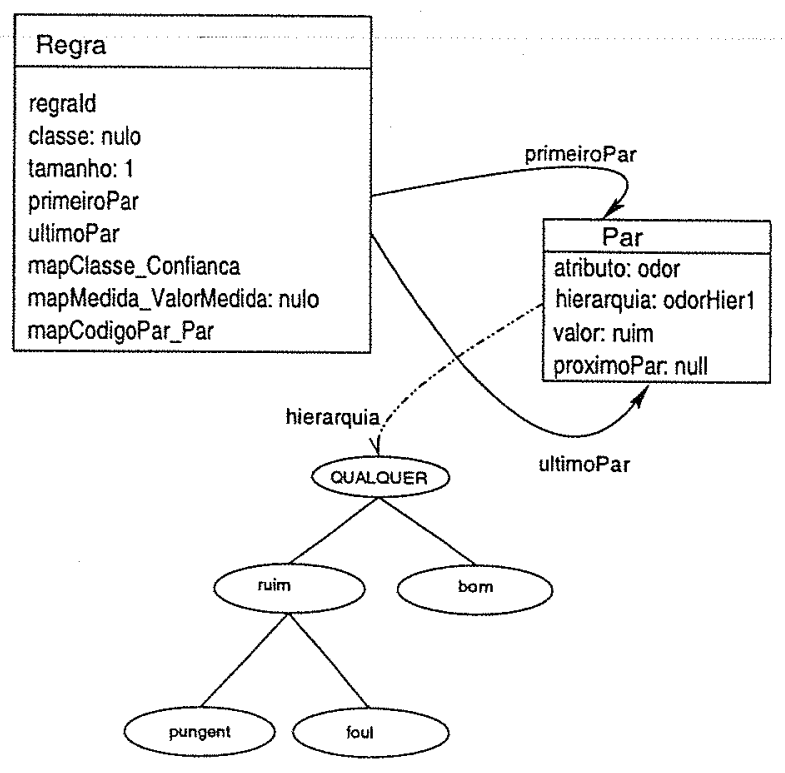

Figura 17: Exemplo de uma hipótese de regra da lista nós_abertos

Cada par atributo-valor é armazenado numa estrutura contendo:

- atributo: nome do atributo.

- hierarquia: ponteiro para a hierarquia do atributo.

- valor: valor do atributo.

- proximo: ponteiro para o próximo par da lista ligada.

Para a execução da mineração dos dados, as tabelas com as hierarquias de conceitos são lidas e armazenadas numa estrutura em árvore e mantidas em memória principal. Como será tratado na Seção 3.5, o algoritmo precisa acessar a hierarquia toda vez que for calcular as medidas de relevância de uma hipótese de regra, visto que a consulta ao BD é construída com base na hierarquia. Por isso, há a necessidade de percorrê-la eficientemente.

$\mathrm{Na}$ estrutura de uma hierarquia conceitual, cada conceito está acessível através de um índice hashing. Deste modo, a obtenção do ascendente de um conceito qualquer, possui complexidade $O(h)$, sendo $h$ a altura da hierarquia. A Figura 18 ilustra a estrutura de uma hierarquia conceitual.

A fim de aproveitar a construção de uma consulta em SQL para atributos que não possuem uma hierarquia conceitual, seus valores são organizados numa estrutura hierárquica, com apenas um nível, como mostrado na Figura 19. 


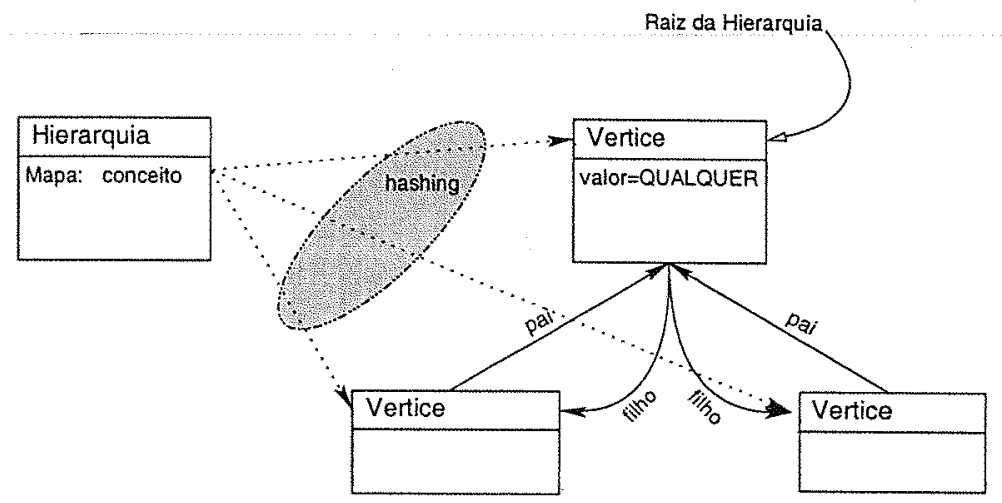

Figura 18: Estrutura de uma hierarquia conceitual

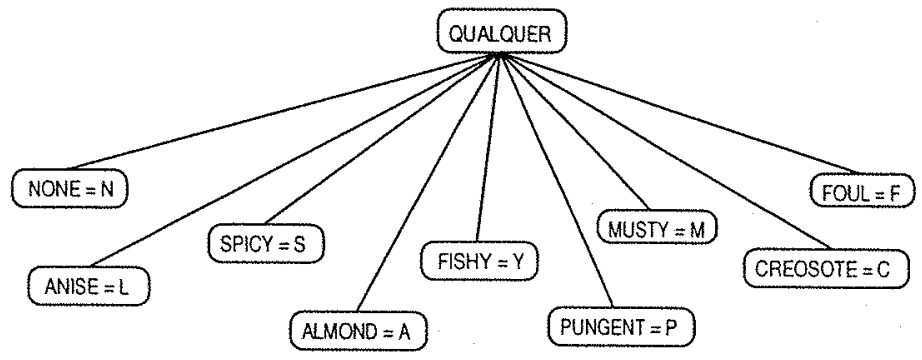

Figura 19: Hierarquia dos valores de um atributo com apenas um nível conceitual

\subsection{Especializando hipóteses}

Para uma dada hipótese $h$ de um conjunto de hipóteses $H$, o suporte e confiança são determinados no $\mathrm{BD}$, traduzindo-se a hipótese $h$ na primitiva de contagem (Seção 3.5). Se em alguma classe, algum valor do último atributo de $h$ atender aos valores mínimos de suporte e confiança, será gerada uma regra descoberta e armazenada no conjunto $R$ de regras descobertas.

Na Figura 20 está representado uma parte do espaço de busca para o BD sobre cogumelos, considerando uma hipótese de regra $\mathbf{H 0}$ que foi especializada pela adição dos atributos cor_esporo, forma e odor, gerando as hipóteses $\mathbf{H 1}, \mathrm{H} 2$ e H3. O antecedente de cada uma das hipóteses sucessoras será formado pelo antecedente de $\mathbf{H 0}$ acrescido dos atributos anteriormente mencionados, cujos valores estarão no nível mais alto da hierarquia conceitual.

\subsubsection{Especialização na hierarquia}

Uma hipótese de regra poderá gerar mais de uma regra descoberta, caso o atributo possua mais de um valor em seu domínio que atenda às medidas de relevância, o que fará com que 


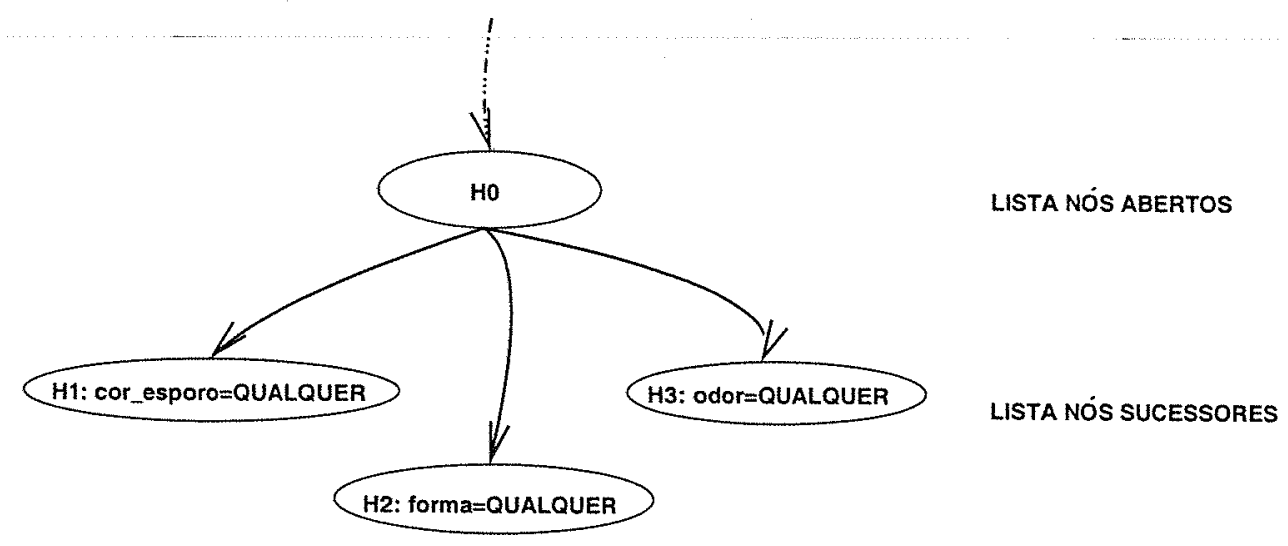

Figura 20: Hipótese de regra $\mathrm{HO}$ e suas hipóteses sucessoras

um nó da lista_feixe gere um conjunto de nós para serem inseridos na lista_nós_sucessores.

Ainda na Figura 20, seja H0 a regra nula. A hipótese de regra $H 3$ poderá corresponder a regra: se odor $=v$ então classe, na qual o valor $v$ do atributo odor poderá ser qualquer um dos conceitos da hierarquia e classe será uma dentre as existentes no BD. Assim, no algoritmo NETUNO, ao ser gerado um nó do espaço de busca, o algoritmo visita um número maior de nós, ou seja, o mesmo número de conceitos na hierarquia do último par da hipótese de regra.

\subsubsection{Geração de uma hipótese de regra}

Para cada conceito da hierarquia e classe do $\mathrm{BD}$, o algoritmo calcula as medidas de relevância e as armazena. Após isto, o algoritmo irá marcar quais conceitos e classes cujas medidas geram regras válidas, ou seja, os conceitos e classes que irão substituir o valor $v$ e classe, respectivamente, da hipótese $H 3$, gerando uma ou mais regras descobertas, bem como uma nova hipótese de regra para ser expandida futuramente.

A Figura 21 representa a hierarquia de conceitos do atributo odor, sendo os conceitos marcados com $\mathbf{V}$, aqueles que geram regras válidas numa determinada classe. Considerando uma determinada classe, conceitos que possuem um ascendente cujo valor gerou uma regra nesta classe não são utilizados para gerar uma nova regra descoberta. Isto porque as tuplas cobertas pela regra do conceito descendente já são cobertas pelo ascendente, ou seja, são um subconjunto destas. Por exemplo, supondo que na Figura 21 os conceitos ruim, creosote e fishy formam regras válidas (atendem às medidas de relevância) numa mesma classe, apenas o valor odor $=$ ruim irá compor uma regra descoberta. Desta maneira, são priorizadas as regras que envolvam conceitos de mais alto nível de generalidade.

O critério de poda utilizado é o valor de suporte. Conceitos cujo valor de suporte seja 


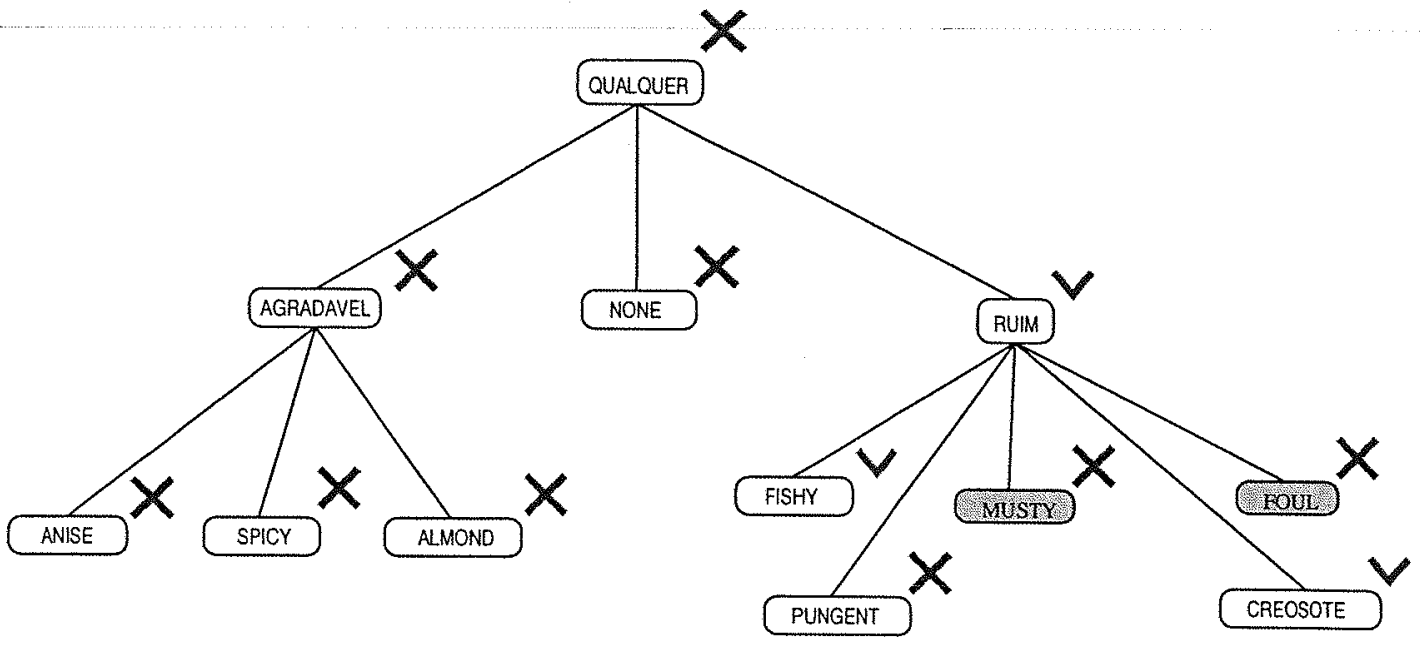

Figura 21: Verificação na hierarquia (os conceitos sombreados atingiram o critério de poda)

inferior ao mínimo são descartados, já que regras mais especializadas terão suporte menor ou igual à regra mais geral.

Os conceitos da hierarquia que não geram regras válidas e não atingem os critérios de poda (pungent na Figura 21) serão armazenados no valor do último par da hipótese (vide Figura 17 página 63), gerando uma nova hipótese para cada um destes valores. Estas novas hipóteses de regras serão inseridas no final da lista_nós_abertos para serem expandidas numa próxima iteração.

O valor de um atributo de uma hipótese de regra pode não melhorar a confiança da hipótese de regra. Neste caso, este atributo é irrelevante para a tarefa de classificação. Além dos critérios de poda citados anteriormente, caso um valor do último atributo da hipótese de regra não melhore sua confiança antes da adição deste atributo, ele é irrelevante e esta hipótese não será inserida na lista_nós_abertos. Este outro critério de poda visa evitar gerar regras contendo atributos com valores irrelevantes para a classificação, o que irá refletir no tamanho das regras descobertas.

\subsubsection{Inclusão entre regras}

Regras iguais ou que contenham outras, isto é, regras que são uma especialização de outra regra, não devem ser geradas. Por exemplo, sejam $H_{1}$ e $H_{2}$ duas hipóteses de regra, em que:

1. $H_{1}:$ ODOR $=$ ANIS

2. $\mathrm{H}_{2}:$ FORMA $=$ CIRCULAR 
A especialização pela adição de atributo, irá gerar duas novas hipóteses, a saber:

1. $H_{1.1}:$ ODOR $=$ ANIS $\wedge$ FORMA $=$ QUALQUER

2. $H_{2.1}:$ FORMA $=$ CIRCULAR $\wedge$ ODOR $=$ QUALQUER

Se o algoritmo verificar a hipótese $H_{1.1}$ antes de $H_{2.1}$ e descobrir uma regra $H_{1.1}^{\prime}$ : ODOR $=$ ANIS $\triangle$ FORMA $=$ CIRCULAR $\rightarrow$ VENENOSO, a mesma regra poderá ser descoberta quando a hipótese $H_{2.1}$ também for examinada, obtendo-se $H_{2.1}^{\prime}$ : FORMA $=$ CIRCULAR $\wedge$ ODOR=ANIS $\rightarrow$ VENENOSO. Ainda na hipótese $H_{2.1}$, o algoritmo poderia descobrir que FORMA $=$ CIRCU$\mathrm{LAR} \wedge$ ODOR $=$ AGRADÁVEL $\rightarrow$ VENENOSO é também uma regra válida, sendo esta última uma regra mais geral, visto que anis $\preceq$ agradável. Logo, o algoritmo deve considerar apenas esta última regra descartando as demais, visto que não é desejável descobrir regras que contêm outras regras. Para resolver este problema, ao obter uma regra válida, o algoritmo compara esta regra com as regras já descobertas, não armazenando regras iguais bem como incluídas por outras.

Uma regra $R_{2}$ está contida em $R_{1}$, escreve-se $R_{2} \subseteq R_{1}$, se os conseqüentes forem os mesmos e:

1. As regras possuem o mesmo tamanho e para cada par atributo-valor $\left(A_{i}, v_{i}\right) \in R_{1}$ há um $\operatorname{par}\left(A_{i}, v_{k}\right) \in R_{2}$ no qual $v_{k} \preceq v_{i}$.

2. As regras possuem tamanhos diferentes e para cada par atributo-valor $\left(A_{i}, v_{i}\right) \in R_{1}$ há um $\operatorname{par}\left(A_{i}, v_{k}\right) \in R_{2}$ no qual $v_{k} \preceq v_{i}$, sendo $R_{1}$ a regra menor.

Uma forma de evitar descobrir regras que contêm outras, quando estas forem do mesmo tamanho, é utilizar o critério de ordenação citado na seção 2.8.2.2 (página 53). Obedecendo este critério, somente uma das hipóteses, $H_{1.1}$ ou $H_{2,1}$, seria gerada, pois se $H_{1.1}$ foi gerada, então o atributo forma possui ordem inferior ao atributo odor. Deste modo, o antecedente de $H_{2.1}$ não poderá conter o atributo odor pois, deverá ser adicionado um atributo cuja ordem seja inferior a forma.

\subsection{Cálculo das medidas de relevância}

Utilizando-se uma hierarquia de conceitos para um atributo, o cálculo das medidas de relevância de conceitos de mais alto nível é feito através da contagem dos conceitos do nível 
folha. Como visto na seção 2.4.1 (página 37), o resultado da consulta em SQL feita ao BD pode ser armazenado numa estrutura em matriz.

Como conceitos de mais alto nível são formados por conceitos de níveis inferiores, somando-se as linhas desta matriz obtém-se os dados necessários para o cálculo das medidas dos conceitos de mais alto nível. Assim, modificando-se a primitiva de contagem pode-se empregar a mesma estrutura para armazenar os resultado das consultas em alto nível ao BD.

\subsubsection{Primitiva de contagem para consultas em alto nível ao BD}

Como foi descrito na Seção 2.4.1, a primitiva de contagem sem considerar hierarquias conceituais é dada por:

SELECT Atributo_Candidato, Atributo_Classe, COUNT $\left(^{*}\right)$

FROM Tabela_Dados

WHERE Descritor_Tuplas

GROUP BY Atributo_Candidato, Atributo_Classe;

sendo:

- Atributo_Candidato, o último atributo adicionado ao antecedente da hipótese de regra;

- Atributo_Classe, o atributo que contém a classe a que pertence a tupla no BD;

- Tabela_Dados, a tabela do BD onde estão armazenados os dados e

- Descritor_Tuplas os atributos pertencentes ao antecedente da regra e seus respectivos valores, excetuando-se o Atributo_Candidato.

Utilizando-se uma hierarquia conceitual, o Descritor_ Tuplas deve ser modificado da seguinte forma: para cada valor de alto nível $v$, de um determinado atributo A que compõem o Descritor_Tuplas, será gerada uma expressão da forma: $\mathbf{A}=v_{1}$ OR $\mathbf{A}=v_{2}$ OR $\mathbf{A}=v_{3}$, em que $\left\{v_{1}, v_{2}, v_{3}\right\} \preceq v$ e $\left\{v_{1}, v_{2}, v_{3}\right\}$ são vértices folha da hierarquia do atributo $\mathbf{A}$.

A modificação acima, terá como resultado a contagem das tuplas do BD que representam o conceito de mais alto nível $v$, e que serão utilizadas para a construção da matriz mostrada na Figura 22

Após uma regra ser especializada, isto é, após ser gerado um nó sucessor, a estrutura irá armazenar os valores das medidas de relevância para cada conceito da hierarquia.

Na Figura 23 é mostrada a estrutura de uma regra especializada pela adição do atributo 


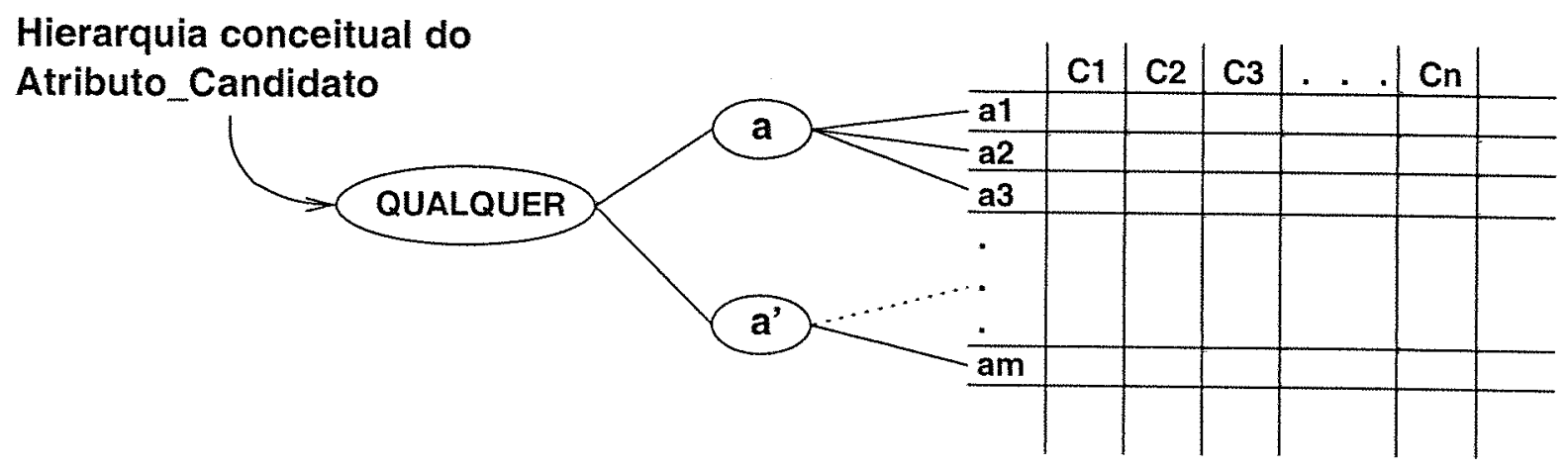

Figura 22: As linhas da matriz representam os conceitos no nível folha da hierarquia

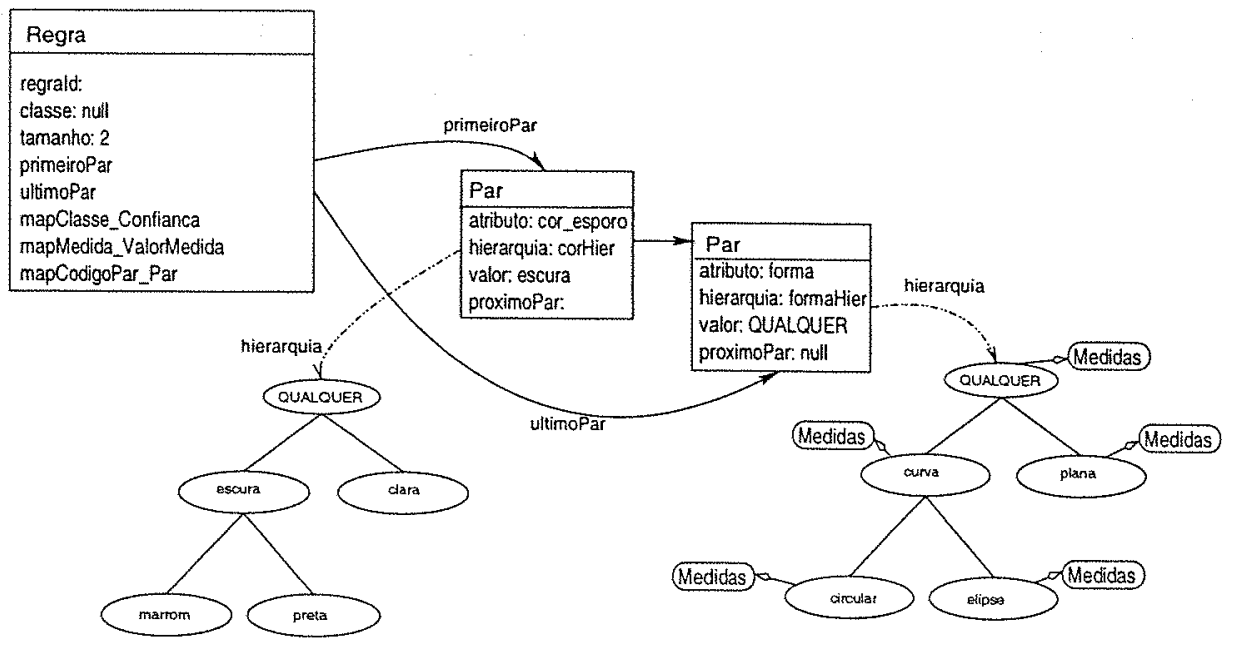

Figura 23: Exemplo de uma hipótese de regra especializada - nó_sucessor 
forma e para a qual já foi feita a consulta para o cálculo das medidas de relevância. Para cada conceito na hierarquia do último par, são armazenados os valores de cada medida de relevância em cada classe. Para uma hipótese de regra como a mostrada na Figura 23, observa-se que o valor do atributo do primeiro par é um valor de alto nível e o Descritor_Tuplas será a expressão:

cor_esporo='marrom' OR cor_esporo='preta'

Logo, a primitiva de contagem será:

SELECT forma, classe, COUNT $\left({ }^{*}\right)$

FROM Tabela_Dados

WHERE cor_esporo='marrom' OR cor_esporo='preta'Descritor_Tuplas

GROUP BY forma, classe;

\subsubsection{Cálculo das medidas de alto nível}

Após formada a matriz, os valores do Atributo_Candidato compõem as linhas da matriz, como mostrado pela Figura 22. Se estes mesmos valores pertencerem a uma hierarquia conceitual, somando-se as linhas da matriz cujos valores precedem um valor de mais alto nível, obtém-se os dados necessários para o cáculo das medidas de relevância deste conceito de alto nível. Este cálculo pode ser realizado de duas formas:

- a cada conceito verificado, as linhas da matriz são somadas; ou

- o somatório das linhas é propagado pela hierarquia, numa abordagem de baixo para cima.

Na primeira abordagem as linhas serão somadas mais de uma vez quando forem utilizadas hierarquias com altura maior que dois, já que o procedimento não aproveita o somatório já realizado para os conceitos em níveis inferiores.

$\mathrm{Na}$ segunda abordagem, percorre-se a hierarquia de maneira pós-fixada, isto é, primeiro os conceitos filhos e depois o raiz, e os valores de níveis inferiores são propagados para níveis superiores, aproveitanto-se o cálculo já efetuado para os vértices filhos. Esta maneira de percorrer a hierarquia e propagar os valores foi proposta em (ARONIS; PROVOST, 1997).

O algoritmo NETUNO emprega a segunda abordagem, por ser mais eficiente. Cada conceito da hierarquia armazena sua linha correspondente na matriz que, em conceitos de 
mais alto nível, é o somatório das linhas de conceitos descendentes. Deste modo, o algoritmo utiliza os valores já calculados, não repetindo operações de soma.

\subsection{Codificação de regras e hierarquias}

Ao inserir uma hipótese na lista_nós_abertos, o algoritmo deverá verificar se a mesma já não se encontra na lista, evitando calcular medidas de uma mesma hipótese duas vezes. Uma hipótese pode ser gerada mais de uma vez, pois há mais de um caminho para se chegar a ela, como foi visto na Seção 2.5.1 (Figura 9 página 40), quando as hipóteses de regra possuem dois atributos ou mais. Devido ao tamanho que a lista_nós_abertos pode assumir e ao número de inserções que são feitas, essa verificação deve ser eficiente. Assim, indexando-se a lista_nós_abertos através de uma função hashing, um elemento qualquer pode ser obtido em tempo $\mathrm{O}(1)$ ou próximo a isto. O problema agora é como representar cada elemento da lista como uma entrada da função hashing, de forma que regras iguais sejam identificadas pela mesma chave.

A forma de representação de uma regra fornece algumas características peculiares, pois uma hipótese de regra não possui atributos repetidos e, para cada atributo, há um valor que pertence ao seu domínio. Logo, uma dupla $P A v_{i d}=($ atributo, valor) identifica unicamente um par atributo-valor.

Como visto na seção 3.4.3, para verificar se uma regra é igual a outra, as regras devem ser comparadas através de cada par atributo-valor. Desta forma, se cada par possuir um código que o identifica individualmente, dentre todos os possíveis pares, pode-se utilizar a concatenação destes códigos como um indentificador da regra, e indexar a lista_nós_abertos.

Além da igualdade entre as hipóteses de regras, também é necessário determinar qual valor é mais geral que o outro, conforme visto na seção 2.2 .2 (página 30) e 3.4 .3 (página 66). A verificação pode ser feita simplesmente consultando-se a hierarquia associada ao atributo, ou codificando-se o valor de um atributo de forma que a codificação dos valores da hierarquia represente a relação de ordem parcial, e numa comparação entre dois valores a verificação será realizada apenas utilizando-se o código e não a hierarquia.

\subsubsection{Algoritmo de codificação de hierarquias}

No algoritmo NETUNO, as hierarquias são armazenadas em memória principal e é necessário determinar de maneira eficiente se um determinado valor de um atributo é mais 
específico ou não que um outro valor, bem como se duas regras são iguais. Como a proposta do algoritmo NETUNO é ser independente do SGBD adotado, a codificação proposta por (WANG; IYER, 1997) (Seção 2.2 .2 página 30) não atende. Por outro lado, o formato de codificação proposto por (LU, 1997), além de ser independente de plataforma, representa a relação $\preceq$ da hierarquia, permitindo verificar eficientemente se um vértice é um ascendente de outro.

Neste trabalho, será proposto e utilizado um critério de codificação de hierarquias que também representa a relação de ordem parcial, mas que segue uma lei de formação diferente da proposta em (LU, 1997), percorrendo a hierarquia de maneira pós-fixada, e que por isso possui complexidade menor.

Algoritmo de Codificação - Codificar cada vértice de uma hierarquia conceitual tal que a relação de ordem parcial esteja representada no código.

\subsubsection{Descrição do algoritmo}

A idéia é recursivamente atributir um código para cada vértice da hierarquia, em que, o código de um vértice filho é obtido pelo deslocamento do código do vértice pai de um número de bits suficiente para que o número máximo de filhos possa ser codificado sem ambigüidade.

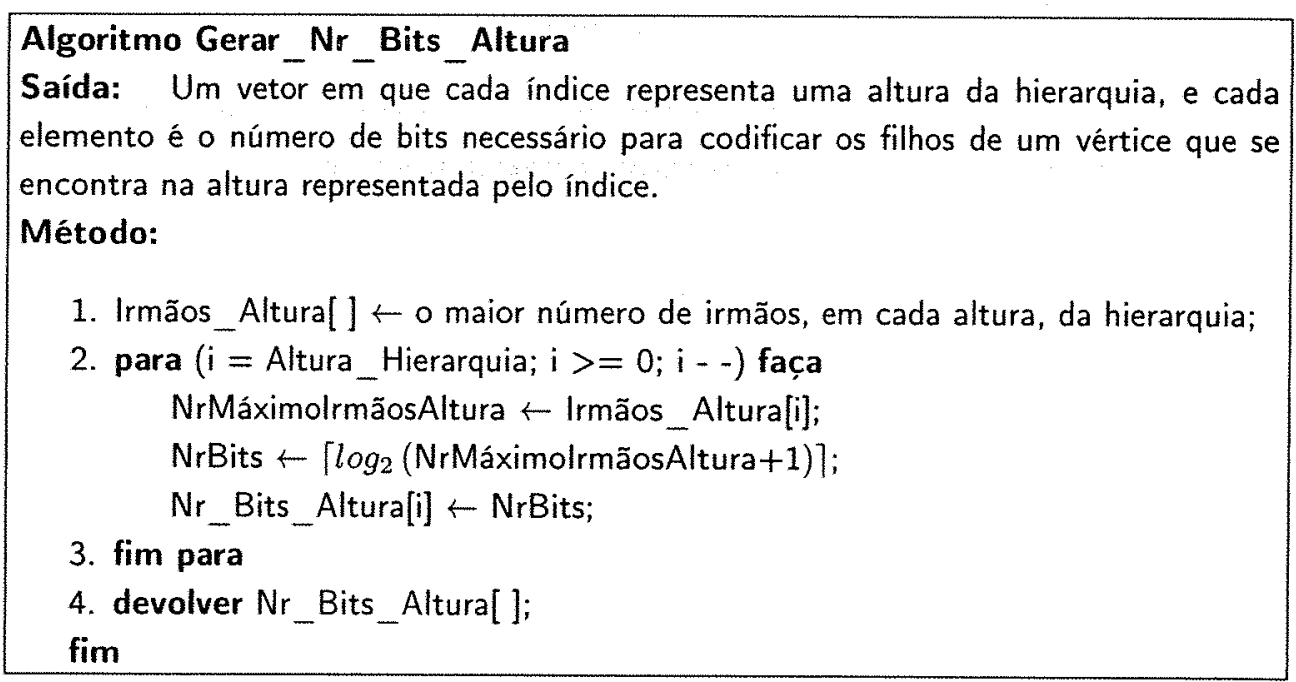

Figura 24: Algoritmo para calcular o número de bits necessários para codificar os vértices em determinada altura da hierarquia

O algoritmo Gerar_Nr_Bits_Altura (Figura 24) devolve um vetor de números, em que o índice representa uma altura $a$ e um elemento deste vetor é o número de bits necessário para codificar os vértices que se encontram na altura $a$. O número de bits é calculado pela 
expressão $\left\lceil\log _{2}(n+1)\right\rceil$, em que $n$ é o número máximo de irmãos numa determinada altura. Por exemplo, uma altura, em que há, no máximo, sete irmãos, três bits são suficientes para codificá-los, ou seja, 1, 10,11,100,101, 110,111. O número 0 não foi considerado aqui pois o algoritmo deve deslocar um valor inicial de tantos bits quanto o necessário para realizar a codificação, o que não seria possivel se esse valor inicial fosse 0 .

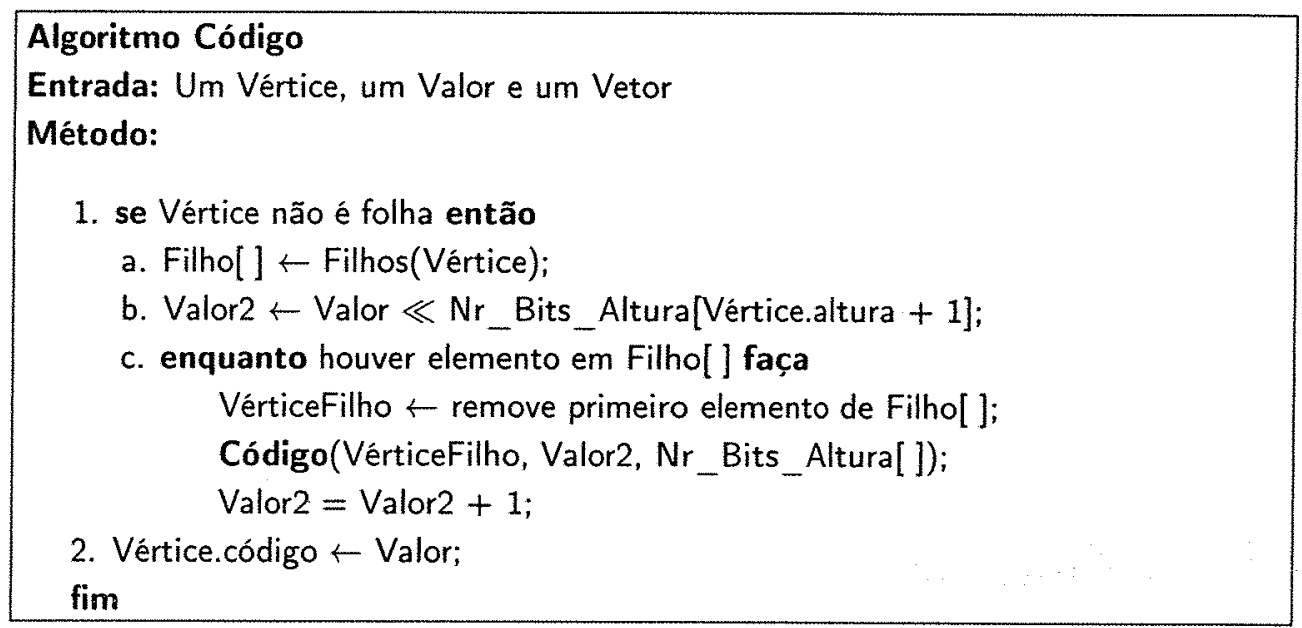

Figura 25: Algoritmo de codificação dos conceitos

O algoritmo Código (Figura 25) percorre a hierarquia de maneira pós-fixada. Para cada sub-árvore da hierarquia, ele codifica primeiro os filhos e depois o pai, recebendo como entrada o código do pai que, caso não seja um vértice folha, será deslocado para a esquerda do número de bits necessários para codificar os filhos.

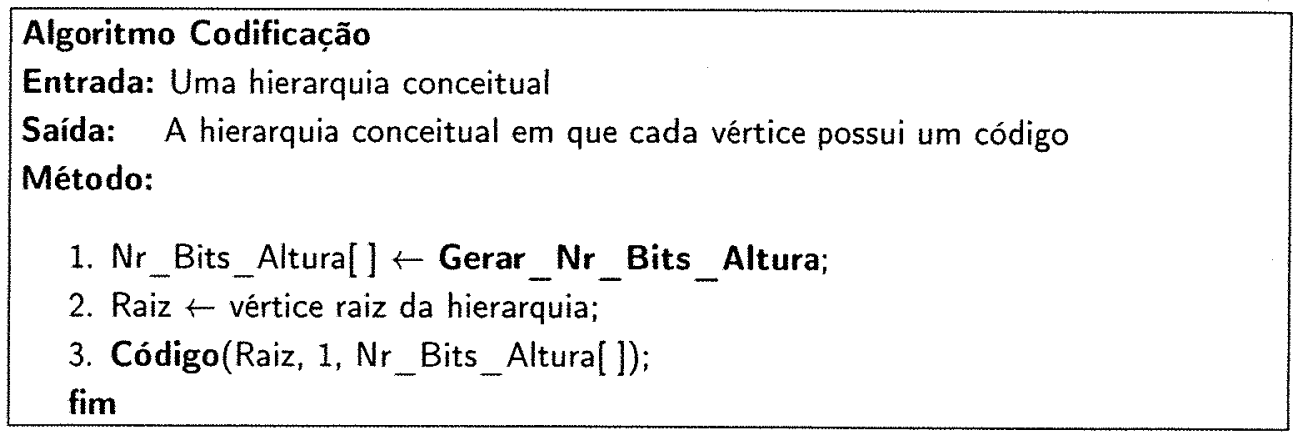

Figura 26: Algoritmo Codificação

Teorema 1 A complexidade do algoritmo Codificação é $O(V)$, em que $V$ é o número de vértices na hierarquia.

Prova Os vértices da hierarquia são visitados duas vezes: uma quando é verificado se é um 
vértice folha e outra quando recebe o respectivo código. Assim, são feitas $2 \times \mathrm{V}$ execuções, o que leva a complexidade $O(V)$.

Na Figura 27 é apresentada a codificação da hierarquia da Figura 5 gerada pelo Algoritmo 3.6.1.

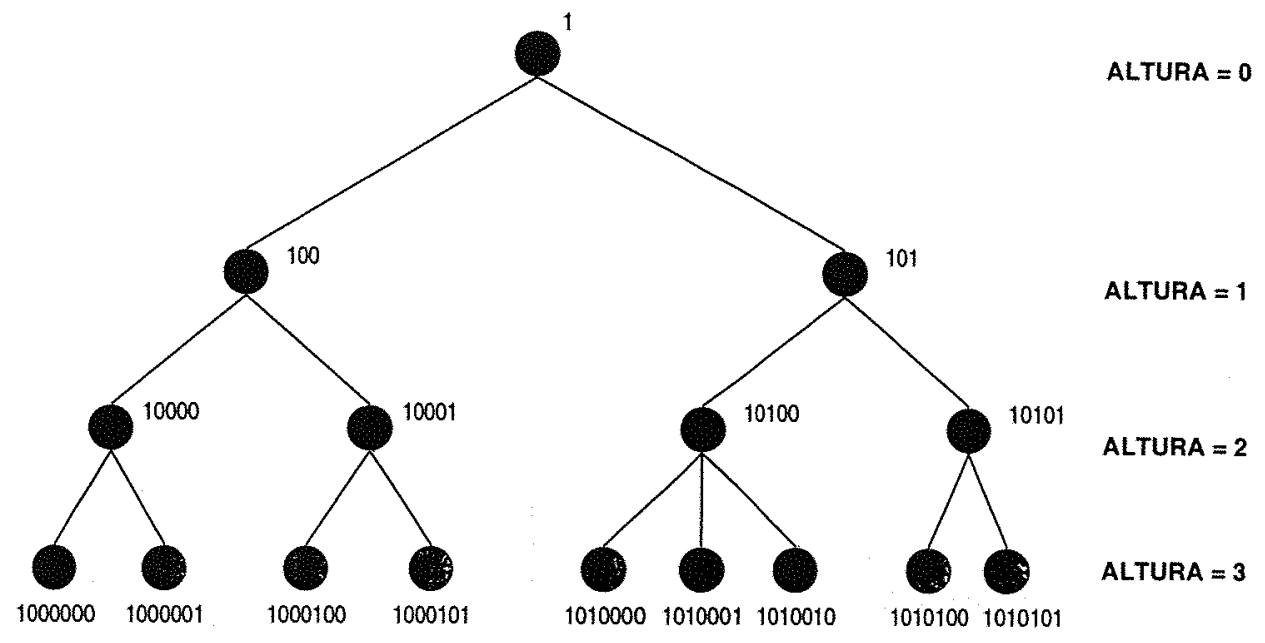

Figura 27: Codificação de uma hierarquia utilizada no Algoritmo NETUNO

\subsection{Uso de atributos com domínio de valores contínuo}

Uma abordagem para utilizar atributos numéricos com valores contínuos na descoberta de regras de classificação é representá-los de forma discreta. Para isto, os valores devem ser agrupados em intervalos que por sua vez podem ser novamente agrupados formando assim uma hierarquia numérica que poderá ser utilizada para gerar as regras de classificação. Há duas abordagens para agrupar os valores de atributos contínuos: considerando ou não a classe da tupla na qual o valor ocorre.

Em (LU, 1997) são propostos dois algoritmos para construção de hierarquia para atributos com valores contínuos. Estes algoritmos utilizam critérios estatísticos sobre os valores do atributo sem levar em consideração a sua distribuição pelas classes. Isto é feito para permitir que outros tipos de padrões possam ser descobertos utilizando-se uma única hierarquia numérica.

Em (FREITAS, 1997) é proposto um algoritmo para agrupar os valores de atributos numéricos em intervalos, considerando a distribuição das classe entre os intervalos obtidos. O critério adotado para agrupar os valores encontrados no BD é minimizar a perda de informação ocasionada pela criação de um intervalo. Este algoritmo não produz uma hierarquia 
numérica, mas pode ser modificado para tal. Neste mesmo trabalho, o autor mostra que o uso de intervalos para agrupar os atributos contínuos não resulta num acréscimo na precisão de classificação, mas reduz significativamente o tempo de execução de um algoritmo de classificação. Isto porque, ao criar os intervalos, os valores contínuos são agrupados de maneira a melhor discriminar a classe.

Neste trabalho, foi feita uma modificação no algoritmo de (FREITAS, 1997) para produzir uma hierarquia numérica e, por não se tratar do objetivo principal desta dissertação, este algoritmo está descrito no apêndice A.

\subsection{Conjunto de teste}

A partir do conjunto de dados foram geradas partições para serem utilizadas como conjunto: de treinamento e teste. Como mencionado na Seção 2.6 (página 49), foi utilizada a validação cruzada com a divisão do conjunto original de dados em dez partes. Esta divisão foi feita distribuindo-se as classes de modo a manter a distribuição do conjunto original. Isto foi feito de maneira automática através de um programa disponibilizado na interface gráfica do Sistema NETUNO-HC (Capítulo 4).

\subsection{Classificando um novo exemplo}

Como mencionado na Seção 2.6 (página 49), após gerar o conjunto de regras, para verificar seu desempenho na tarefa de classificar novos exemplos, deve-se testá-lo num conjunto de teste. A saída do algoritmo NETUNO é uma lista de regras não ordenada, pois esta maneira de apresentação do conjunto de regras facilita a compreeensão de um usuário.

Para classificar um novo exemplo do conjunto de teste, todas as regras da lista serão verificadas buscando-se uma regra que cubra o exemplo. Caso haja mais de uma regra nesta última condição, e dentre estas regras as classes sejam diferentes, deverá haver um critério de desempate a ser obedecido para efetuar a classificação. Em (CLARK; BOSWELL, 1991) é proposto um critério de desempate utilizando-se o número de tuplas que são cobertas (no conjunto de treinamento) por cada regra. Para cada classe, esse número é somado e a classe que possuir a maior soma será o rótulo do exemplo.

Neste trabalho, o critério utilizado será o mesmo para ordenar as hipóteses na lista_nós_abertos, ou seja, o exemplo será classificado na classe da regra que possuir o maior 
valor no produto do suporte pela confiança. Caso ainda permaneça o empate, o critério utilizado será a classe que possuir a maior ocorrência no BD de treinamento.

Exemplos que não forem cobertos por uma regra permanecerão não classificados e serão computados como exemplos não classificados. No Capítulo 4, será testado o resultado de se empregar um critério alternativo de classificação quando um exemplo não for coberto por uma regra.

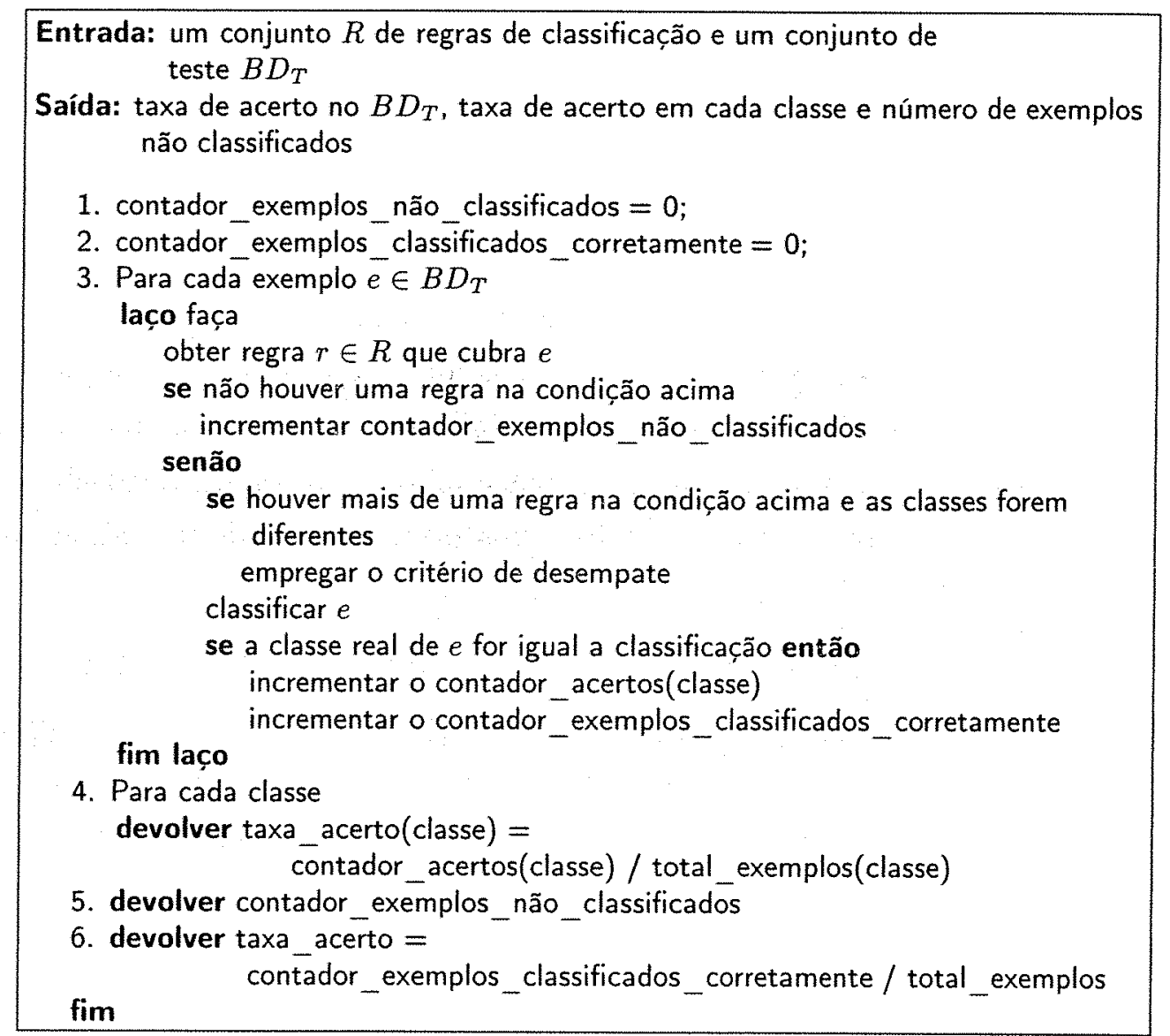

Figura 28: Procedimento para o cálculo da taxa de acerto

Após o exemplo ser rotulado pelo procedimento de teste, a classe real será comparada com o rótulo para atualizar os contadores do número de tuplas classificadas e não classificadas. Serão medidas a taxa de acerto para cada classe, bem como para todo o conjunto de teste. $\mathrm{Na}$ Figura 28 é apresentado o procedimento para obtenção das taxas de acerto e do número de tuplas não classificadas. 


\subsection{Características funcionais}

Inicialmente, o conjunto de dados, no qual será realizada a mineração, deve estar representado como uma única tabela, i.e., caso os dados estejam armazenados em diversas tabelas, eles devem ser unidos numa única tabela. A utilização de uma única tabela visa reduzir o número de operações de JOIN que serão necessárias para que o sistema possa extrair as regras de classificação.

O Sistema Gerenciador de Banco de Dados Relacional utilizado é o PostgreSQL 7.3.2. Além deste, o algoritmo também foi testado no MySQL 3.22.32. A linguagem de programação empregada é Java 1.4 e o desenvolvimento do algoritmo utiliza a plataforma Eclipse 2.1.1.

O usuário, através de uma interface gráfica, seleciona os seguintes parâmetros de entrada:

- o BD que ele deseja utilizar;

- a tabela que contém os dados e o atributo classificador desta tabela;

- os atributos de interesse;

- as hierarquias que serão utilizadas para cada atributo;

- os valores mínimos das medidas de relevância utilizadas, neste caso, o suporte e confiança;

- a largura do feixe de busca.

A partir do conjunto inicial de atributos e suas respectivas hierarquias, o algoritmo irá ler os dados das hierarquias que se encontram em tabelas no BD. Caso seja selecionado um atributo numérico que não possua uma hierarquia já representada numa tabela, o algoritmo irá gerar a respectiva hierarquia numérica.

A indicação do atributo classificador ao algoritmo permite ao usuário testar BD que não possuam uma classe pré-definida ou sobre o qual se deseja obter alguma informação, por exemplo: saber se dois atributos estão correlacionados.

Na seção 2.4 (página 36) foi apresentada a primitiva de contagem para as consultas ao BD. Esta primitiva é construída automaticamente pelo algoritmo, utilizando-se as hierarquia de conceitos de cada atributo do antecedente da regra, e enviada ao SGBD. A resposta a esta consulta é utilizada para preencher uma estrutura de dados em matriz da Tabela 5 (página 
38), que irá possibilitar o cálculo dos valores de suporte e confiança da hipótese de regra investigada. 


\section{Experimentos com o Algoritmo}

Neste capítulo será investigado se o uso de hierarquias conceituais permite descobrir padrões mais interessantes, ou seja, envolvendo conceitos em níveis intermediários de uma hierarquia conceitual. Para avaliar os resultados da descoberta de conhecimento empregandose o algoritmo NETUNO, bem como os procedimentos de pré e pós-processamento descritos no Capítulo 3, estes foram integrados formando um sistema que será denominado de Sistema NETUNO-HC (Figura 29). Como visto na Seção 1.1 (página 17), o processo de Descoberta de Conhecimento envolve a realização de diversas etapas para a obtenção do conhecimento desejado. A Tabela 10 faz um paralelo entre as etapas do processo de KDD (Figura 1, Seção 1.1) e o Sistema NETUNO-HC.

\begin{tabular}{|l|l|}
\hline Etapa do KDD & Procedimentos do NETUNO-HC \\
\hline \hline Seleção & $\begin{array}{l}\text { Seleção do BD } \\
\text { Seleção dos Atributos e Seleção de Hierarquias }\end{array}$ \\
\hline Pré-processamento & $\begin{array}{l}\text { Geração das Hierarquias Numéricas } \\
\text { Criação da Tabela Unica }\end{array}$ \\
\hline Mineração & Execução do algoritmo NETUNO \\
\hline Interpretação e Ajuste dos parâmetros & Apoiado pelas medidas de relevância das regras \\
\hline
\end{tabular}

Tabela 10:

Uma vez que o usuário tenha identificado o problema de descoberta de regras de classificação e selecionado o BD (Seleção do BD), os atributos (diretamente pelo usuário ou por algum método alternativo) (Seleção dos Atributos) e as hierarquias conceituais de interesse (Seleção de Hierarquias) é necessário que os dados sejam agrupados numa única tabela ( $C r i-$ ação da Tabela Única) para que o algoritmo NETUNO possa ser executado. Obtidos os dados-alvo, eles serão pré-processados, criando-se as hierarquias numéricas necessárias ( $G e$ ração das Hierarquias Numéricas), selecionando-se e definindo-se as medidas de relevância. A etapa de mineração é realizada pelo algoritmo NETUNO que utiliza, como conhecimento prévio, as hierarquias conceituais durante sua execução. As regras descobertas na etapa de mineração deverão ser testadas a fim de fornecer subsídios ao usuário: 


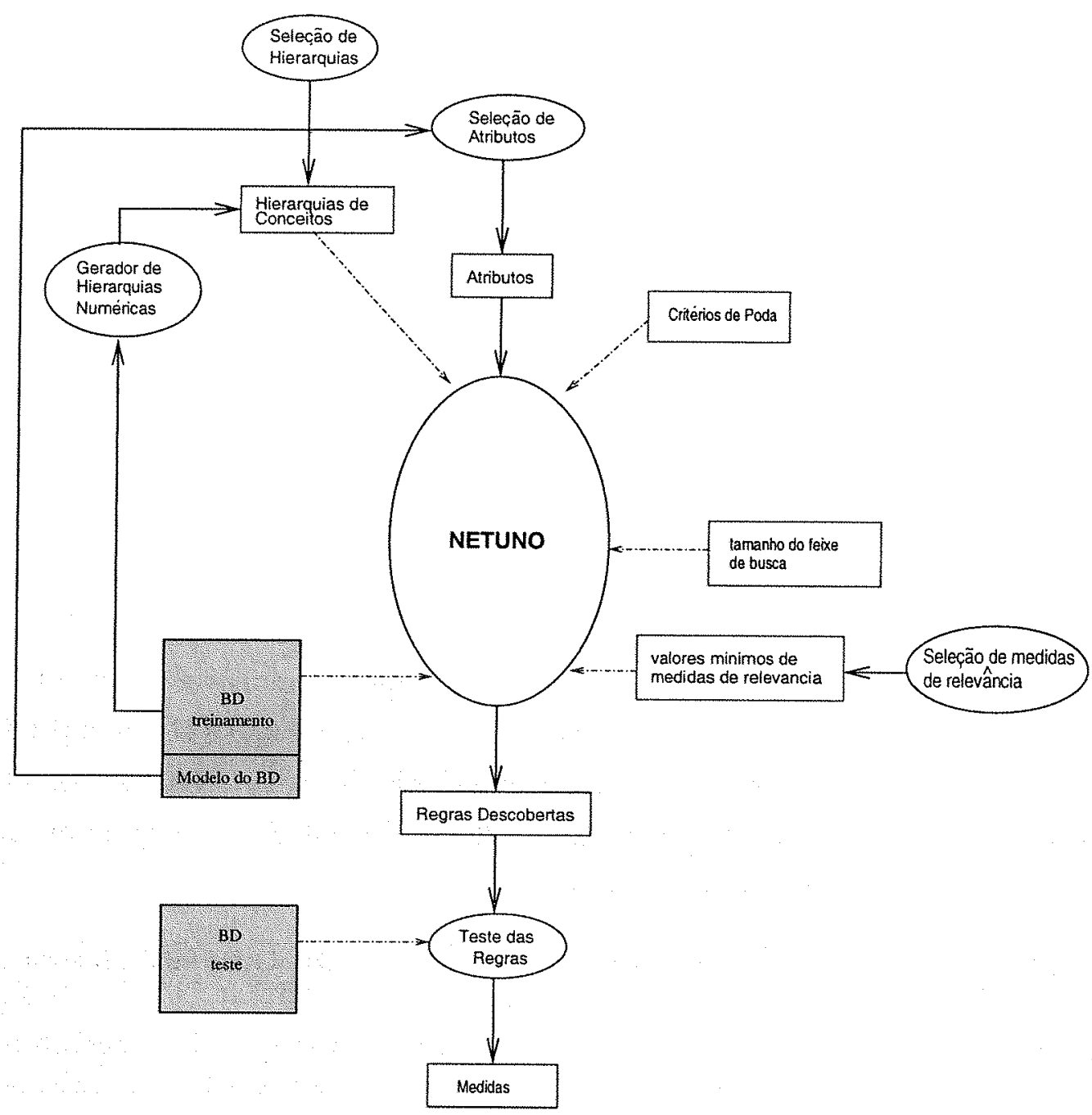

Figura 29: Diagrama funcional envolvendo o algoritmo NETUNO e o conjunto de procedimentos de pré e pós-processamento que integram o Sistema NETUNO-HC

1. para ajuste das medidas de relevância.

2. para a escolha do tamanho do feixe que será melhor na busca.

3. para finalmente ser entregue ao especialista para interpretá-las como conhecimento descoberto.

\subsection{Bancos de dados utilizados}

Foram utilizados dois $\mathrm{BD}$ obtidos do repositório de dados para aprendizado de máquina da Universidade da Califórnia, Irvine, EUA (BLAKE; MERZ, 1998). 
$\mathrm{O}$ primeiro $\mathrm{BD}$ trata sobre cogumelos. O conjunto de dados inclui a descrição de 23 espécies de cogumelos da família Agaricus Lepiota, no qual cada espécie é classificada como venenosa ou comestível. Este BD será denominado BD Cogumelo, contém 8416 tuplas, 23 atributos (todos nominais) e no apêndice B é apresentada a descrição de cada atributo, seguida das hierarquias conceituais utilizadas, retiradas do trabalho de (TAYLOR, 1999).

O outro BD utilizado, denominado BD Adulto, inclui dados sobre censo demográfico, no qual cada pessoa entrevistada é classificada de acordo com sua renda anual em duas classes: $>U S \$ 50.000$ ou $\leq U S \$ 50.000$. O BD contém 48842 tuplas, 13 atributos (cinco contínuos e oito categóricos) e no apêndice B é apresentada a descrição de cada atributo, seguida das hierarquias conceituais utilizadas.

Para as próximas seções, é importante ter como referência as taxas de acerto de outros algoritmos, obtidas em (BLAKE; MERZ, 1998), para os mesmos BD.

\begin{tabular}{|l|l|}
\hline Algoritmo & Taxa de acerto \\
\hline \hline C4.5 rules (QUINLAN, 1993) & $100 \%$ \\
\hline CN2 (CLARK; BOSWELL, 1991) & $100 \%$ \\
\hline
\end{tabular}

Tabela 11: Taxas de acerto obtidas por outros algoritmos no BD Cogumelo

\begin{tabular}{|l|l|}
\hline Algoritmo & Taxa de acerto \\
\hline \hline C4.5 rules (QUINLAN, 1993) & $84.46 \%$ \\
\hline CN2 (CLARK; BOSWELL, 1991) & $84 \%$ \\
\hline
\end{tabular}

Tabela 12: Taxas de acerto obtidas por outros algoritmos no BD Adulto

\section{$4.2 \quad$ Experimentos preliminares}

A introdução das hierarquias conceituais acarreta num aumento considerável do espaço de busca, sendo necessárias técnicas para percorrê-lo de maneira eficiente. São duas as principais técnicas que serão investigadas neste capítulo, a saber:

1. Consultas eficientes ao $\mathrm{BD}$ - para reduzir o número de acessos ao $\mathrm{BD}$. Isto será feito pela extensão da primitiva de contagem (Seção 4.2.1).

2. Estratégia de busca - tipo de algoritmo de busca utilizado (Seção 4.2.2).

Os resultados da mineração variando-se os parâmetros da busca dependem dos valores mínimos de suporte e confiança. Isto será tratado na Seção 4.3 . 


\subsubsection{Eficiência nas consultas a BD}

Neste trabalho, foi implementada uma versão do algoritmo ParDRI (Seção 2.8.2) com o objetivo de avaliar a redução de consultas ao BD com a utilização da primitiva de contagem.

No algoritmo ParDRI (TAYLOR, 1999), as consultas de alto nível são feitas para os valores dos filhos da raiz da hierarquia. Deste modo, uma hierarquia cuja raiz ( $Q U A L Q U E R$ ) tenha três filhos irá gerar três consultas, enquanto apenas uma poderia ser utilizada.

Na Tabela 13 são comparados os resultados no BD Cogumelo dos dois algoritmos implementados, ParDRI e ParDRI-com primitiva de contagem, mostrando uma redução de $40 \%$ no número de acessos a utilizar-se a primitiva de contagem.

\begin{tabular}{|l|l|l|}
\hline Algoritmo & Número de consultas & Número de regras descobertas \\
\hline \hline ParDRI & 117 & 26 \\
\hline ParDRI - com primitiva de contagem & 70 & 26 \\
\hline
\end{tabular}

Tabela 13: Comparação do resultado da utilização da primitiva de contagem para o BD Cogumelo

Uma vez que foram mantidas as mesmas condições em ambas as implementações, podemos concluir que o uso da primitiva de contagem reduz o número de consultas. Isso se deve ao fato da primitiva de contagem agregar mais valores numa única consulta, não afetando o conjunto de regras descobertas.

\subsubsection{Estratégia de busca: Eficiência da Busca em Feixe}

Para avaliar o tamanho do espaço de busca gerado por um algoritmo de busca em largura que utiliza como critério de poda o valor mínimo de suporte, foram realizados três experimentos: (i) mineração sem hierarquias conceituais usando Busca em Largura; (ii) mineração com hierarquias conceituais usando Busca em Largura, e (iii) mineração com hierarquias conceituais usando a Busca em Feixe.

Na Figura 30 é apresentado o gráfico da Busca em Largura com e sem hierarquias conceituais, indicando o número de nós da lista de nós abertos versus o número de ciclos do algoritmo de busca, isto é, o número de retiradas de nós da lista de nós abertos, sem utilizar hierarquias conceituais. Esse experimento traz informações sobre a quantidade de memória necessária durante a mineração.

$\mathrm{O}$ uso de hierarquias conceituais causa um aumento do espaço de busca devido: (i) ao incremento no número de hipóteses decorrente de um número de valores maior que os 


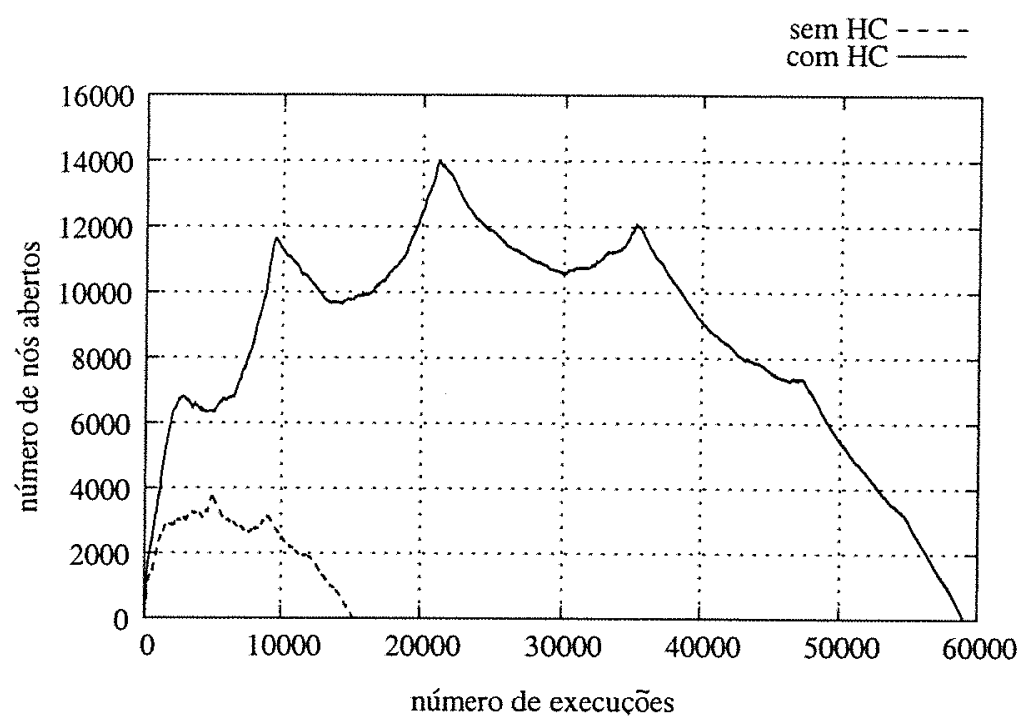

Figura 30: Execução de um algoritmo de Busca em Largura para a descoberta de regras de classificação no BD Cogumelo ( $\sup =20 \%$, conf $=90 \%$ )

atributos poderão assumir; e (ii) à redução no efeito da poda obtido pelo valor de suporte mínimo. Esta redução na poda do espaço é decorrente dos valores de mais altónível que cobrem um maior número de tuplas.

Como previsto, a Figura 30 mostra o crescimento do espaço de memória devido ao uso de hierarquias conceituais, para o BD Cogumelo que contém apenas 22 atributos e 12 hierarquias conceituais consideradas pequenas. Deste modo, a estratégia de Busca em Largura não é adequada para a mineração com hierarquias conceituais, fazendo-se necessário empregar uma busca mais eficiente como a Busca em Feixe (Seção 2.5.3, página 45).

Na tabela 14 são comparadas a execução da Busca em Largura versus a Busca em Feixe, para o BD Cogumelo, empregando hierarquias conceituais e utilizando-se um computador com processador Pentium III 800MHz com $256 \mathrm{MB}$ de memória RAM. Note que, apesar da busca em feixe não ser completa, ela fornece um conjunto de regras que possui uma taxa de acerto bem próximo daquele obtido por uma busca em largura, num tempo de execução inferior.

\begin{tabular}{|l|l|l|}
\hline & Busca em Largura & Busca em Feixe \\
\hline \hline número de regras & 78 & 52 \\
\hline taxa de acerto & $89,49 \%$ & $89,42 \%$ \\
\hline número de exemplos não classificados & 0 & 0 \\
\hline tempo de execução & 23 horas 35 minutos & 27,5 minutos \\
\hline
\end{tabular}

Tabela 14: Comparação do algoritmo de Busca em Largura e Busca em Feixe, para o BD Cogumelo utilizando hierarquias conceituais, e com sup $=20 \%$, conf $=90 \%$ e largura do feixe $=256$ 
Apesar de mais eficiente, a escolha da largura do feixe que leva a um melhor resultado depende dos valores mínimos de suporte e confiança definidos pelo usuário, como será mostrado mais adiante.

\subsubsection{Seleção de atributos}

A seleção de um conjunto de atributos, além de melhorar a precisão de classificação, também pode ser usada para diminuir o espaço de busca (HOLMES; NEVILL-MANNING, 1995). Entretanto, com o uso de hierarquias conceituais, valores de mais alto nível podem não discriminar as classes tão bem quanto valores de nível inferior. O uso de hierarquias conceituais traz um novo problema que é a seleção de atributos considerando que seus valores estão agrupados numa hierarquia. Como já foi dito, não é interessante descobrir padrões no mesmo nível do $\mathrm{BD}$ e selecionar um conjunto de atributos que não possua uma hierarquia associada não irá atender a este objetivo. Na Seção 4.3.4, serão comparados os resultados obtidos pelo uso de um número menor de atributos com relação ao conjunto completo. Os principais experimentos que serão realizados na próxima seção consideram todos os atributos dos BD de teste.

\subsection{Experimentos sobre o uso de hierarquias conceituais}

Nesta seção, serão apresentados os resultados dos experimentos realizados com o algoritmo NETUNO com variações dos valores de medidas de relevância e largura de feixe, a saber:

- variação do suporte mínimo: $20 \%, 12 \%$ e $4 \%$.

- variação da confiança mínima: 90\%, 94\%, 98\%.

- variação da largura do feixe: $1,2,4,8,16,32,64,128,256$ e 512 (somente com hierarquias).

Para cada execução do algoritmo, o conjunto de regras será avaliado através dos seguintes aspectos:

1. Taxa de acerto - utilização de um conjunto de teste para medir a taxa de acerto em todo o conjunto e em cada classe existente. 
2. Número de exemplos não classificados pelo conjunto de regras.

3. Complexidade do conjunto de regras - cálculo do número de regras do conjunto.

4. Tamanho médio de cada regra.

5. Percentual do conjunto de regras que contêm atributos de alto nível.

A taxa de acerto e o número de exemplos não classificados serão avaliados para cada parâmetro de entrada do algoritmo NETUNO, ou seja, valor da largura do feixe, bem como valores mínimos de suporte e confiança.

\subsubsection{Taxa de acerto}

Nas Tabelas 15 e 16 são apresentadas as taxas de acerto para os dois BD utilizados, obtidas pelos conjuntos de regras descobertas, com e sem o uso de hierarquias conceituais, para diferentes valores de suporte, confiança e com largura de feixe $=256$. Os dados destas tabelas também são utilizados para gerar os gráficos mostrados nas Figuras 31 e 32 .

\begin{tabular}{|c|l|l|}
\hline Suporte / Confiança & $\begin{array}{l}\text { Taxa de acerto } \\
\text { sem hierarquias }\end{array}$ & $\begin{array}{c}\text { Taxa de acerto } \\
\text { com hierarquias }\end{array}$ \\
\hline \hline $20 \% / 90 \%$ & $0.9061 \sigma=0.002$ & $0.8942 \sigma=0.002$ \\
\hline $20 \% / 94 \%$ & $0.9572 \sigma=0.005$ & $0.9311 \sigma=0.005$ \\
\hline $20 \% / 98 \%$ & $0.9596 \sigma=0.004$ & $0.9845 \sigma=0.002$ \\
\hline $12 \% / 90 \%$ & $0.8991 \sigma=0.004$ & $0.8931 \sigma=0.002$ \\
\hline $12 \% / 94 \%$ & $0.9572 \sigma=0.002$ & $0.9299 \sigma=0.003$ \\
\hline $12 \% / 98 \%$ & $0.9738 \sigma=0.002$ & $0.9845 \sigma=0.003$ \\
\hline $4 \% / 90 \%$ & $0.8954 \sigma=0.003$ & $0.8931 \sigma=0.004$ \\
\hline $4 \% / 94 \%$ & $0.9524 \sigma=0.003$ & $0.9275 \sigma=0.004$ \\
\hline $4 \% / 98 \%$ & $0.9881 \sigma=0.003$ & $0.9845 \sigma=0.002$ \\
\hline
\end{tabular}

Tabela 15: BD Cogumelo - Média e desvio padrão $(\sigma)$ da taxa de acerto para cada valor de suporte e confiança e com largura do feixe $=256$

De uma forma geral, o comportamento dos resultados obtidos com e sem hierarquias se mantém.

Em ambos $B D$ pode-se observar que a redução do valor de suporte mínimo tende a aumentar a taxa de acerto, usando ou não hierarquias conceituais. Isto acontece devido à descoberta de regras que cobrem conjuntos de exemplos cuja ocorrência dentro da classe é pequena, isto é, um valor de suporte pequeno, e não eram cobertos pelas regras obtidas com valores maiores de suporte. 


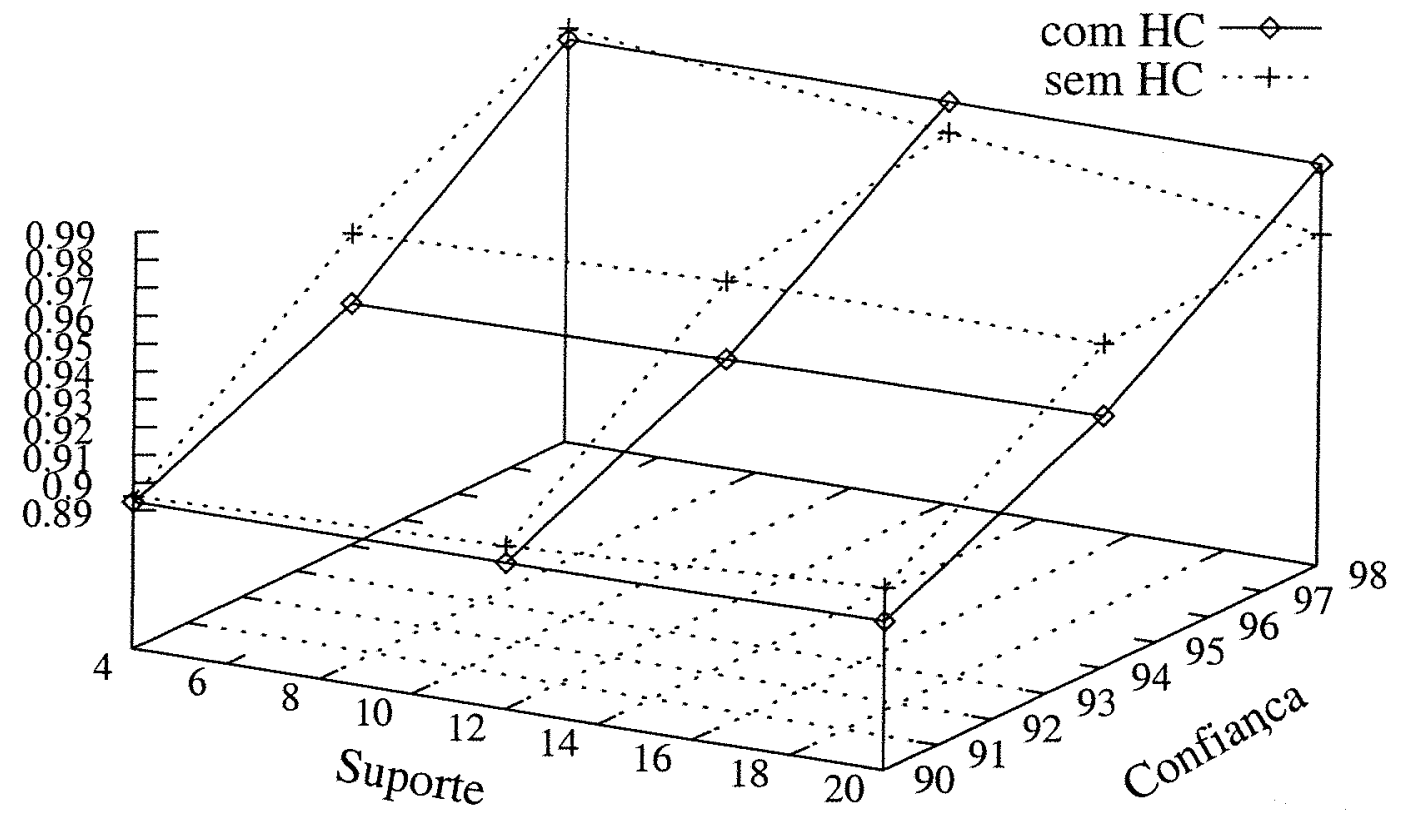

Figura 31: BD Cogumelo - taxa de acerto versus valor de suporte e confiança com largura de feixe $=256$

\begin{tabular}{|c|l|l|}
\hline Suporte / Confiança & $\begin{array}{l}\text { Taxa de acerto } \\
\text { sem hierarquias }\end{array}$ & $\begin{array}{l}\text { Taxa de acerto } \\
\text { com hierarquias }\end{array}$ \\
\hline \hline $20 \% / 90 \%$ & $0.6717 \sigma=0.003$ & $0.6762 \sigma=0.004$ \\
\hline $20 \% / 94 \%$ & $0.5672 \sigma=0.004$ & $0.5851 \sigma=0.005$ \\
\hline $20 \% / 98 \%$ & $0.3701 \sigma=0.002$ & $0.5146 \sigma=0.004$ \\
\hline $12 \% / 90 \%$ & $0.7048 \sigma=0.002$ & $0.7031 \sigma=0.006$ \\
\hline $12 \% / 94 \%$ & $0.6559 \sigma=0.003$ & $0.6598 \sigma=0.005$ \\
\hline $12 \% / 98 \%$ & $0.4112 \sigma=0.002$ & $0.5566 \sigma=0.005$ \\
\hline $4 \% / 90 \%$ & $0.7229 \sigma=0.004$ & $0.7235 \sigma=0.003$ \\
\hline $4 \% / 94 \%$ & $0.6797 \sigma=0.005$ & $0.6646 \sigma=0.002$ \\
\hline $4 \% / 98 \%$ & $0.5513 \sigma=0.005$ & $0.6035 \sigma=0.002$ \\
\hline
\end{tabular}

Tabela 16: BD Adulto - Média e desvio padrão $(\sigma)$ da taxa de acerto para cada valor de suporte e confiança e com largura do feixe $=256$

Quanto à confiança, no BD Cogumelo um valor mínimo de confiança maior aumenta a taxa de acerto utilizando-se ou não hierarquias conceituais. Já no BD Adulto a taxa de acerto aumenta com a redução do valor mínimo de confiança com ou sem o uso de hierarquias conceituais.

Comparando-se a melhor taxa de acerto sem o uso de hierarquias conceituais com a taxa obtida com o uso de hierarquias, nos dois $\mathrm{BD}$, observa-se que, o uso das hierarquias conceituais não acarretou num melhor resultado, o que era esperado pois conceitos mais gerais tendem a apresentar maior inconsistência do que conceitos em níveis inferiores. Entretanto, para 


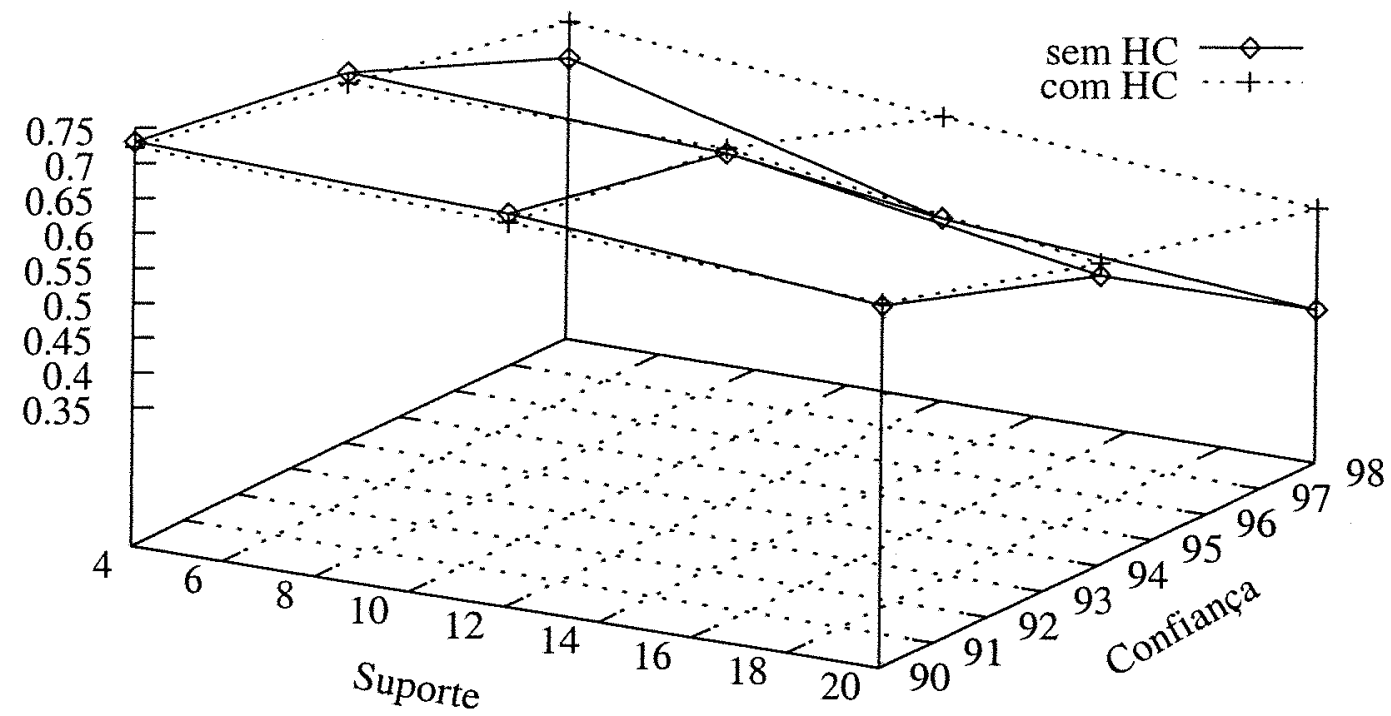

Figura 32: BD Adulto - taxa de acerto versus valor de suporte e confiança com largura de feixe $=256$

valores altos de suporte e confiança, nos dois $\mathrm{BD}$ o uso de hierarquias melhorou a taxa de acerto obtida. Isto se deve ao fato do uso de hierarquias descobrir regras com cobertura maior (como será visto na Seção 4.3.2), e sendo os conceitos mais gerais, reduz-se assim o número de exemplos não classificados. Esses exemplos somente seriam cobertos por regras mais específicas cuja descoberta somente ocorreria com um menor valor mínimo de suporte na mineração sem hierarquias conceituais.

Pode-se concluir que as medidas de relevância para um BD especifico devem ser selecionadas através de uma análise empírica como realizado neste trabalho.

\subsubsection{Efeito da variação da largura do feixe na taxa de acerto e no número de exemplos não classificados}

Intuitivamente, pode-se pensar que um feixe maior irá descobrir um conjunto de regras com melhor taxa de acerto, uma vez que a busca se aproxima mais de uma busca completa. Porém, isto pode não ocorrer dependendo do valor de suporte e confiança utilizados na mineração, bem como do BD minerado. Em (QUINLAN; CAMERON-JONES, 1995) foi feito um experimento em que é medida a taxa de acerto para cada valor de largura do feixe em doze $\mathrm{BD}$ diferentes. Os resultados mostraram que um aumento na busca (aumento da largura do feixe) não resultou numa melhor taxa de acerto em alguns dos BD utilizados, concluindo-se que mais busca pode não conduzir a um melhor resultado, sendo este efeito denominado de oversearching pelos autores. 
Nas Figuras 33 e 34 são mostrados os gráficos da variação da taxa de acerto versus a largura do feixe em cada um dos BD.

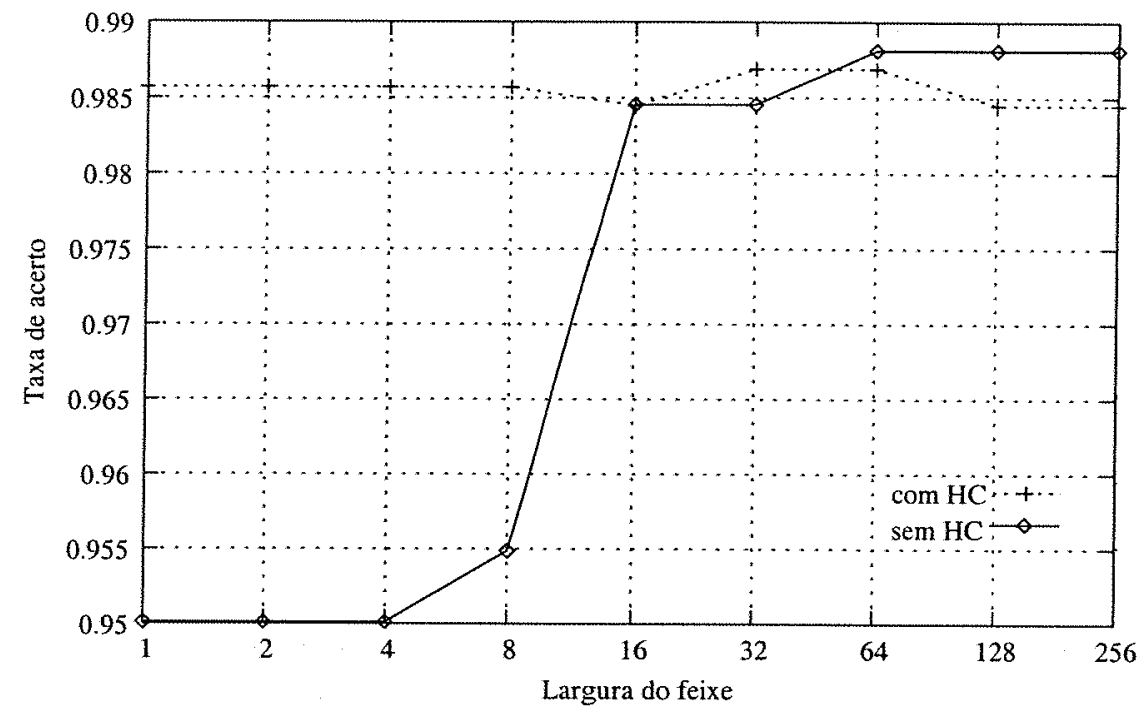

Figura 33: BD Cogumelo - Taxa de acerto versus valor de largura do feixe para sup=4\%, conf $=98 \%$

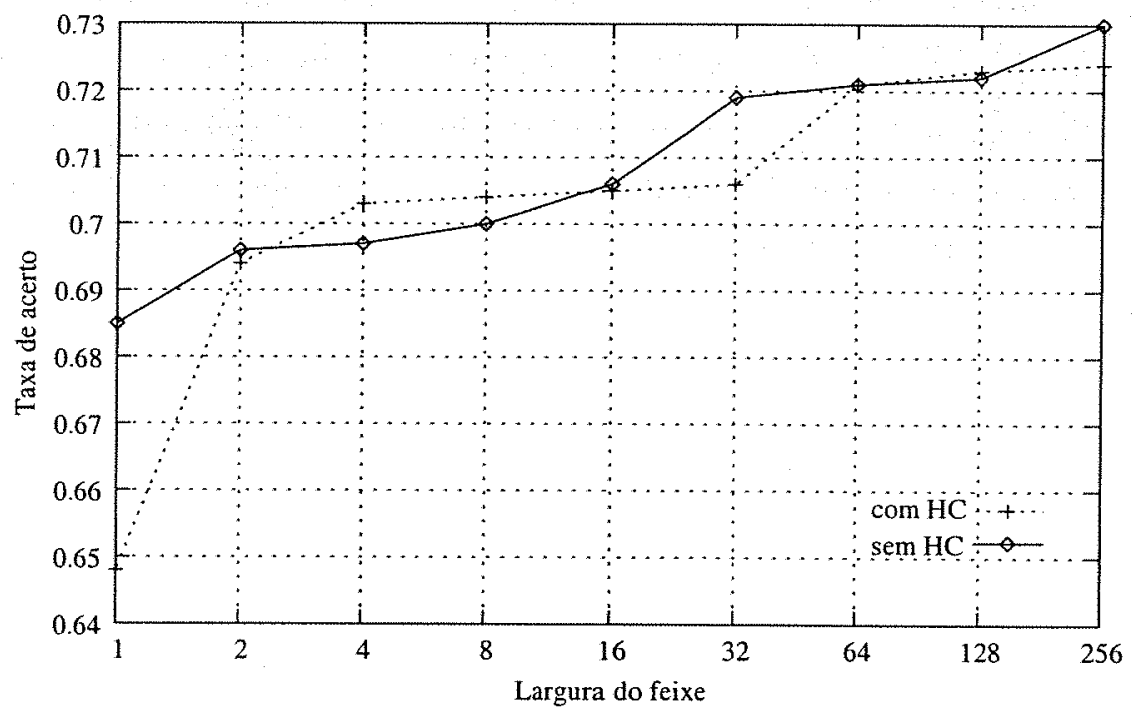

Figura 34: BD Adulto - Taxa de acerto versus valor de largura do feixe para sup $=4 \%$, conf $=90 \%$

Tanto para o BD Cogumelo, como para o BD Adulto um aumento na largura do feixe aumenta a taxa de acerto obtida com e sem hierarquias conceituais. Os valores mínimos de largura de feixe para os quais a taxa de acerto tende a ser constante são 128 para o BD Cogumelo e 256 para o BD Adulto.

É interessante notar que, para o BD Cogumelo, com larguras de feixe pequenas, a mineração sem hierarquias conceituais apresenta uma taxa de acerto menor do que a obtida 
com hierarquias, observando-se também um maior número de exemplos não classificados (Tabela 17).

\begin{tabular}{|l|l|l|l|}
\hline BD - sup/conf & $\begin{array}{l}\text { largura } \\
\text { do feixe }\end{array}$ & $\begin{array}{l}\text { Nr de exemplos } \\
\text { não classificados } \\
\text { sem HC }\end{array}$ & $\begin{array}{l}\text { Nr de exemplos } \\
\text { não classificados } \\
\text { com HC }\end{array}$ \\
\hline \hline Cogumelo - 4\%/98\% & 1 & 37 & 2 \\
& 2 & 37 & 2 \\
& 4 & 37 & 2 \\
& 8 & 33 & 2 \\
& 16 & 7 & 2 \\
& 32 & 7 & 0 \\
& 64 & 4 & 0 \\
& 128 & 4 & 0 \\
& 256 & 4 & 0 \\
\hline
\end{tabular}

Tabela 17: BD Cogumelo - Número de exemplos não classificados para cada largura do feixe

Por outro lado, na mineração com hierarquias conceituais, para feixes pequenos pode-se observar valores altos de taxa de acerto e uma menor quantidade de exemplos não classificados (Tabela 17). Isto pode ser explicado observando-se as regras abaixo relacionadas que foram retiradas dos conjuntos de regras descobertas do BD Cogumelo, com e sem hierarquias (com feixe $=1$ ), sendo que $R_{1}$ pertence ao conjunto obtido com hierarquias conceituais, e $R_{5}$ e $R_{22}$ pertencem ao conjunto obtido sem hierarquias conceituais.

- $R_{1}:$ odor $=\mathrm{BAD}->$ POISONOUS - Sup: 0.822 Conf: 1.0

- $R_{22}$ : odor $=$ CREOSOTE $->$ POISONOUS - Sup: 0.048 Conf: 1.0

- $R_{5}:$ odor $=$ FOUL $->$ POISONOUS - Sup: 0.549 Conf: 1.0

A regra de alto nível $R_{1}$ cobre todos os exemplos cobertos pelas regras $R_{5}, R_{22}$ além dos exemplos nos quais os valores do atributo odor correspondem a conceitos descendentes de $B A D(\{C R E O S O T E, F O U L, M U S T Y, F I S H Y, P U N G E N T\} \preceq B A D)$. Como pode ser visto pelo valor de suporte de $R_{1}=0.822>(0.048+0.549)$, há outros valores descendentes de $B A D$ que são cobertos pela regra, mas que não foram descobertos porque não atenderam ao valor de suporte mínimo.

\subsubsection{Complexidade do conjunto de regras}

Nas Figuras 35 e 36, observa-se que o número de regras descobertas aumenta com a redução do valor mínimo de suporte. Como já foi comentado anteriormente, as regras des- 
cobertas com um valor mínimo de suporte menor são um superconjunto das regras com um valor maior.

Já o aumento do valor mínimo de confiança fará o algoritmo especializar mais as hipóteses de regra sem, necessariamente, descobrir as mesmas regras que seriam descobertas com um valor menor. Como pode ser visto através das Figuras 35 e 36 , nos dois BD o número de regras descobertas pode ser menor com um valor de confiança maior.
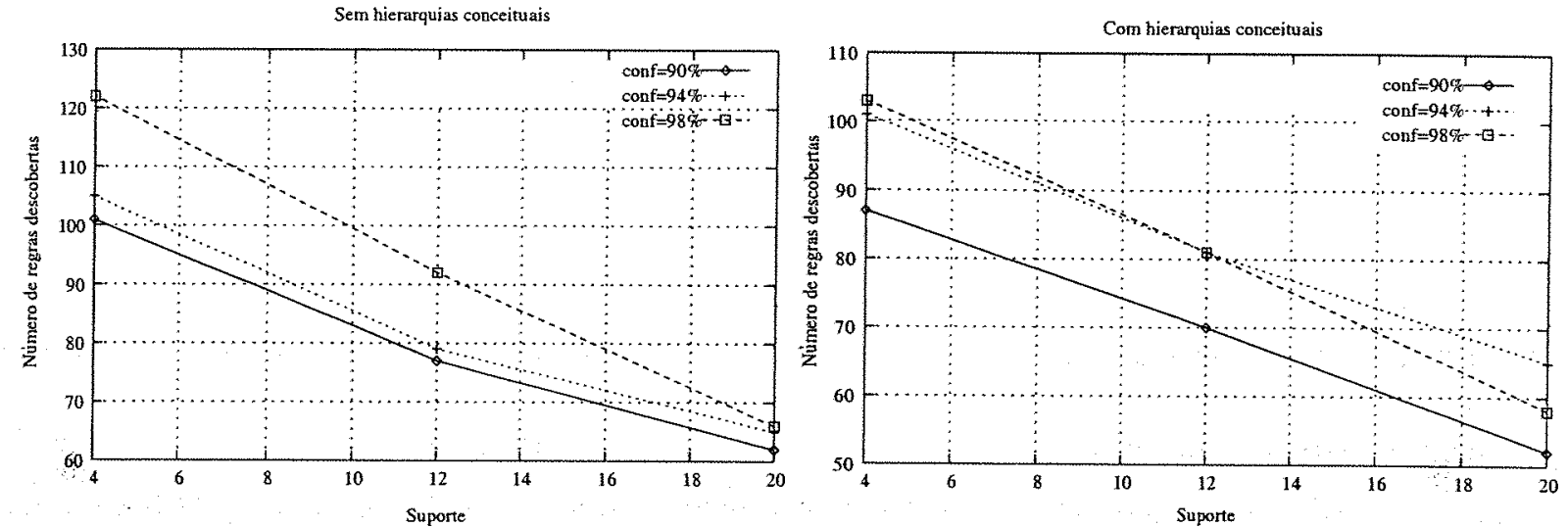

Figura 35: BD Cogumelo - Número de regras descobertas versus valor de suporte em diferentes níveis de confiança e com largura do feixe $=256$
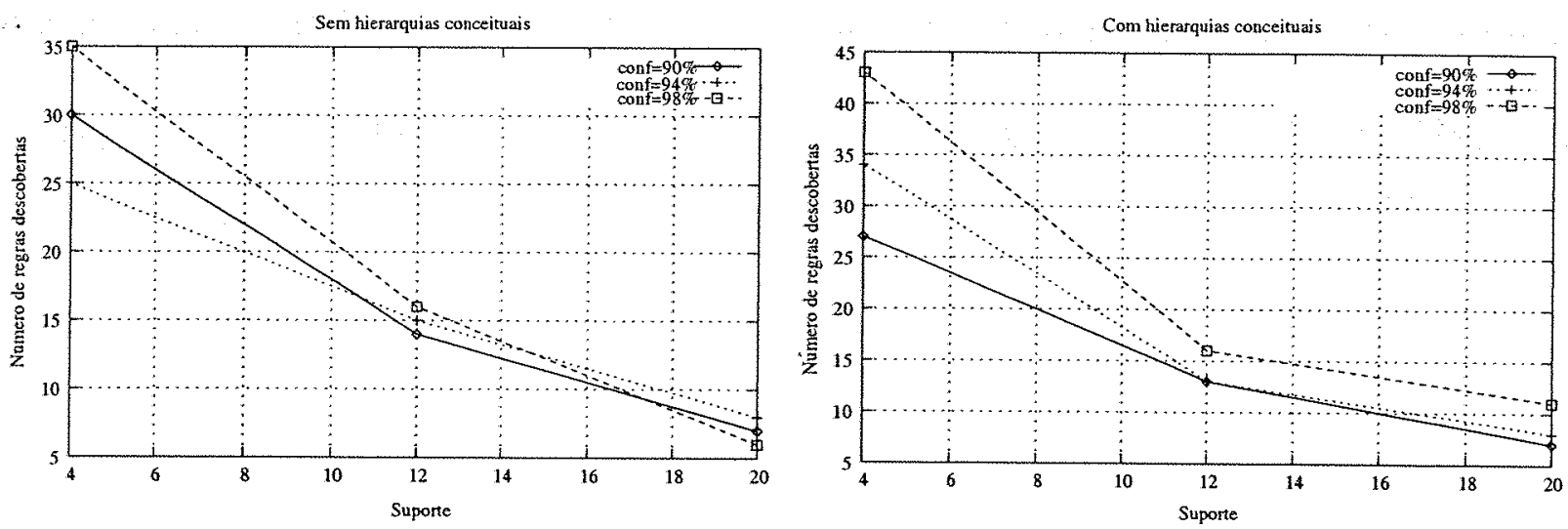

Figura 36: BD Adulto - Número de regras descobertas versus valor de suporte em diferentes níveis de confiança e com largura do feixe $=256$

No BD Cogumelo (Figura 35), o uso de hierarquias reduziu o número de regras descobertas, pois regras com valores de alto nível podem incluir regras com valores no nível folha, como mostrado na Seção 4.3.2. Entretanto, o mesmo não acontece com o BD Adulto (Figura 36), indicando que as hierarquias utilizadas neste BD não fornecem uma descrição mais compacta. Neste $\mathrm{BD}$, o maior número de regras é devido a um acréscimo no número de 
especializações realizadas pelo algoritmo até obter uma regra válida e pelo menor efeito da poda obtido pelo valor mínimo de suporte.

Portanto, o uso de hierarquias pode fornecer um conjunto de regras mais compacto, isto é, um menor número de regras que possuem uma descrição mais geral dos conceitos do BD. No entanto isso depende dos hierarquias conceituais utilizadas: no BD Cogumelo as hierarquias favorecerem esse resultado, enquanto que para o BD Adulto, isso não ocorreu.

\subsubsection{Tamanho médio das regras descobertas}

Na Tabela 18 é mostrado o comprimento médio das regras descobertas. Observa-se que as regras não ficaram menores, isto é, menor número de pares atributo-valor. Como visto anteriormente, o que houve foi uma redução no tamanho do conjunto de regras descobertas.

\begin{tabular}{|l|l|l|}
\hline $\mathrm{BD}$ & $\begin{array}{l}\text { Tamanho médio das regras - } \\
\text { sem HC }\end{array}$ & $\begin{array}{l}\text { Tamanho médio das regras - } \\
\text { com HC }\end{array}$ \\
\hline \hline Cogumelo & 2,24 & 2,23 \\
\hline Adulto & 1,71 & 1,71 \\
\hline
\end{tabular}

Tabela 18: Tamanho médio das regras descobertas em cada BD, com sup $=20 \%$, conf $=90 \%$ e feixe $=256$

\subsubsection{Valores de alto nivel nas regras}

Nas Figuras 37 e 38 é apresentado o percentual de regras de alto nível presentes no conjunto de regras descobertas obtidos nos dois $\mathrm{BD}$, para diferentes valores de suporte e um valor de confiança no qual as taxas de acerto foram maiores. Uma regra de alto nível é qualquer regra do conjunto de regras descobertas na qual há um atributo cujo valor não é uma folha da hierarquia.

Observa-se que uma redução do suporte tende a reduzir o percentual de regras de alto nível. Em relação ao BD Cogumelo, na Figura 31 (página 86) observa-se que uma redução no valor de suporte afeta pouco a taxa de acerto, mas reduz o percentual de regras de alto nível do conjunto descoberto. Portanto, um conjunto de regras mais interessante pode ser obtido utilizando-se um valor alto de suporte mínimo. 


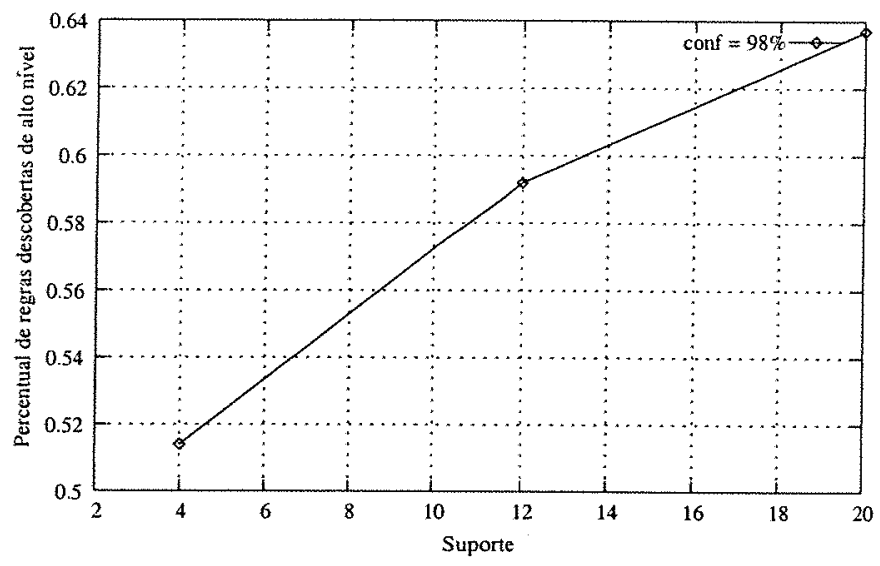

Figura 37: BD Cogumelo - Percentual de regras de alto nível no conjunto de regras descobertas versus valor de suporte para conf $=98 \%$ e largura do feixe $=256$

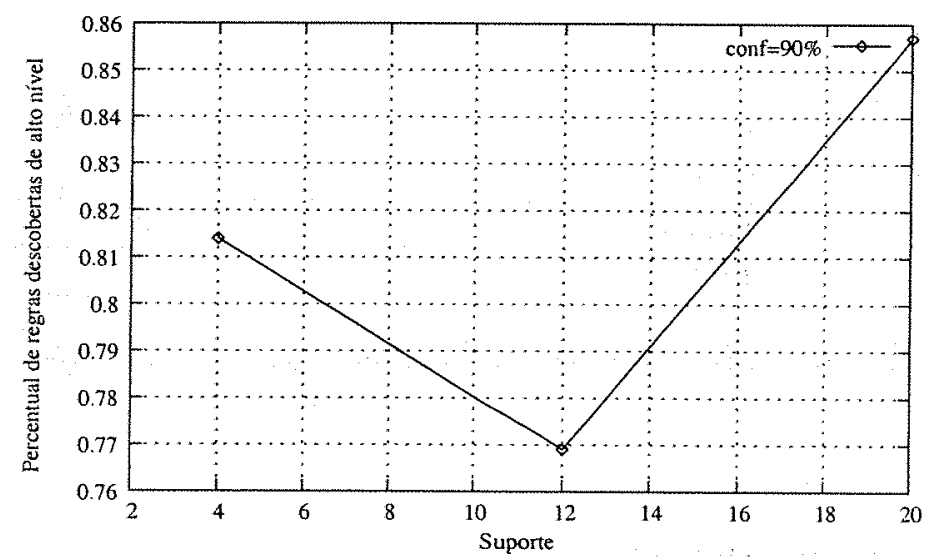

Figura 38: BD Adulto - Percentual de regras de alto nivel no conjunto de regras descobertas versus valor de suporte para conf $=90 \%$ e largura do feixe $=256$

\subsubsection{Seleção de atributos}

Ao invés de utilizar todos os atributos disponíveis no BD Cogumelo, será selecionado um subconjunto destes. Serão utilizados dois subconjuntos, a saber: (1) atributos descritos nas regras apresentadas em (BLAKE; MERZ, 1998), e (2) atributos obtidos pela seleção através do cáculo do valor da entropia da informação de cada atributo, para valores no nível folha, implementado neste trabalho para o Sistema NETUNO-HC.

Na Tabela 20, são apresentados os resultado obtidos pela execução do NETUNO com os dois conjuntos de atributos descritos na Tabela 19. Foram utilizados os mesmos valores mínimos das medidas e a largura do feixe em que foi obtida a melhor taxa de acerto utilizando os 22 atributos disponíveis. Uma vez que esse não é o tema principal deste trabalho, o experimento apenas mostrou que métodos de seleção de atributos podem ajudar na redução 


\begin{tabular}{|l|l|}
\hline Seleção utilizada & Atributos \\
\hline \hline 1) Atributos de (BLAKE; MERZ, 1998) & $\begin{array}{l}\text { odor, spore_print_color, stalk_color_below_ring, } \\
\text { stalk_surface_below_ring, habitat, cap_color }\end{array}$ \\
\hline 2) Entropia da Informação & $\begin{array}{l}\text { odor, spore_print_color, stalk_color_below_ring, } \\
\text { stalk_surface_below_ring, gill_color, ring_type }\end{array}$ \\
\hline
\end{tabular}

Tabela 19: Atributos do BD Cogumelo

do espaço de busca sem afetar a taxa de acerto, como ocorreu para o conjunto 2 da Tabela 19.

Entretanto, para o conjunto 1 de atributos, a taxa de acerto diminui quando foram consideradas hierarquias conceituais, o que mostra que deve ser levado em consideração as hierarquias conceituais quando se realizar uma seleção de atributos.

Além disso, os atributos selecionados fornecem um conjunto de regras mais interessante, como pode ser visto no percentual de regras de alto nível.

\begin{tabular}{|l|l|l|l|}
\hline Conjunto utilizado & Taxa de acerto & $\begin{array}{l}\text { Percentual de regras } \\
\text { de alto nível }\end{array}$ & Tempo de execução \\
\hline \hline 1 & 0,9744 & $69 \%$ & $8 \mathrm{seg}$ \\
\hline 2 & 0,9869 & $67,8 \%$ & $7 \mathrm{seg}$ \\
\hline Todos os 22 atributos & 0,9869 & $51,8 \%$ & $72 \mathrm{seg}$ \\
\hline
\end{tabular}

Tabela 20: BD Cogumelo - Taxa de acerto para a mineração com conjuntos selecionados de atributos, com sup $=4 \%$, conf $=98 \%$ e largura do feixe $=16$

\subsubsection{Eficiência do Sistema NETUNO-HC}

Nas diversas execuções, foram medidos os seguintes tempos:

- Intervalo de tempo gasto nas consultas ao $\mathrm{BD}$.

- Intervalo de tempo total de execução do algoritmo.

A diferença entre esses dois intervalos de tempo indica o quanto o algoritmo consome na geração e avaliação das hipóteses de regras. Para as execuções do algoritmo utilizando hierarquias conceituais, foi calculada a média dessa diferença obtendo-se o valor 1,87\% (com máximo de $2,32 \%$ ) do intervalo de tempo total de execução. Deste modo, observa-se que o tempo de execução é dominado pelas consultas feitas ao BD e que o método de geração e avaliação das hipóteses empregado pelo NETUNO é eficiente. 
Dentre as alternativas para redução do tempo gasto com o acesso ao BD pode-se citar: (i) utilização de um SGBD com processamento paralelo; (ii) modificação das estruturas de dados de armazenamento do BD como, por exemplo, uso de tabelas binárias (TAYLOR, 1999; HOLSHEIMER; KERSTEN; SIEBES, 1996); e (iii) uso do cache das tuplas cobertas pelas hipóteses de regras (TAYLOR, 1999), o que reduz o tempo gasto na consulta de uma hipótese especializada. Ressalta-se que as duas últimas alternativas implicam na alteração da forma de representação do BD e na criação de novas tabelas.

\subsubsection{Avaliação semântica}

O uso de hierarquias conceituais introduz conceitos novos e mais gerais. Além disso, regras descobertas num conjunto podem estar contidas num outro conjunto (Seção 3.4 .3 página 66). Nas Tabelas 21 e 22 estão listadas as regras descobertas com e sem o uso de hierarquias conceituais, respectivamente, utilizando os mesmos valores de medidas de relevância e largura do feixe. Observe na Tabela 21 que as regras $R 1$ e $R 3$ incluem, cada uma, duas regras na Tabela 22, a saber: $\{R 22, R 5\} \subseteq R 1$ e $\{R 8, R 9\} \subseteq R 3$. Isto mostra que a generalização dos conceitos fornecida pela hierarquia é correta para a classificação desejada descobrindo um conhecimento novo que não poderia ser obtido apenas utilizando o nível de abstração do BD.

\begin{tabular}{|c|c|}
\hline Regra & medidas \\
\hline R1) odar = BAD $>$ POISONOUS & Sup: 0.822 Conf: 1.0 \\
\hline R2) odor $=$ NONE $\rightarrow$ EDIBLE & Sup: 0.821 Conf: 0.968 \\
\hline R3) spore print_color $=$ DARK $1 \wedge$ gill size $=B R O A D->$ EDIBLE & Sup: 0.781 Conf: 1.0 \\
\hline R4) spore print color $=$ DARK $1 \wedge$ cap surface $=$ ROUGH $->$ EDIBLE & Sup: 0.626 Conf: 0.925 \\
\hline R5) stalk surface above ring $=$ SILKY $->$ POISONOUS & Sup: 0.57 Conf: 0.939 \\
\hline R6) spore print color $=$ DARK1 $\wedge$ bruises $=$ BRUISES $\rightarrow>$ EDIBLE & Sup: 0.553 Conf: 0.906 \\
\hline R7) stalk surface below ring $=$ SILKY $\rightarrow>$ POISONOUS & Sup: 0.549 Conf: 0.937 \\
\hline R8) spore print color $=$ DARK1 $\wedge$ gill color $=$ DARK $\rightarrow$ EDIBLE & Sup: 0.453 Conf: 0.901 \\
\hline R9) gill color = BUFF $\rightarrow$ POISONOUS & Sup: 0.439 Conf: 1.0 \\
\hline R10) spore_print_color $=$ DARK1 $\wedge$ cap shape $=$ FLAT $->$ EDIBLE & Sup: 0.344 Conf: 0.923 \\
\hline R11) gill spacing $=$ CROWDED $\rightarrow$ EDIBLE & Sup: 0.329 Conf: 0.929 \\
\hline R12) gill_color $=$ BROWN $\rightarrow$ EDIBLE & Sup: 0.223 Conf: 0.9 \\
\hline R13) population $=$ NUMEROUS $->$ EDIBLE & Sup: 0.092 Conf: 1.0 \\
\hline R14) odor $=A L M O N D \rightarrow$ EDIBLE & Sup: 0.089 Conf: 1.0 \\
\hline R15) odor $=$ ANISE $->$ EDIBLE & Sup: 0.088 Conf: 1.0 \\
\hline
\end{tabular}

Tabela 21: BD Cogumelo - conjunto de regras descobertas com $\sup =4 \%$, conf $=90 \%$, largura do feixe $=1$, COM hierarquias conceituais 


\begin{tabular}{|c|c|}
\hline Regra & medidas \\
\hline R1) odor $=$ NONE $->$ EDIBLE & Sup: 0.821 Conf: 0.968 \\
\hline R2) gill size $=$ BROAD $\wedge$ stalk_surface_above_ring = SMOOTH $>$ EDIBLE & Sup: 0.780 Conf: 0.942 \\
\hline R3) gill size $=$ BROAD $\wedge$ stalk surface below ring $=$ SMOOTH $\rightarrow$ EDIBLE & Sup: 0.738 Conf: 0.938 \\
\hline R4) stalk surface above ring = SILKY $->$ POISONOUS & Sup: 0.570 Conf: 0.939 \\
\hline R5) odor $=$ FOUL $->$ POISONOUS & Sup: 0.549 Conf: 1.0 \\
\hline R6) stalk surface below ring $=$ SILKY $\rightarrow$ POISONOUS & Sup: 0.549 Conf: 0.937 \\
\hline R7) gill color = BUFF $\rightarrow$ POISONOUS & Sup: 0.439 Conf: 1.0 \\
\hline R8) gill size $=$ BROAD $\wedge$ spore print color $=$ BROWN $->$ EDIBLE & Sup: 0.395 Conf: 1.0 \\
\hline R9) gill size $=$ BROAD $\wedge$ spore print color $=$ BLACK $\rightarrow$ EDIBLE & Sup: 0.385 Conf: 1.0 \\
\hline R10) gill size $=\mathrm{BROAD} \wedge$ stalk root $=\mathrm{EQUAL} \rightarrow>$ EDIBLE & Sup: 0.378 Conf: 1.0 \\
\hline R11) gill spacing $=$ CROWDED $\wedge \rightarrow>$ EDIBLE & Sup: 0.329 Conf: 0.929 \\
\hline $\begin{array}{l}\text { R12) gill size }=\text { BROAD } \wedge \text { veil type }=\text { PARTIAL } \wedge \text { gill attachment }=\text { FREE } \wedge \text { veil_color }= \\
W H I T E \wedge \text { ring type }=\text { PENDANT } \wedge \text { cap shape }=\text { CONVEX } \rightarrow \text { EDIBLE }\end{array}$ & Sup: 0.296 Conf: 0.902 \\
\hline R13) gill size $=$ BROAD $\wedge$ cap color $=\overline{B R O W N}->$ EDIBLE & Sup: 0.265 Conf: 0.979 \\
\hline $\begin{array}{l}\text { R14) gill size }=\text { BROAD } \wedge \text { veil type }=\text { PARTIAL } \wedge \text { gill attachment }=\text { FREE } \wedge \text { veil color }= \\
\text { WHITE } \wedge \text { ring type }=\text { PENDANT } \wedge \text { stalk shape }=\text { ENLARGING } \wedge->\text { EDIBLE }\end{array}$ & Sup: 0.231 Conf: 0.935 \\
\hline R15) gill color $=$ BROWN $->$ EDIBLE & Sup: 0.223 Conf: 0.9 \\
\hline R16) odor $=$ SPICY $->$ POISONOUS & Sup: 0.211 Conf: 1.0 \\
\hline $\begin{array}{l}\text { R17) gill size }=\text { BROAD } \wedge \text { veil type }=\text { PARTIAL } \wedge \text { gill attachment }=\text { FREE } \wedge \text { veil color }= \\
\text { WHITE } \wedge \text { ring type }=\text { PENDAÑ } \wedge \text { population }=\text { SOLITARY }>\text { EDIBLE }\end{array}$ & Sup: 0.199 Conf: 1.0 \\
\hline R18) gill size $=$ BROAD $\wedge$ cap shape $=B E L L->$ EDIBLE & Sup: 0.089 Conf: 0.916 \\
\hline R19) odor = ALMOND $->$ EDIBLE & Sup: 0.089 Conf: 1.0 \\
\hline R20) odor $=$ ANISE $->$ EDIBLE & Sup: 0.088 Conf: 1.0 \\
\hline R21) gill size $=$ BROAD $\wedge$ gill color $=$ BLACK $>$ EDIBLE & Sup: 0.085 Conf: 1.0 \\
\hline R22) odor $=$ CREOSOTE $\wedge \rightarrow>$ POISONOUS & Sup: 0.048 Conf: 1.0 \\
\hline
\end{tabular}

Tabela 22: BD Cogumelo - conjunto de regras descobertas com $\sup =4 \%$, conf $=90 \%$, largura do feixe $=1$, SEM hierarquias conceituais

\subsection{Experimentos adicionais}

Os efeitos da variação dos parâmetros de entrada que podem ser modificados pelo usuário foram testados na seção anterior. Nesta seção, será verificado o efeito na taxa de acerto da variação dos seguintes parâmetros internos do Sistema NETUNO-HC:

1. Redução do conjunto de regras descobertas (Seção 3.2.2) - variação do percentual de tuplas que pertencem ao conjunto intersecção de duas regras.

2. Critério para a classificação de um novo exemplo (Seção 3.9) - emprego de um critério diferente para classificar um novo exemplo, bem como para efetuar o desempate na classificação.

3. Classificação de exemplos não rotuladoss - exemplos de teste que não foram cobertos por uma regra, serão rotulados numa classe padrão: a classe que possuir a maior ocorrência no BD de treinamento.

4. Critério de seleção das hipóteses de regra (Seção 3.2.1) - utilização de uma outra medida para ordenar as hipóteses de regra na lista_nós_abertos e que serão selecionadas de acordo com a largura do feixe. 


\subsubsection{Redução do conjunto de regras descobertas}

Na Seção 3.2 .2 foi comentado que a redução do conjunto de regras descobertas é feita utilizando-se o valor de $100 \%$ para o conjunto interseç̧ão. Como conseqüência, apenas regras que cobrem tuplas totalmente cobertas por uma outra regra são eliminadas. Neste seção, será investigado se um percentual menor que $100 \%$ melhora a taxa de acerto.

Na Figura 39 observa-se que para o valor de $90 \%$, houve um aumento na taxa de acerto para diferentes larguras de feixe. Isso indica que alterações no valor deste parâmetro podem afetar o resultado obtido de maneira favorável. Quanto ao número de regras descobertas, pode ser visto através da Figura 40 que a redução ocorreu em todos os valores de largura de feixe.

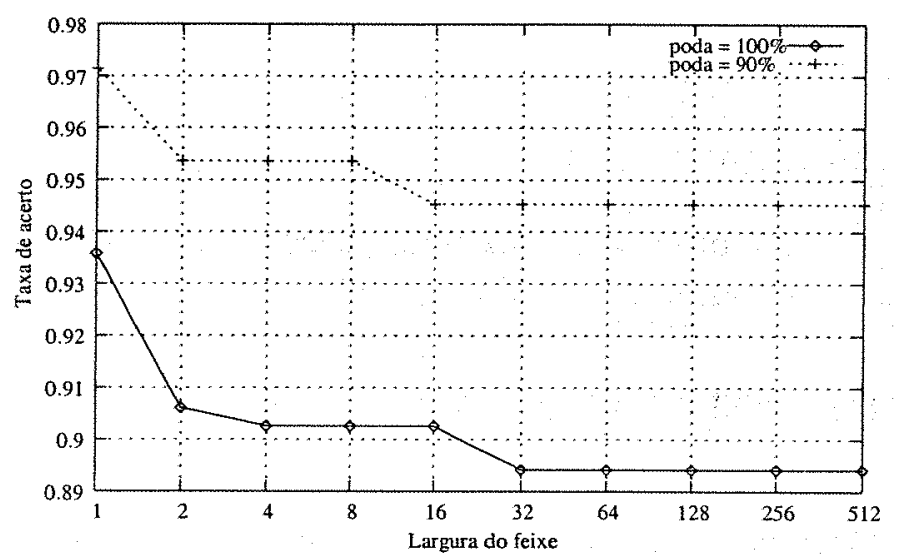

Figura 39: BD Cogumelo - variação da taxa de acerto versus largura do feixe para diferentes percentuais na redução do conjunto de regras, COM hierarquias conceituais, sup $=20 \%, \operatorname{conf}=90 \%$

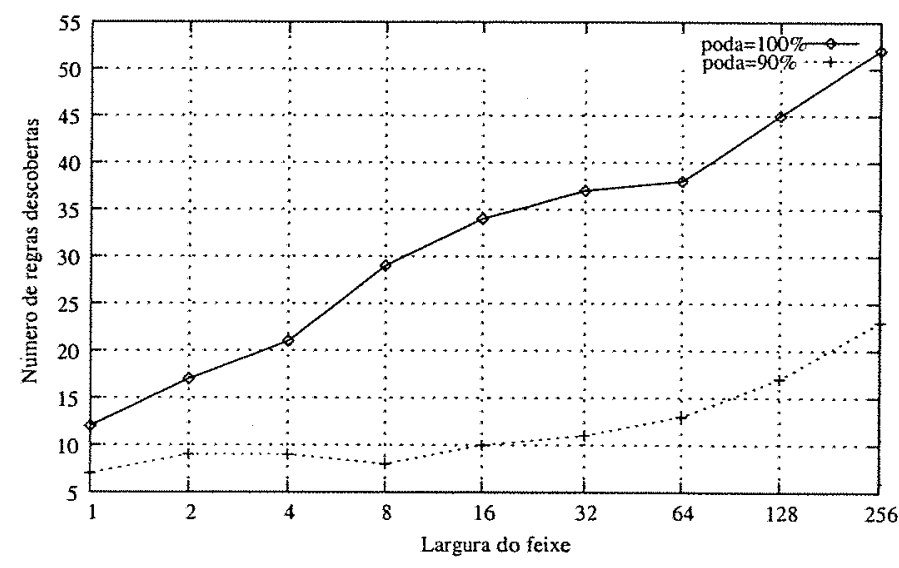

Figura 40: BD Cogumelo - variação do número de regras descobertas versus largura do feixe para diferentes percentuais na redução do conjunto de regras, COM hierarquias conceituais, sup $=20 \%$, conf $=90 \%$ 


\subsubsection{Critério de classificação do conjunto de teste}

Além do critério de classificação e desempate descrito na Seção 3.9, será testado mais um outro: rotula-se o exemplo na classe da regra que possuir o maior valor de confiança e caso haja duas regras com o mesmo valor de confiança, o exemplo será rotulado na classe da regra que possuir o maior valor de suporte, ou seja, a que cobre mais exemplos da classe.

$\mathrm{Na}$ Tabela 23 está resumida a taxa de acerto média para cada critério de classificação. O algoritmo foi executado com diferentes valores de suporte e confiança e calculou-se a média das taxas de acerto obtidas, utilizando-se hierarquias conceituais.

\begin{tabular}{|l|l|}
\hline Critério de desempate & taxa de acerto média \\
\hline \hline sup $\times$ conf & $93,53 \%$ \\
\hline maior conf / maior sup & $92,17 \%$ \\
\hline
\end{tabular}

Tabela 23: Comparação do resultado obtido por diferentes critérios de classificação do conjunto de teste para o BD Cogumelo, utilizando hierarquias conceituais, com suporte $=20 \%, 12 \%, 4 \%$ e confiança $=90 \%, 94 \%, 98 \%$, e largura do feixe $=256$.

Observa-se que a utilização do critério de sup $\times$ conf obteve um melhor resultado diante do outro critério.

\subsubsection{Exemplos não classificados}

Se um exemplo do conjunto de teste não for coberto por uma regra então este não será rotulado. Dependendo do problema desejado, é melhor não rotular um exemplo do que fazê-lo erradamente. Entretanto, se for desejado que os exemplos sejam sempre rotulados, independente da possibilidade de erro, pode-se empregar uma classe padrão para ser atribuída a exemplos nesta situação, como utilizado em (CLARK; NIBLETT, 1989).

No BD Adulto, observa-se que o número de tuplas não classificadas é elevado (Tabela 24). Para este BD, será verificado se a utilização de uma classe padrão melhora a taxa de acerto.

$\mathrm{Na}$ Tabela 25 é mostrado uma melhora considerável na taxa de acerto. Isto ocorre porque a distribuição de classes neste BD não é balanceada (classe $<=50 K=76,2 \%$ e classe $>50 K$ $=23,8 \%$ ) e o número de exemplos não classificados é elevado. Utilizando-se a classe padrão, aproximadamente $76 \%$ dos exemplos não classificados serão rotulados na classe $<=50 K$, elevando a taxa de acerto nesta classe e por conseguinte a taxa de acerto em todo o conjunto de teste. 


\begin{tabular}{|l|l|l|l|}
\hline $\mathrm{BD}$ - sup/conf & $\begin{array}{l}\text { largura } \\
\text { do feixe }\end{array}$ & $\begin{array}{l}\mathrm{Nr} \text { de exemplos } \\
\text { não classificados } \\
\text { sem HC }\end{array}$ & $\begin{array}{l}\mathrm{Nr} \text { de exemplos } \\
\text { não classificados } \\
\text { com HC }\end{array}$ \\
\hline \hline Adulto HC - 4\%/90\% & 1 & 1150 & 1130 \\
& 2 & 1083 & 1055 \\
& 4 & 1070 & 995 \\
& 8 & 1048 & 982 \\
& 16 & 1000 & 981 \\
& 32 & 892 & 979 \\
& 64 & 885 & 972 \\
& 128 & 877 & 860 \\
& 256 & 787 & 840 \\
\hline
\end{tabular}

Tabela 24: BD Adulto - Número de exemplos não classificados para cada largura do feixe

\begin{tabular}{|l|l|}
\hline Critério utilizado & taxa de acerto média \\
\hline \hline SEM classe padrão & $72,35 \%$ \\
\hline COM classe padrão & $81,62 \%$ \\
\hline
\end{tabular}

Tabela 25: Comparação do resultado obtido pela utilização de uma classe padrão para exemplos não cobertos por regras utilizando hierarquias conceituais, com sup $=4 \%$, conf $=90 \%$ e largura do feixe $=256$.

\subsubsection{Critério de seleção das hipóteses de regra para o feixe dalbusca}

Para selecionar quais hipóteses de regras entrarão no feixe de busca, além do critério citado na Seção 3.2.1, será utilizado o critério de maior valor de confiança da hipótese. Como uma hipótese não possui uma classe determinada, será obtido o maior valor de confiança dentre as classes que possuem valor de suporte maior que o mínimo.

Na Tabela 26 está resumida a taxa de acerto média para cada critério de ordenação. O algoritmo foi executado em diferentes valores de suporte e confiança e calculou-se a média das taxas de acerto obtidas, utilizando-se hierarquias conceituais. O critério de $\mathbf{s u p} \times$ conf obteve um resultado melhor do que a utilização da do critério de seleção com base no valor de confiança.

\begin{tabular}{|l|l|}
\hline Critério utilizado & taxa de acerto média \\
\hline \hline sup $\times$ conf & $93,53 \%$ \\
\hline confiança & $91,62 \%$ \\
\hline
\end{tabular}

Tabela 26: Comparação do resultado obtido por diferentes critérios de ordenação da lista_nós_abertos, utilizando hierarquias conceituais, com suporte $=20 \%, 12 \%, 4 \%$ e confiança $=90 \%, 94 \%, 98 \%$, e largura do feixe $=256$. 


\subsection{Extensão na semântica da regra de classificação}

Na representação de uma regra de classificação, as condições que relacionam um atributo e seu valor são: (i) a igualdade, para atributos categóricos; e (ii) a inclusão num intervalo, para atributos numéricos (Seção 2.3).

A fim de aumentar a capacidade de expressão de uma regra, serão acrescentadas a condição de negação de cada uma das condições anteriores, ou seja, para atributos categóricos será a condição de desigualdade, (e.g., $A_{1} \neq v$ ou $A_{1}<>v$ ), e para atributos numéricos será a condição de não inclusão num determinado intervalo, (e.g., $A_{2} \notin[1,4)$ ou $A_{2}<1 \vee A_{2} \geq 4$ ).

A adição desta nova condição irá refletir diretamente no tamanho do espaço de busca que será gerado pelo algoritmo de descoberta devido ao aumento do número de hipóteses de regras pois, quando o algoritmo for verificar um valor de um atributo, ele deverá testar um conjunto maior de condições.

Empregando-se a mesma primitiva de contagem de alto nível (Seção 3.5.1), podem-se obter os dados necessários para o cálculo das medidas de relevância para as novas condições. Através da matriz gerada pela primitiva de contagem, o cálculo da linha referente à condição de negação do valor de um atributo é feito subtraindo-se a linha do total de tuplas em cada classe, isto é, linha Total na Figura 27, da linha na qual se encontrâ o valor desejado, ou seja:

$$
A<>v_{i}=\left[T_{+1}, \ldots, T_{+n}, T_{++}\right]-\left[T_{i 1}, \ldots, T_{i n}, T_{i+}\right]
$$

A expressão em SQL da primitiva de contagem deverá ser modificada para que o Descritor_Tuplas possa representar a desigualdade de valores de alto nível. Para cada valor de alto nível $v$, de um determinado atributo $\mathbf{A}$ que compõem um par atributo-valor em que a condição seja a negação, será gerada uma expressão da forma: $\mathbf{A}<>v_{1}$ AND $\mathbf{A}<>v_{2}$ AND $\mathbf{A}<>v_{3}$, em que $\left\{v_{1}, v_{2}, v_{3}\right\} \preceq v$ e $\left\{v_{1}, v_{2}, v_{3}\right\}$ são vértices folha da hierarquia do atributo $\mathbf{A}$.

Para avaliar a extensão da representação de regras proposta na seção anterior, foi escolhido um BD, denominado MONK-3 problem (BLAKE; MERZ, 1998), com dados artificiais no qual a descrição da classe envolve a negação entre um atributo e um valor. Os exemplos do conjunto de dados são descritos através de seis atributos categóricos (Tabela 28) e cada exemplo pode pertencer a uma das duas classes, cujos valores são 0 ou 1 . O conjunto de testes possui 122 tuplas e o conjunto de treinamento 432 tuplas. A classe 1 é descrita através das seguintes regras: 


\begin{tabular}{|c|c|c|}
\hline & $C_{1} \ldots C_{j} \ldots C_{n}$ & Total \\
\hline$A v_{1}$ & $\bar{T}_{11} \ldots \ldots T_{1 n}$ & $T_{1+}$ \\
\hline - & $\cdots \cdots$ & \\
\hline$A v_{i}$ & $\ldots T_{i j} \ldots$ & $T_{i+}$ \\
\hline . & $\ldots \ldots$ & . \\
\hline . & $\ldots \ldots$ & \\
\hline$A v_{m}$ & $T_{m 1} \ldots \ldots T_{m n}$ & $T_{m+}$ \\
\hline Total & $T_{+1} \ldots T_{+j} \ldots T_{+n}$ & $T_{++}$ \\
\hline
\end{tabular}

Tabela 27: Estrutura geral da saída da primitiva de contagem - a condição de desigualdade é obtida pela diferença entre a linha Total e a linha onde se encontra o valor do atributo $A v_{i}$

$\mathrm{a} 5=3 \wedge \mathrm{a} 4=1 \rightarrow 1$

a5 $<>4 \wedge$ a $2<>3 \rightarrow 1$

$\mathrm{O} \mathrm{BD}$ possui $5 \%$ de ruído, isto é, tuplas que descrevem o mesmo exemplo mas que pertencem a classes diferentes.

\begin{tabular}{|l|l|}
\hline Atributo & valores \\
\hline \hline $\mathrm{a} 1$ & $1,2,3$ \\
\hline $\mathrm{a} 2$ & $1,2,3$ \\
\hline $\mathrm{a} 3$ & 1,2 \\
\hline $\mathrm{a} 4$ & $1,2,3$ \\
\hline $\mathrm{a} 5$ & $1,2,3,4$ \\
\hline $\mathrm{a} 6$ & 1,2 \\
\hline
\end{tabular}

Tabela 28: Dados do BD MONK-3

Na Tabela 29 estão listados os algoritmos e as taxas de acerto obtidas.

A extensão da representação da regra de classificação permitiu descobrir um conjunto de regras mais próximo dos conceitos representados no BD minerado, aumentando as possibilidades de representação e melhorando a taxa de acerto, indicando a utilização desta extensão também na descoberta de regras de alto nível.

\begin{tabular}{|l|l|}
\hline Algoritmo & Taxa de acerto \\
\hline \hline C4.5 (QUINLAN, 1993) & $97,2 \%$ \\
\hline CN2 (CLARK; BOSWELL, 1991) & $89,1 \%$ \\
\hline Netuno (extensão) & $97,2 \%$ \\
\hline Netuno & $83,3 \%$ \\
\hline
\end{tabular}

Tabela 29: Taxa de acerto obtidas por outros algoritmos e pelo Sistema NETUNO-HC no BD Monk-3 


\begin{tabular}{|l|l|}
\hline Regra & medidas \\
\hline \hline R1) $a 4<>2 \wedge a 2<>3 \wedge a 5<>4->1$ & Sup: 0.666 Conf: 0.930 \\
\hline R2) $a 4<>3 \wedge a 2<>3 \wedge a 5<>4->1$ & Sup: 0.583 Conf: 0.921 \\
\hline R3) $a 6<>1 \wedge a 2<>3 \wedge a 5<>4->1$ & Sup: 0.55 Conf: 0.970 \\
\hline R4) $a 2=1 \wedge a 5<>4->1$ & Sup: 0.433 Conf: 0.963 \\
\hline R5) $a 2=2 \wedge a 5<>4 \wedge a 1<>2->1$ & Sup: 0.383 Conf: 0.983 \\
\hline
\end{tabular}

Tabela 30: Conjunto de regras descobertas para a classe 1 com sup $=30 \%$, conf $=90 \%$ e largura do feixe $=16$, pelo Sistema NETUNO-HC

\begin{tabular}{|l|l|}
\hline Regra & medidas \\
\hline \hline R6) $a 5=4->0$ & Sup: 0.483 Conf: 0.967 \\
\hline R7) a2=3 $>0$ & Sup: 0.612 Conf: 0.926 \\
\hline
\end{tabular}

Tabela 31: Conjunto de regras descobertas para a classe 0 com sup $=30 \%$, conf $=90 \%$ e largura do feixe $=16$, pelo Sistema NETUNO-HC 


\section{Conclusões}

Este trabalho apresenta um estudo e análise do uso de hierarquias conceituais na descoberta de regras de classificação. Foi implementado um sistema, denominado NETUNO-HC, sobre o qual foram realizados um conjunto de testes sobre bancos de dados do repositório de (BLAKE; MERZ, 1998).

A decisão de se realizar a mineração com hierarquias conceituais envolve o compromisso entre a busca por regras que possuem um maior grau de interesse, expressas através de conceitos de maior nível de abstração, versus um maior custo computacional para a sua obtenção. Deste modo, faz-se necessário o uso de técnicas para resolver os problemas decorrentes desse novo problema de mineração de dados, com geração de padrões de alto nível.

O algoritmo NETUNO foi projetado para trabalhar com dados gerenciados por SGBD relacionais e representar as hierarquias conceituais através de estruturas em memória. Os resultados da mineração obtidos pelo Sistema NETUNO-HC foram satisfatórios, quando comparados com as taxas de acerto alcançadas por outros algoritmos de mineração que não empregam hierarquias conceituais (Tabelas 11 e 12).

Para realizar a mineração usando hierarquias conceituais, foram utilizadas:

- Técnicas eficientes de representação das hierarquias conceituais. $O$ uso de uma estrutura interna para representação e manipulação das hierarquias conceituais torna o algoritmo independente de outras ferramentas para executar estas tarefas, como utilizado em (TAYLOR, 1999). A técnica utilizada para a codificação dos conceitos da hierarquia reduz o tempo consumido nas operações de verificação do relacionamento entre dois conceitos, aumentando a eficiência do algoritmo na geração e verificação das hipóteses de regra.

- Estratégias de busca. O uso da Busca em Feixe permite percorrer o espaço de busca gerado de maneira mais eficiente e com resultados satisfatórios quando comparada à Busca em Largura utilizada por (TAYLOR, 1999). 
- Técnicas de redução do número de acessos ao BD. Foi proposto neste trabalho uma extensão da primitiva de contagem proposta em (FREITAS, 1997) para a mineração com hierarquias conceituais. Demonstrou-se que essa extensão reduz o número de acessos ao $\mathrm{BD}$, sendo essa a operação que consome mais tempo durante a etapa de mineração.

Os experimentos realizados com variações dos diferentes parâmetros da mineração e do algoritmo de busca mostraram como esses valores afetam o conjunto de regras descobertas, ou seja:

- Alterações do valor mínimo de suporte - a redução do valor mínimo de suporte tende a aumentar a taxa de acerto, usando ou não hierarquias conceituais, bem como aumenta o número de regras descobertas. Um aumento do valor mínimo de suporte tende a descobrir um conjunto de regras mais interessante, isto é, um conjunto com mais regras contendo valores de alto nível.

- Alterações do valor mínimo de confiança - o efeito de alterações no valor mínimo de conniança depende do domínio no qual é realizada a mineração de dados, pois um valor maior pode não melhorar a taxa de acerto (utilizando ou não hierarquias conceituais).

- Alterações da largura do feixe - um valor maior de feixe tende a aumentar a taxa de acerto. Porém, dependendo do domínio dos dados, a melhor taxa de acerto pode ser obtida em larguras de feixe menores (utilizando-se ou não hierarquias conceituais). Dependendo da hierarquia conceitual, pode-se descobrir um conjunto de regras com uma elevada taxa de acerto em larguras de feixe pequenas.

- Redução do conjunto de regras descobertas - A redução do conjunto de regras descobertas através de critérios de intersecção de cobertura pode melhorar a taxa de acerto deste conjunto, bem como aumentar a generalidade do conjunto obtido.

- Escolha do critério de classificação de um exemplo - diferentes critérios para a classificação de um exemplo não visto alteram a taxa de acerto de um conjunto de regras, indicando que devem ser testados diferentes critérios a fim de selecionar o mais adequado para o domínio em questão.

- Seleção das hipóteses de regra para o feixe de busca - a eficiência da Busca em Feixe reside em explorar uma parte do espaço de busca, através de alguma função 
heurística, que possui maior chance de se tornar uma regra descoberta. Deste modo, diferentes funções heurísticas devem ser testadas para se verificar quais apresentam melhor resultado e em que condições, para o BD que se deseja minerar.

Escolhida uma representação da regra de classificação, o algoritmo irá gerar as possíveis hipóteses de regras e testar sua validade junto ao BD. Quanto maior o número de possibilidades, maior a capacidade de representar a classe que se deseja aprender. Novas formas de representar uma regra de classificação podem, não somente melhorar a taxa de acerto, mas também facilitar a compreensão pelo usuário, como foi obtido pela introdução da condição de desigualdade. Foi proposta uma maneira de realizar a mineração com hierarquias conceituais com regras envolvendo a negação das condições, empregando a primitiva de contagem para hierarquias conceituais. Foram feitos testes sobre um BD artificial com ruído a os resultados apresentados mostram que os conceitos contidos neste BD artificial foram aprendidos.

Os experimentos conduzidos nesta pesquisa mostram que as técnicas de indução empregadas no algoritmo NETUNO não necessitam de um BD previamente generalizado, como no caso de (HAN; CAI; CERCONE, 1992) e (FU, 1996). Evitando-se a pré-generalização obtém-se a capacidade de induzir regras em múltiplos níveis de generalidade, sem uma prévia definição do nível desejado. A capacidade de induzir regras em múltiplos níveis do algoritmo NETUNO é devida à representação e manipulação das hierarquias conceituais, bem como das consultas em alto nível expressas através da primitiva de contagem. Esta representação das hierarquias também traz maior independência do algoritmo em relação a um outro sistema, como no caso do algoritmo ParDRI (TAYLOR, 1999), que utiliza uma ferramenta dedicada para representar e manipular hierarquias conceituais.

O uso da primitiva de contagem implementada no algoritmo NETUNO torna desnecessário o pré-processamento para a geração das tabelas de co-ocorrência utilizadas no algoritmo ParDRI (TAYLOR, 1999). Além disso, um efeito colateral deste tipo de pré-processamento é a possibilidade de que estas tabelas adquiram um tamanho elevado, caso o BD a ser minerado tenha um número grande de exemplos diferentes entre si e diferentes valores para o domínio dos atributos, o que pode ocorrer no caso de atributos numéricos.

No algoritmo ParDRI (TAYLOR, 1999), a especialização de uma hipótese de regra pela adição de um atributo é feita obedecendo um critério de ordem entre os atributos que, apesar de reduzir o espaço de busca, deixa de avaliar hipóteses de regras que poderiam ser descobertas. Além disso, a decisão de escolher o valor do último atributo para gerar uma hipótese de regra a ser expandida posteriormente não considera todos os valores da hierarquia, e sim aqueles de mais alto nível, evitando descobrir uma regra que inclua outra. No algoritmo 
NETUNO, a estratégia da Busca em Feixe reduz o espaço de busca e a verificação da inclusão entre regras permite que todos os valores da hierarquia possam ser considerados.

Finalmente, é importante observar que o processo de execução dos experimentos realizados neste trabalho, correspondem às etapas do processo de KDD descrito por (FAYYAD; PIATESKY-SHAPIRO; SMYTH, 1996). 


\section{Trabalhos futuros}

\subsection{Hierarquias conceituais para os valores da classe}

Neste trabalho, o uso das hierarquias ficou restrito aos valores dos atributos que descrevem um determinado objeto. Entretanto, os valores do atributo classificador também poderiam estar organizados desta forma. A estrutura em matriz que armazena a saída da primitiva de contagem pode ser aproveitada para o cálculo de regras nas quais o atributo classificador possui uma hierarquia associada aos seus valores.

Do mesmo modo que as linhas da matriz representam conceitos do nível folha, as colunas também irão representar os conceitos folha da hierarquia do atributo classificador (Figura 41) e somando-se as colunas obtêm-se os valores de mais alto nível nesta hierarquia.

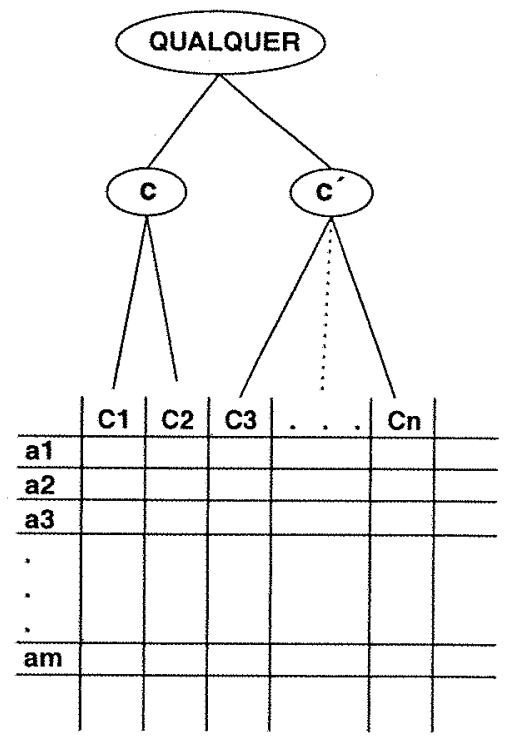

Figura 41: As colunas da matriz representam os conceitos no nivel folha da hierarquia do atributo classe 


\subsection{Uso de outros tipos de conhecimento prévio}

Como mostrado na seção 2.2 , há outras tipos de hierarquia que representam relações mais complexas, como o caso das hierarquias condicionais, bem como relações entre atributos que não são apenas relações de generalização-especialização.

Por exemplo, num domínio de dados meteorológicos os atributos direção do vento, intensidade do vento e direção das ondas podem não ter uma relação de causalidade, se for desejado obter a previsão da ocorrência de nevoeiro ou não. Porém, se houver interesse em prever qual a altura que uma onda poderá atingir, eles serão interessantes. Um especialista deste tipo de domínio pode saber, ou mesmo ter descoberto uma regra, na qual os atributos anteriores possuem a seguinte relação:

SE INTENSIDADE DO VENTO $>50 \mathrm{KM} / \mathrm{H}$ E DIREÇÃO DO VENTO = DIREÇÃO DAS ONDAS ENTÃO ALTURA DA ONDA $>2 \mathrm{M}$

O conceito altura da onda $>2 m$ poderá não estar representado no $\mathrm{BD}$, mas o seu uso na descoberta de regras de classificação, como mais um par do antecedente de uma regra, pode conduzir a descoberta de regras mais interessantes. Um tópico importante para estudo é como representar este tipo de relação para poder utilizá-la na descoberta de conhecimento; permitindo reaproveitar o conhecimento já descoberto.

\subsection{Seleção de atributos}

A seleção de um conjunto de atributos, além de melhorar a precisão de classificação, pode também ser usada para diminuir o espaço de busca. Entretanto, com o uso de hierarquias conceituais, valores de mais alto nível podem não discriminar as classes tão bem quanto valores de nível inferior. O uso de hierarquias conceituais traz um novo problema que é a seleção de atributos considerando que seus valores estão agrupados numa hierarquia.

\subsection{Linguagem de consulta para a mineração de BD re- lacionais}

A representação do conjunto de exemplos numa única tabela facilita o teste das hipóteses de regras geradas pelo algoritmo, além de diminuir o tempo das consultas ao BD. Entretanto, 
nem sempre um $\mathrm{BD}$ poderá ser representado através de uma única tabela, ou porque o proprietário do BD não deseja alterar a sua representação ou porque não há espaço físico para transformar os dados de diferentes tabelas numa única tabela.

Uma forma de permitir o uso de dados armazenados em diferentes tabelas, como é o caso do modelo relacional, seria codificar os relacionamentos entre as tabelas nas consultas feitas ao $\mathrm{BD}$ durante o processo de busca pelas regras, isto é, a primitiva de contagem teria na cláusula WHERE os relacionamentos entre as tabelas que contêm os atributos de interesse, e o SGBD iria efetuar as operações de JOIN determinadas.

Isto pode ser feito estendendo-se a linguagem SQL para permitir executar a mineração de dados, a fim de fornecer ao usuário uma interface na qual ele poderá utilizar todo o conjunto de dados de um BD relacional. Uma das linguagens propostas é a $D M Q L-D a t a$ Mining Query Language (HAN et al., 1996b) utilizada no sistema DBMiner (HAN et al., 1996a). O usuário interage com o sistema através desta linguagem, que utiliza uma sintaxe parecida com a SQL e na qual podem ser escolhidos os padrões que se deseja minerar, os atributos e suas hierarquias conceituais. A partir dos atributos o sistema irá gerar a tabela generalizada na qual será feita a busca pelos padrões desejados. Apesar do sistema criar a tabela generalizada a partir dos atributos e tabelas selecionadas numa expressão em $D M Q L$, a proposta da linguagem pode ser aplicada num sistema que fará a mineração num conjunto de dados disposto através de tabelas relacionais sem, necessariamente, criar uma tabela única.

\subsection{Outros bancos de dados}

$\mathrm{O}$ uso de $\mathrm{BD}$ conhecidos permite avaliar o desempenho de um algoritmo de mineração com relação a outros disponíveis na literatura. Entretanto, a mineração em BD reais com o auxílio de um especialista do domínio permitirá modelar e refinar as hierarquias utilizadas bem como interpretar os padrões descobertos. 


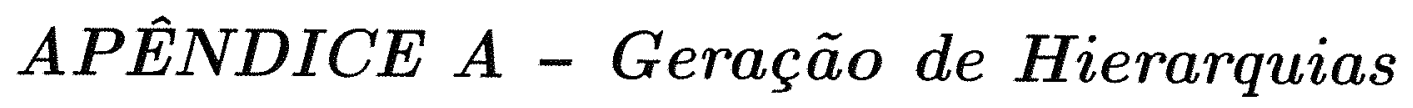 Numéricas}

\section{A.1 Introdução}

Atributos, cujo domínio de valores é contínuo, podem ter uma hierarquia de conceitos sobre esses valores. Este tipo de hierarquia pode ser obtido de duas formas:

1. previamente codifícada pelo usuário ou um especialista e lida por ocasião da mineração de dados, ou

2. geradas a partir dos dados que serão minerados, numa etapa anterior à mineração de dados.

A idéia principal para a geração de hierarquias numéricas é agrupar os valores de um atributo contínuo em intervalos sucessivos, cada vez maiores, até formar um intervalo que contém toda a faixa possível de valores encontrada no BD para este atributo. Esses intervalos serão os vértices da hierarquia.

Este apêndice irá tratar da geração de hierarquias numéricas, como no item 2, e está organizado da seguinte forma. Na seção A.2 são descritas as abordagens para geração das hierarquias numéricas. Na seção A.3 é apresentada a motivação para a criação dos intervalos. Finalmente, na seção A.4 é mostrado o algoritmo para geração de hierarquias utilizado no sistema NETUNO.

\section{A.2 Abordagens para criação dos intervalos}

A geração dos intervalos pode levar em conta ou não a distribuição dos valores do atributo entre as classes. Em (LU, 1997), são propostos algoritmos para geração de hierarquias numéricas sem considerar o atributo classificador, apenas utilizando a distribuição da freqüência 
relativa dos valores do atributo no $\mathrm{BD}$. Este tipo de abordagem é útil quando se deseja construir uma hierarquia numérica que será utilizada para a descoberta de diferentes padrões num mesmo BD.

Em (FREITAS, 1997), é proposto um algoritmo para geração de intervalos numéricos denominado InfoMerge, que leva em conta a distribuição dos valores do atributo contínuo por entre as classes. Utilizando-se como base de comparação o algoritmo C4.5 (QUINLAN, 1993), este foi executado com os intervalos gerados pelo InfoMerge e sem os intervalos. No primeiro caso, o tempo de execução foi sensivelmente reduzido, sem apresentar um decréscimo significativo na precisão de classificação. Isto porque o processamento de valores contínuos é mais demorado que o processamento de atributos discretos.

\section{A.3 Motivação}

Como citado na seção A.1, uma hierarquia numérica poderá ser codificada numa tabela relacional e lida por ocasião da descoberta das regras de classificação. Porém, nem sempre este tipo de hierarquia estará disponível, ou porque não foi estabelecida ou porque não se sabe que critério deverá ser obedecido para a delimitação dos intervalos.

O uso de intervalos, além de aumentar a compreenssão de uma regrấ de classificação que os utilize, reduz o tempo de execução do algoritmo de mineração de regras de classificação, sem afetar a precisão de classificação do conjunto de regras obtido, como mostrado no item A.2.

Como esta dissertação trata sobre regras de classificação, será empregado um algoritmo para geração de hierarquias numéricas utilizando como base o algoritmo InfoMerge (FREITAS, 1997).

\section{A.4 Algoritmo para a geração de hierarquias numéricas}

O algoritmo utilizado no sistema NETUNO utiliza a abordagem orientada à classe, e foi baseado no algoritmo InfoMerge proposto em (FREITAS, 1997). 


\section{A.4.1 Algoritmo InfoMerge}

O algoritmo InfoMerge é um algoritmo orientado à classe, de baixo para cima (bottom-up) e baseado na Teoria da Informação.

Primeiramente os valores do atributo são ordenados e a distribuição de freqüência entre as classes para cada valor do atributo é calculada. Em seguida, o algoritmo iterativamente calcula a perda de informação decorrente do processo de união de intervalos para cada grupo de $k$ intervalos adjacentes, em que $k$ é um parâmetro especificado pelo usuário, e une os $k$ intervalos adjacentes cuja perda de informação é a menor, seguindo o paradigma de baixo para cima (bottom-up).

Em cada iteração do processo de união, o InfoMerge primeiramente calcula a entropia de cada intervalo utilizando a distribuição de freqüências da classe deste intervalo. A seguir, é calculado, para cada grupo de $k$ intervalos adjacentes, a perda de informação associada com a união destes $k$ intervalos. A perda de informação é calculada da seguinte forma:

$$
\text { PERDA_INFO }=\text { INFO_DEPOIS_UNIÃO }- \text { INFO_ANTES_UNIÃO }
$$

na qual INFO_DEPOIS_UNIÃo é a quantidade de informação necessária para identificar a classe de uma tupla depois da união, medida pela fórmula A.2, e INFO_ANTES UNIÃo é a quantidade de informação antes da união, medida pela fórmula A.3. Nestas fórmulas, $n$ é o número de classe e $k$ denota o número de intervalos adjacentes considerados para a união. Os valores $T_{i j}, T_{i+}, t_{+j}$ e $t_{++}$tem o mesmo significado que o descrito na seção ??, com a diferença que aqui, o valor $t_{+j}$ representa o total de tuplas que pertencem a classe $C_{j}$ no intervalo $1 \ldots k$, e $t_{++}$significa o total de tuplas neste mesmo intervalo.

$$
\begin{gathered}
\text { INFO_DEPOIS_UNIÃO }=-\sum_{j=1}^{n}\left(\frac{t_{+j}}{t_{++}}\right) \log _{2}\left(\frac{t_{+j}}{t_{++}}\right) \\
\text {INFO_ANTES_UNIÃO }=\sum_{i=1}^{k}\left(\frac{T_{i+}}{t_{++}}\right)\left(-\sum_{j=1}^{n}\left(\frac{T_{i j}}{T_{i+}}\right) \log _{2}\left(\frac{T_{i j}}{T_{i+}}\right)\right)
\end{gathered}
$$

A minimização da perda de informação pode ser vista como uma operação dual da maximização do ganho de informação ao se particionar um vértice da árvore de decisão (QUINLAN, 1993). O objetivo do algoritmo InfoMerge é obter intervalos mais largos, nos quais a perda de separação entre as classes seja a menor possivel. 
Além de considerar intervalos cuja perda de informação é a menor, o algoritmo também leva em conta o tamanho dos intervalos que serão unidos. É melhor unir dois intervalos menores, i.e. menor frequência relativa de tuplas, do que dois intervalos maiores. Deste modo, o valor PERDA_INFO na fórmula A.1 é poderado com o tamanho do intervalo, i.e., a frequiencia relativa das tuplas contidas no intervalo em relação a todo o conjunto de dados. Esta nova medida é denominada PERDA_INFO_PONDERADA e o seu cálculo é obtido através da fórmula A.4, na qual $T_{++}$é o total de tuplas no conjunto de dados.

$$
\text { PERDA_INFO_PONDERADA }=\left(\frac{t_{++}}{T_{++}}\right) \text {PERDA_INFO }
$$

Agora, a cada iteração, o algoritmo une os $k$ intervalos adjacentes com valor mínimo de PERDA_INFO_PONDERADA.

\section{A.4.2 Algoritmo implementado para a criação de hierarquias nu- méricas}

Numa hierarquia numérica, um vértice é um intervalo I, representado da seguinte forma:

$$
I=V A L O R \_I N F E R I O R \sim V A L O R \_S U P E R I O R
$$

em que, $\forall x \in \mathbb{R}, x \in \mathrm{I}$ se VALOR_INFERIOR $\leq x<$ VALOR_SUPERIOR.

Seguindo a abordagem do InfoMerge, o algoritmo irá gerar, a cada iteração, os vértices de cada altura da hierarquia até formar o vértice raiz, que será um intervalo compreendendo toda a faixa de valores do atributo no BD, quando encerra sua execução. O critério para gerar estes intervalos é minimizar a PERDA_INFO_PONDERADA (fórmula A.4), ao agrupar-se $k$ intervalos adjacentes.

Ao gerar os vértices de uma determinada altura da hierarquia, alguns valores podem não pertencer aos intervalos gerados pelo algoritmo, pois o número de valores restante é menor que $k$. Neste caso, antes de passar ao nível superior, estes valores são unidos, gerando um vértice.

O tamanho dos intervalos adjacentes que serão unidos (o valor $k$ ), é armazenado na tabela que contém os dados das hierarquias que serão lidas ou geradas pelo NETUNO.

$\mathrm{Na}$ Figura 42, é mostrada a geração de uma hierarquia numérica utilizando-se o algoritmo do sistema NETUNO, com valor de $k$ igual a 3. No lado esquerdo da Figura, os valores 
do BD são ordenados e agrupados em intervalos, como mostrado pelas elipses pontilhadas, obedecendo o critério de minimização da PERDA_INFO_PONDERADA. Valores que não foram agrupados pelo critério anterior são agrupados para formar os vértices que contém estes valores, como mostrado pelas setas pontilhadas. Sucessivamente, o algoritmo gera os vértices em cada altura e no lado direito da Figura pode-se observar a hierarquia obtida dos valores do $B D$.

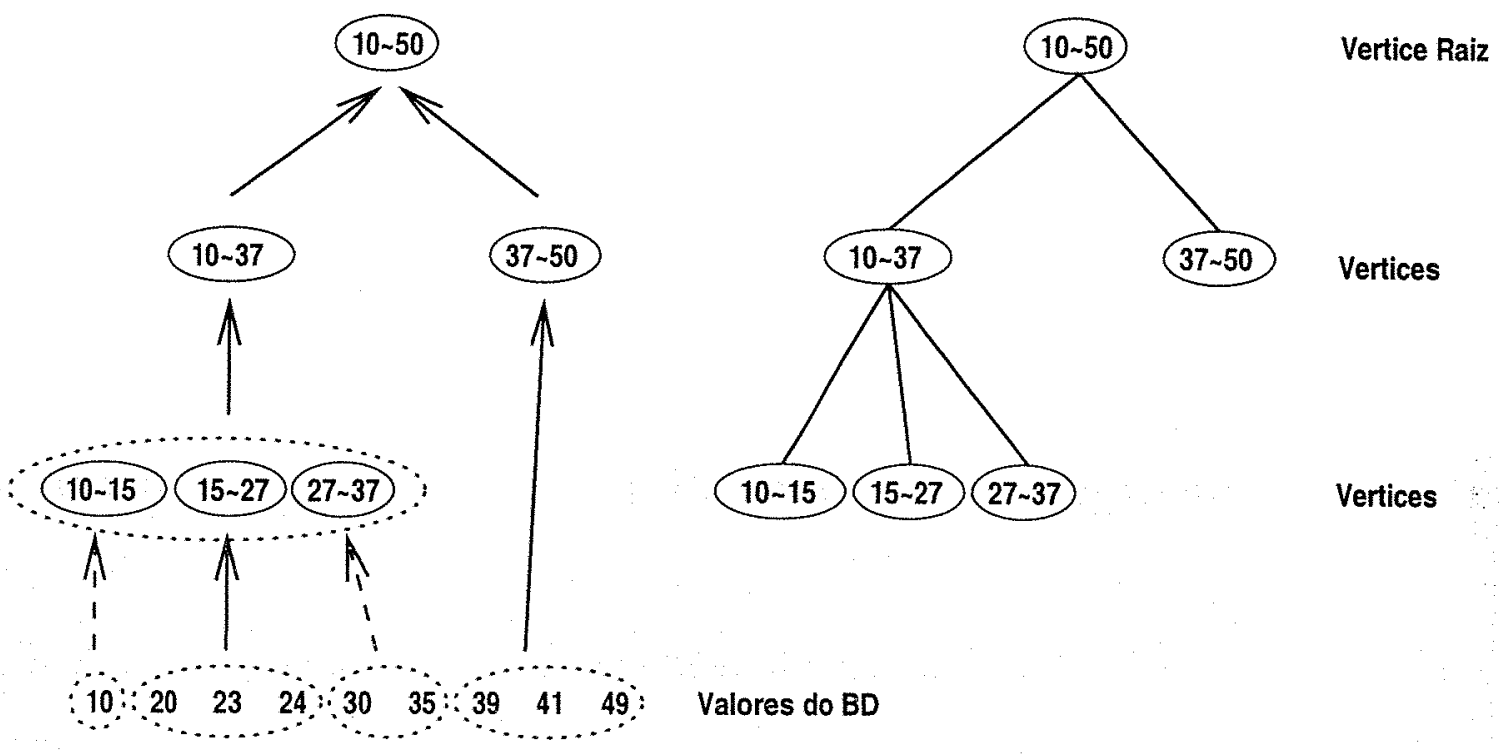

Figura 42: Geração de uma hierarquia numérica 


\section{APÊNDICE B - Banco de dados utilizados}

\section{B.1 Banco de dados sobre cogumelos}

A seguir estão descritos os atributos e respectivos valores, do $\mathrm{BD}$ sobre cogumelo, bem como as hierarquias dos atributos odor, population, ring_type, atributos cujo domínio seja cor e atributos cujo domínio seja surface.

\begin{tabular}{|l|l|l|}
\hline NR & Atributo & Valores \\
\hline 1 & cap-shape & bell, conical, convex, flat, knobbed, sunken \\
\hline 2 & cap-surface & fibrous, grooves, scaly, smooth \\
\hline 3 & cap-color & brown, buff, cinnamon, gray, green, pink, purple, red, white, yellow \\
\hline 4 & bruises & bruises, no \\
\hline 5 & odor & almond, anise, creosote, fishy, foul, musty, none, pungent, spicy \\
\hline 6 & gill-attachment & attached, descending, free, notched \\
\hline 7 & gill-spacing & close, crowded, distant \\
\hline 8 & gill-size & broad, narrow \\
\hline 9 & gill-color & black, brown, buff, chocolate, gray, green, orange, pink, purple, red, white, \\
& & yellow \\
\hline 10 & stalk-shape & enlarging, tapering \\
\hline 11 & stalk-root & bulbous, club, cup, equal, rhizomorphs, rooted, missing=? \\
\hline 12 & stalk-surface-above-ring & fibrous, scaly, silky, smooth \\
\hline 13 & stalk-surface-below-ring & fibrous, scaly, silky, smooth \\
\hline 14 & stalk-color-above-ring & brown, buff, cinnamon, gray, orange, pink, red, white, yellow \\
\hline 15 & stalk-color-below-ring & brown, buff, cinnamon, gray, orange, pink, red, white, yellow \\
\hline 16 & veil-type & partial, universal \\
\hline 17 & veil-color & brown, orange, white, yellow \\
\hline 18 & ring-number & none, one, two \\
\hline 19 & ring-type & cobwebby, evanescent, flaring, large, none, pendant, sheathing, zone \\
\hline 20 & spore-print-color & black, brown, buff, chocolate, green, orange, purple, white, yellow \\
\hline 21 & population & abundant, clustered, numerous, scattered, several, solitary \\
\hline 22 & habitat & grasses, leaves, meadows, paths, urban, waste, woods \\
\hline 23 & classe & edible, poisonous \\
\hline
\end{tabular}

Tabela 32: Descrição dos valores dos atributos do BD Cogumelo 


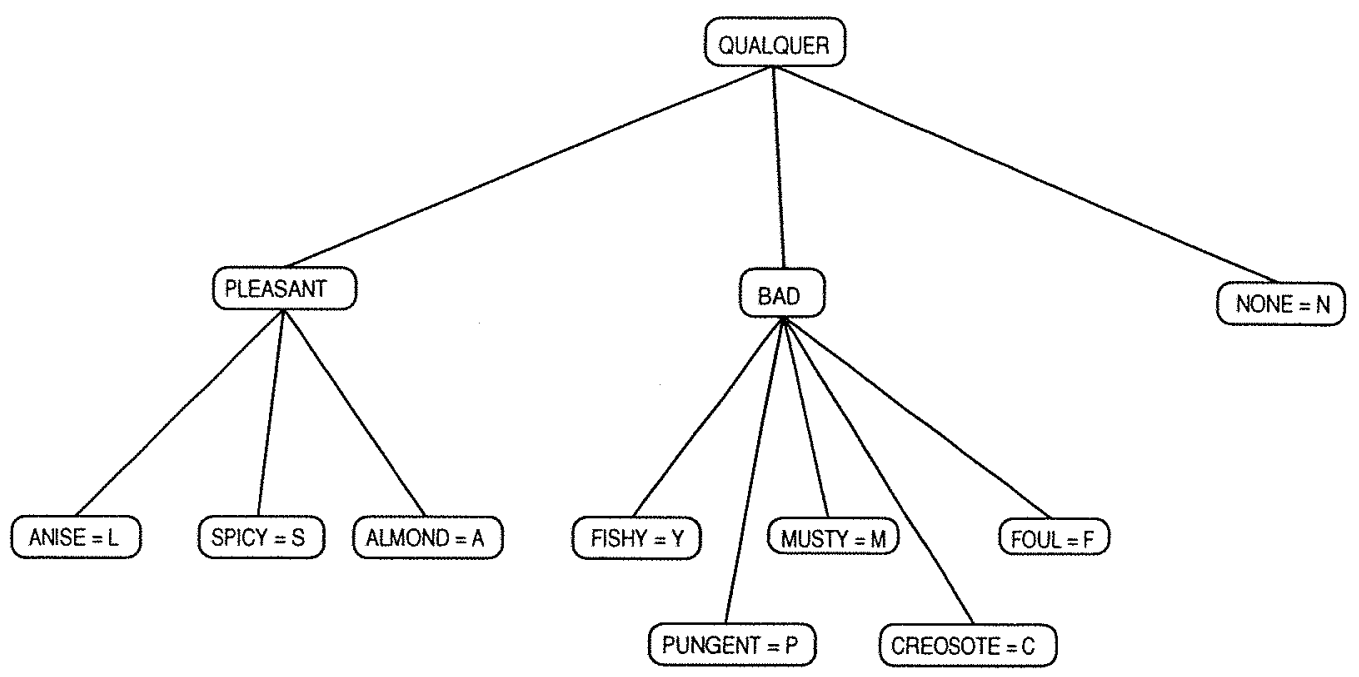

Figura 43: Hierarquia de conceitos para o atributo odor

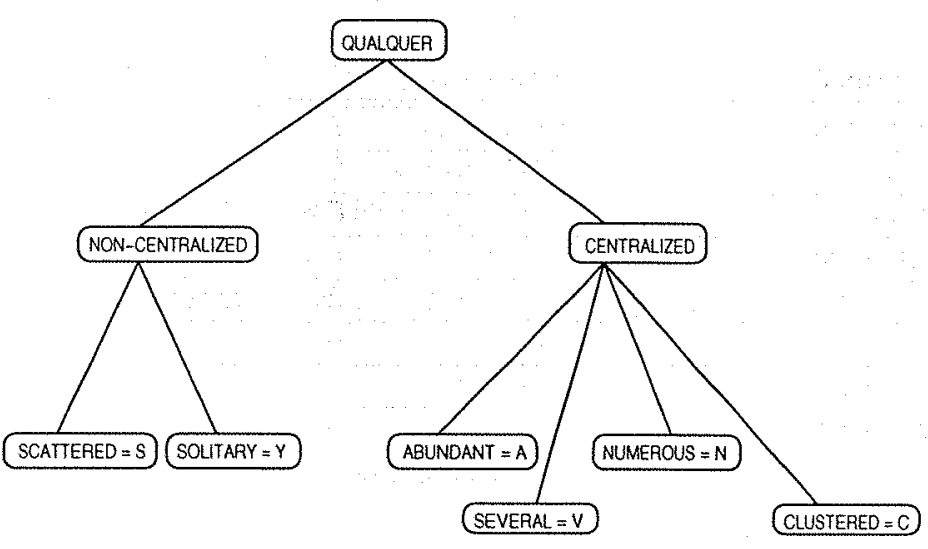

Figura 44: Hierarquia de conceitos para o atributo population

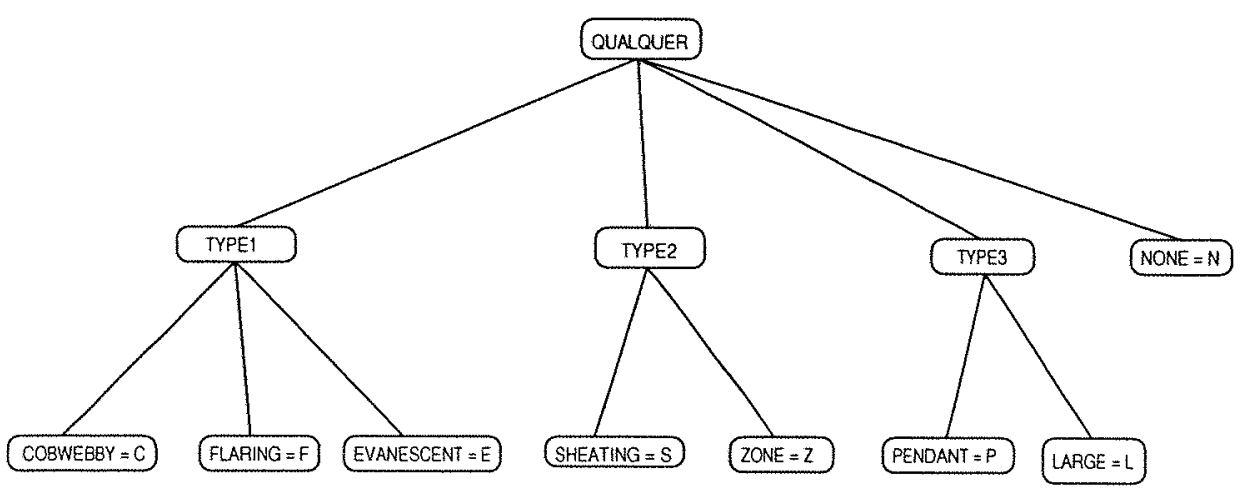

Figura 45: Hierarquia de conceitos para o atributo ring-type 


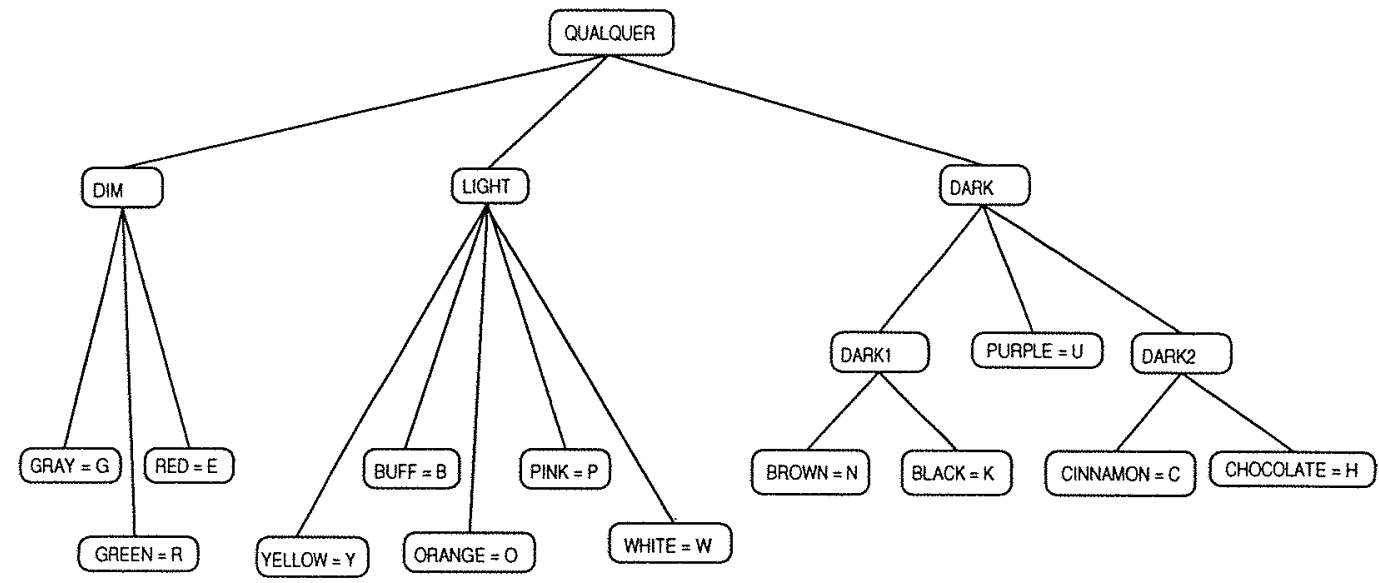

Figura 46: Hierarquia de conceitos para os atributos cujo domínio seja cor

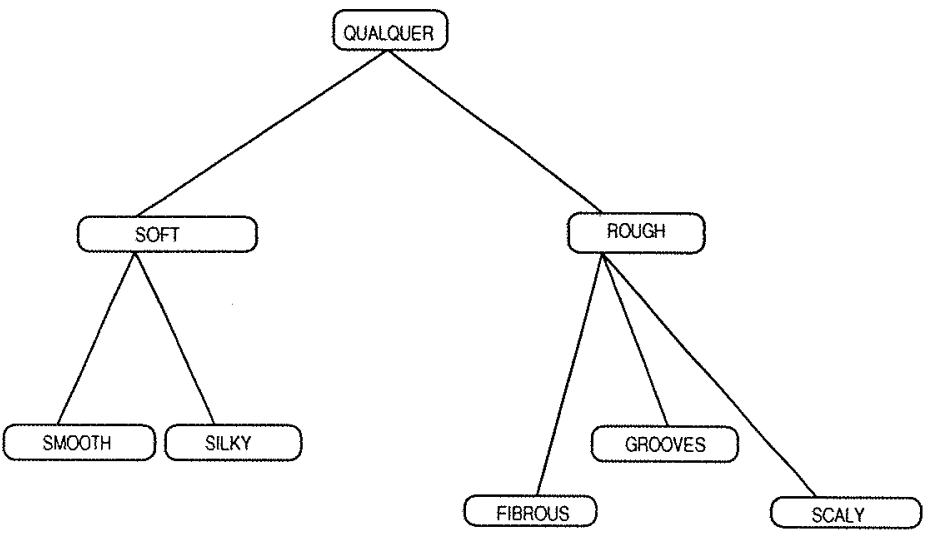

Figura 47: Hierarquia de conceitos para os atributos cujo domínio seja surface 


\section{B.2 Banco de dados sobre censo demográfico}

A seguir estão descritos os atributos e respectivos valores do BD Adulto, bem como as hierarquias dos atributos age, education, education_num, marital_status, capital_gain, capital_loss, hours_per_week e native_country.

\begin{tabular}{|c|c|c|}
\hline NR & Atributo & Valores \\
\hline 1 & age & contínuo \\
\hline 2 & workclass & $\begin{array}{l}\text { Private, Self-emp-not-inc, Self-emp-inc, Federal-gov, Local-gov, State-gov, } \\
\text { Without-pay, Never-worked }\end{array}$ \\
\hline 3 & education & $\begin{array}{l}\text { Bachelors, Some-college, 11th, HS-grad, Prof-school, Assoc-acdm, Assoc- } \\
\text { voc, 9th, 7th-8th, 12th, Masters, 1st-4th, 10th, Doctorate, 5th-6th, Pres- } \\
\text { chool }\end{array}$ \\
\hline 4 & education_num & contínuo \\
\hline 5 & marital_status & $\begin{array}{l}\text { Married-civ-spouse, Divorced, Never-married, Separated, Widowed, } \\
\text { Married-spouse-absent, Married-AF-spouse }\end{array}$ \\
\hline 6 & occupation & $\begin{array}{l}\text { Tech-support, Craft-repair, Other-service, Sales, Exec-managerial, Prof- } \\
\text { specialty, Handlers-cleaners, Machine-op-inspct, Adm-clerical, Farming- } \\
\text { fishing, Transport-moving, Priv-house-serv, Protective-serv, Armed-Forces }\end{array}$ \\
\hline$\frac{7}{9}$ & relationship & Wife, Own-child, Husband, Not-in-family, Other-relative, Unmarried \\
\hline 8 & race & White, Asian-Pac-Islander, Amer-Indian-Eskimo, Other, Black \\
\hline 9 & sex & Female, Male \\
\hline 10 & capital_gain & contínuo \\
\hline 11 & Capital_loss & contínuo \\
\hline 12 & hours_per_week & contínuo \\
\hline 13 & native_country & $\begin{array}{l}\text { United-States, Cambodia, England, Puerto-Rico, Canada, Germany, } \\
\text { Outlying-US(Guam-USVI-etc), India, Japan, Greece, South, China, Cuba, } \\
\text { Iran, Honduras, Philippines, Italy, Poland, Jamaica, Vietnam, Mexico, Por- } \\
\text { tugal, Ireland, France, Dominican-Republic, Laos, Ecuador, Taiwan, Haiti, } \\
\text { Columbia, Hungary, Guatemala, Nicaragua, Scotland, Thailand, Yugoslavia, } \\
\text { El-Salvador, Trinadad Tobago, Peru, Hong, Holand-Netherlands }\end{array}$ \\
\hline 14 & classe & $<=50 \mathrm{~K},>50 \mathrm{~K}$ \\
\hline
\end{tabular}

Tabela 33: Descrição dos valores dos atributos do BD Adulto

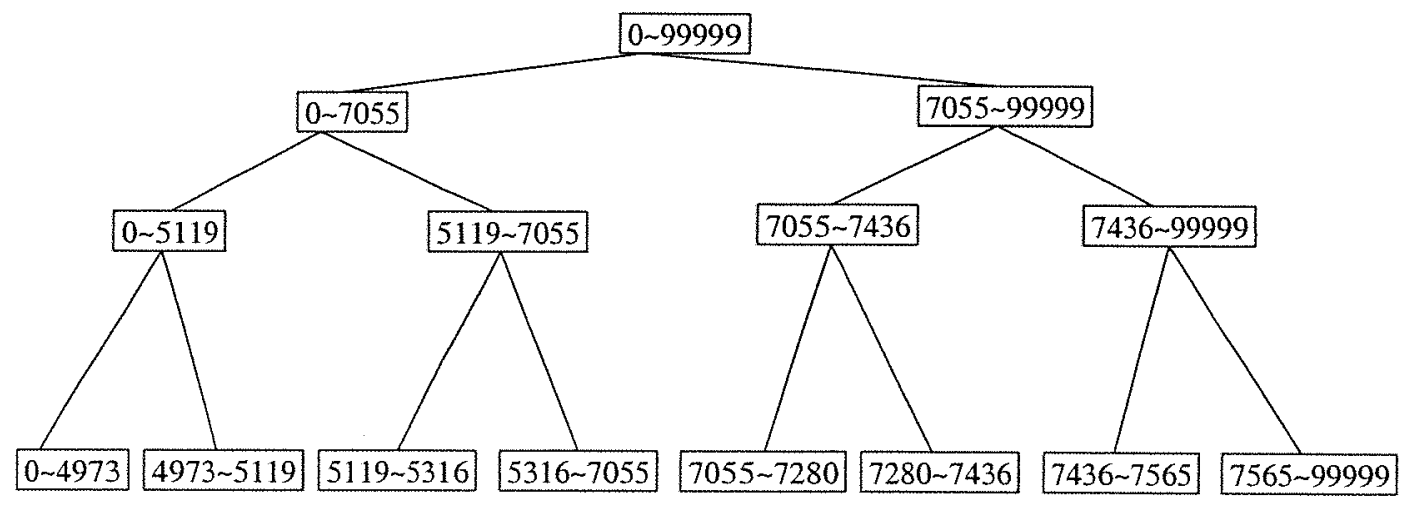

Figura 48: Hierarquia de conceitos para o atributo capital_gain 


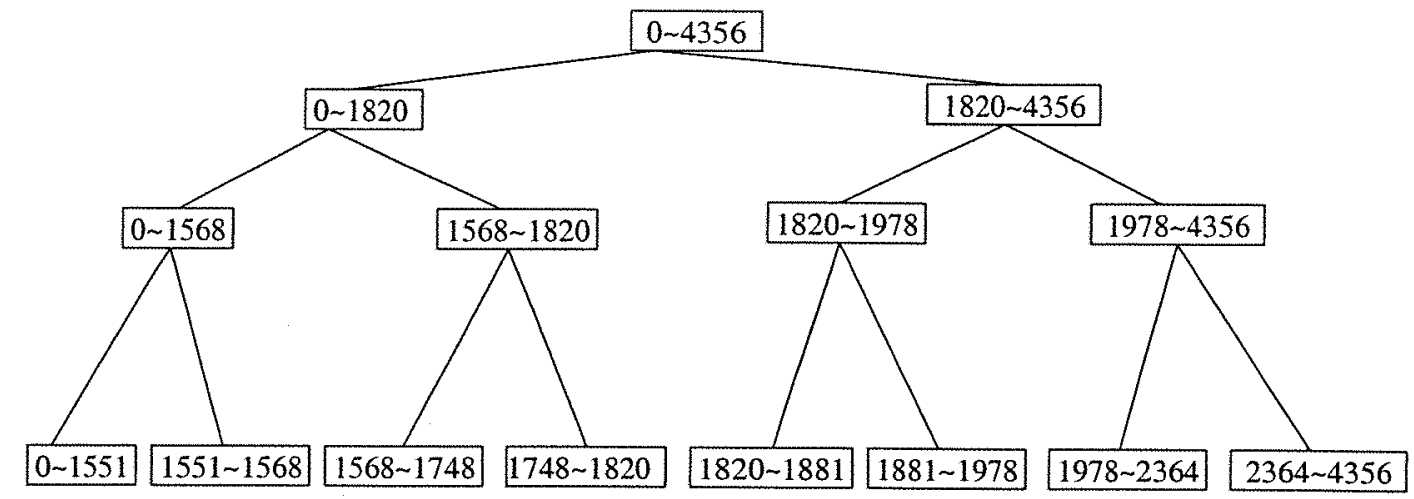

Figura 49: Hierarquia de conceitos para o atributo capital loss

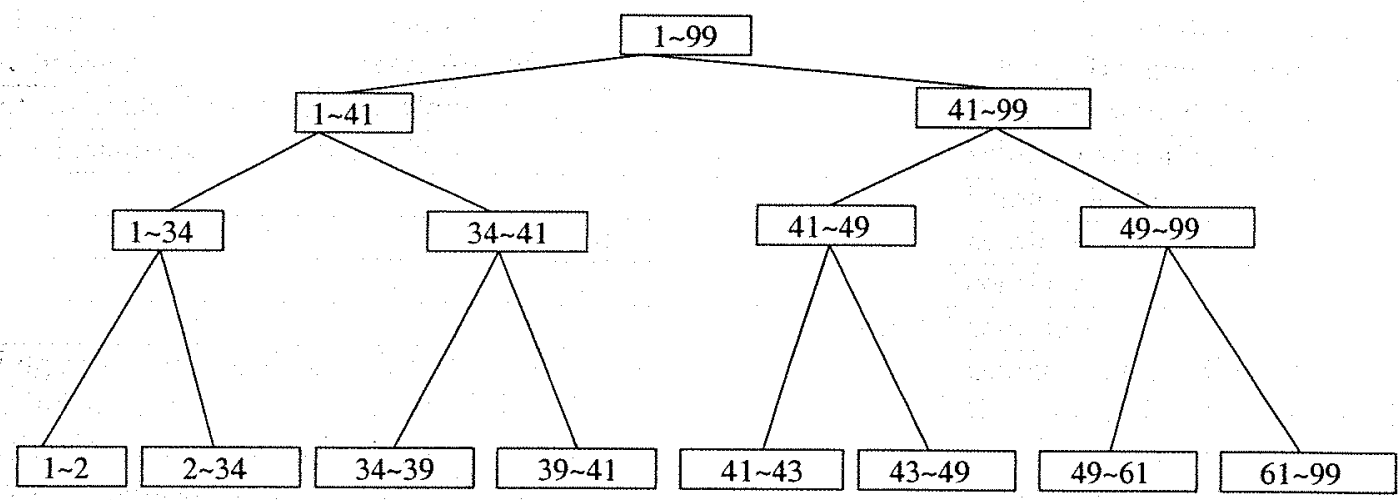

Figura 50: Hierarquia de conceitos para o atributo hours_per_week

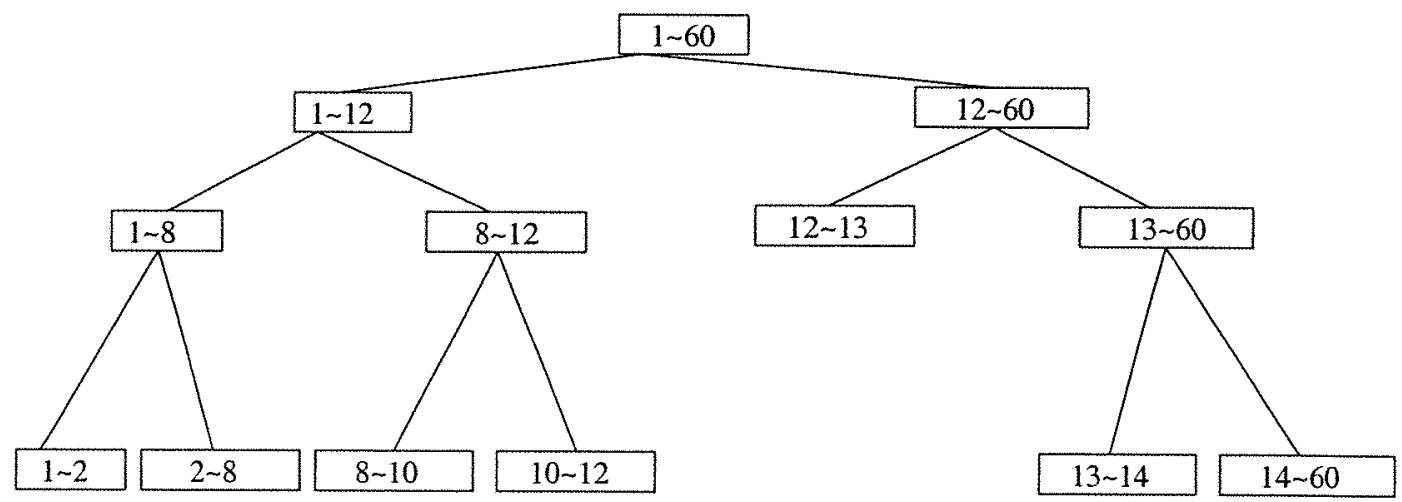

Figura 51: Hierarquia de conceitos para o atributo education _num 


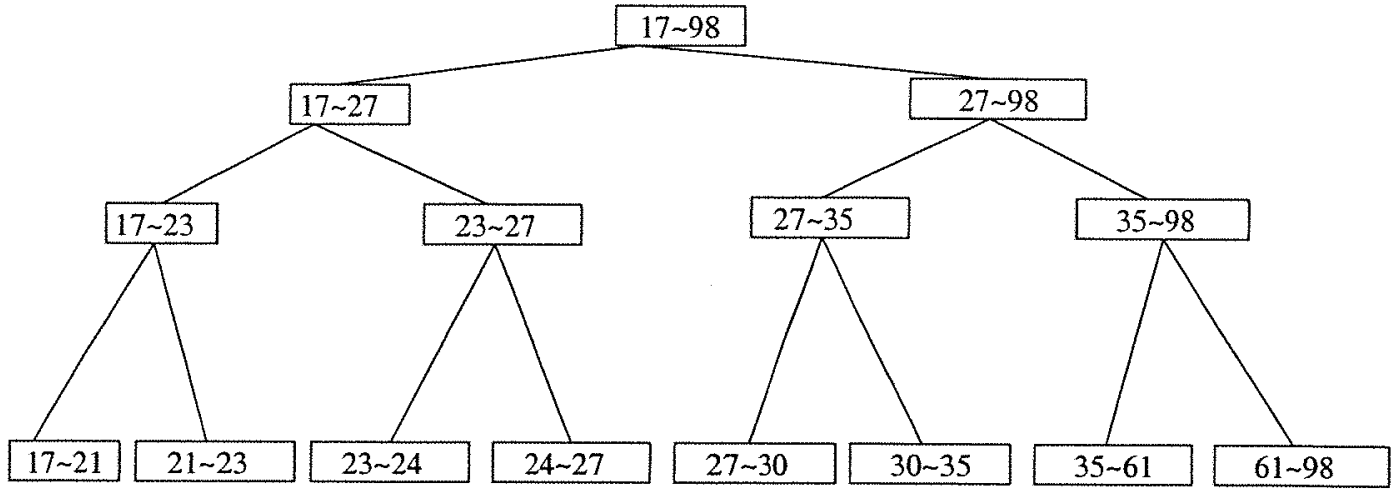

Figura 52: Hierarquia de conceitos para o atributo age

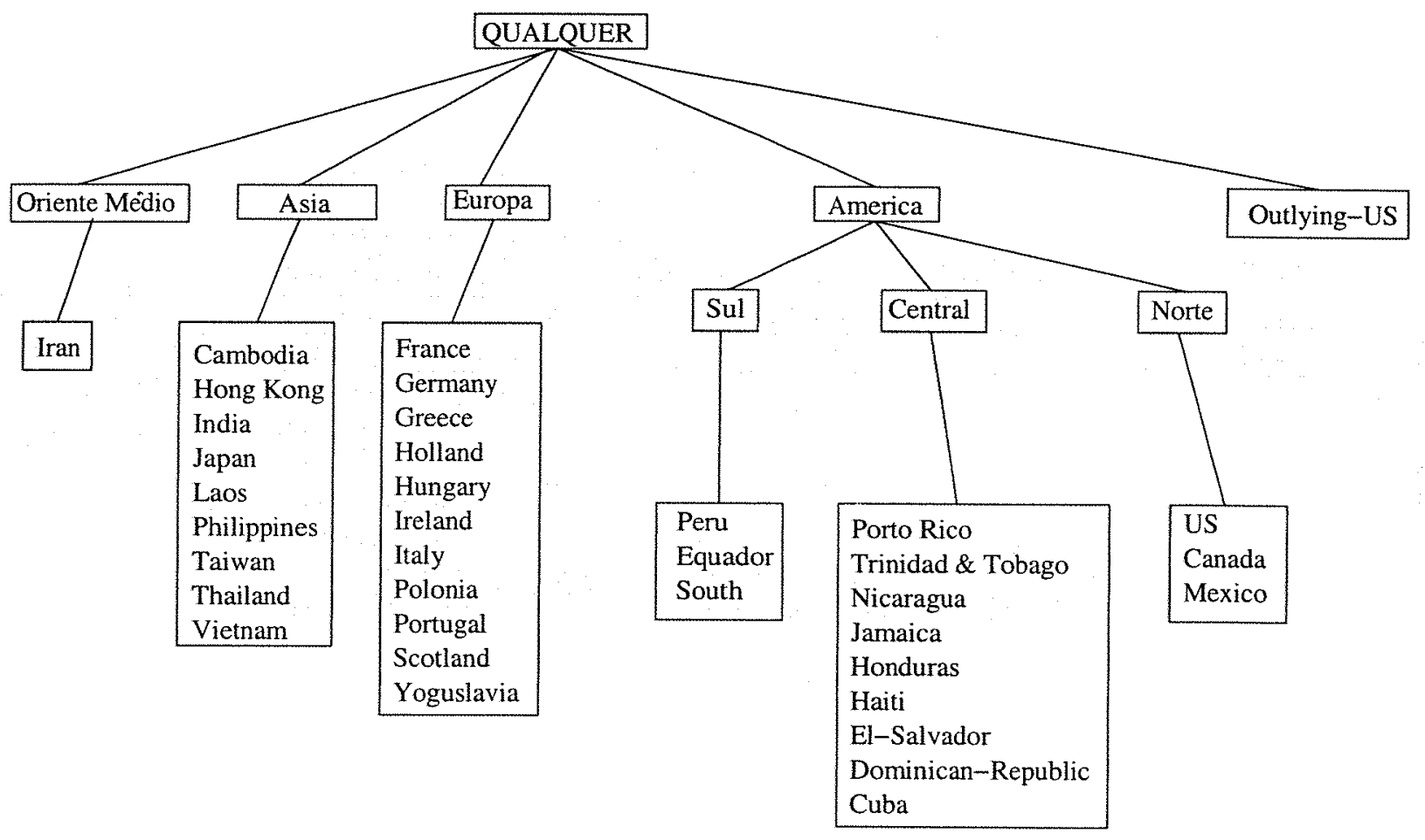

Figura 53: Hierarquia de conceitos para o atributo nationality

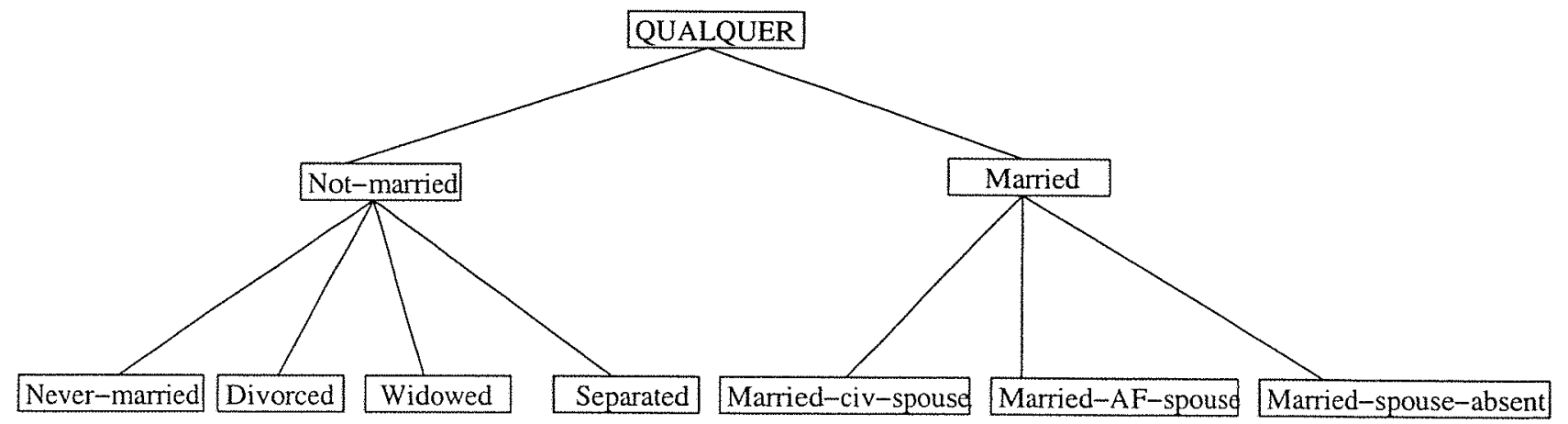

Figura 54: Hierarquia de conceitos para o atributo marital 


\section{Referências Bibliográficas}

AGRAWAL, R.; SRIKANT, R. Mining generalized association rules. In: Proceedings of 21st VLDB Conference. Zurique, Suíça.: [s.n.], 1995. p. 13.

AN, A.; CERCONE, N. ELEM2: A learning system for more accurate classifications. In: Proceedings of the 12th Biennial Conference of the Canadian Society for Computational Studies of Intelligence on Advances in Artificial Intelligence. [S.1.]: Springer-Verlag, 1998. p. 426-441. ISBN 3-540-64575-6.

ARONIS, J. M.; PROVOST, F. J. Increasing the efficiency of data mining algorithms with breadth-first marker propagation. In: Knowledge Discovery and Data Mining. [s.n.],1997. p. 119-122. Disponivel em: <citeseer.nj.nec.com/aronis97increasing.html>. Acesso em: 10 ago. 2003.

BLAKE, C.; MERZ, C. UCI Repository of machine learning databases. 1998. Disponível em: <http://www.ics.uci.edu/ mlearn/MLRepository.html>. Acesso em: 20 abr. 2003.

BRAMER, M. A. Automatic induction of classification rules from examples using'n-prism: Research and Development in Intelligent Systems XVI, p. 99-121, 2000.

CLARK, P.; BOSWELL, R. Rule induction with CN2: Some recent improvements. In: KODRATOFF, Y. (Ed.). Proceedings of the European Working Session on Learning : Machine Learning (EWSL-91). Porto, Portugal: Springer Verlag, 1991. (LNAI, v. 482), p. 151-163. ISBN 3-540-53816-X.

CLARK, P.; NIBLETT, T. The CN2 induction algorithm. Machine Learning, v. 3, p. 261-283, 1989. Disponível em: <citeseer.nj.nec.com/clark89cn.html>. Acesso em: 18 set. 2003.

FAYYAD, U. M.; PIATESKY-SHAPIRO, G.; SMYTH, P. From Data Mining to Knowledge Discovery in Databases: An Overview. Menlo Park, Califórnia, EUA: AAAI Press, 1996. (Advances in Knowledge Discovery in Databases).

FREITAS, A. A. Generic, Set-Oriented Primitives to Support Data-Parallel Knowledge Discover in Relational Database Systems. Tese (Doutorado) - University of Essex, Essex, Reino Unido, 1997.

FU, Y. Discovery of Multiple-Level Rules from Large Databases. Tese (Doutorado) - School of Computer Science of Simon Fraser University, Burnaby, B.C., Canadá., 1996. 
HAN, J. Mining knowledge at multiple concept levels. In: Proc. 4th Int'l Conf. on Information and Knowledge Management (CIKM'95). Baltimore, Maryland, EUA: [s.n.], 1995. p. 19-24.

HAN, J.; CAI, Y.; CERCONE, N. Knowledge discovery in databases: An attribute-oriented approach. In: Proceedings of the 18th VLDB Conference. Vancouver, British Columbia, Canadá: [s.n.], 1992.

HAN, J. et al. DBLearn: A system prototype for knowledge discovery in relational databases. In: Proceedings 1994 ACM-SIGMOD Conference Management of Data. Minneapolis, MN, EUA: [s.n.], 1994.

HAN, J. et al. DBMiner: A system for mining knowledge in large relational databases. In: SIMOUDIS, E.; HAN, J. W.; FAYYAD, U. (Ed.). Proceedings of the Second International Conference on Knowledge Discovery and Data Mining (KDD-96). [S.1.]: AAAI Press, 1996. p. 250.

HAN, J. et al. DMQL: A data mining query language for relational databases. In: SIGMOD'96 Workshop on Research Issues in Data Mining and Knowledge Discovery (DMKD'96). Montreal, Canada: [s.n.], 1996.

HASTIE, T.; TIBSHIRANI, R.; FRIEDMAN, J. The Elements of Statistical Learning. [S.1.]: Springer-Verlag, 2001.

HILDERMAN, R. J.; HAMILTON, H. J. Knowledge discovery and interestingness measures: A survey. Regina, Saskatchewan, Canadá, Outubro 1999. Disponível em: <citeseer.nj.nec.com/hilderman99knowledge.html>. Acesso em: 03 mai. 2003.

HOLMES, G.; NEVILL-MANNING, C. Feature selection via the discovery of simple classification rules. In: Proc. International Symposium on Intelligent Data Analysis (IDA-95), Baden-Baden, Alemanha: [s.n.], 1995.

HOLSHEIMER, M.; KERSTEN, M. L.; SIEBES, A. P. J. M. Data surveyor: the nuggets in parallel. American Association for Artificial Intelligence, p. 447-467, 1996.

ITALIANO, I. C.; FERREIRA, J. E.; TAKAI, O. K. Aspectos Conceituais em Datawarehouse. RT-MAC-2001-08 - Instituto de Matemática e Estatística, Universidade de São Paulo, São Paulo, SP, Brasil, setembro 2001.

KODRATOFF, Y. Comparing machine learning and knowledge discovery in databases: An application to knowledge discovery in texts. In: Artificial Intelligence. [S.1.]: Springer Verlag, 2001. p. $1-21$.

LU, Y. Concept Hierarchy in Data Mining: Specification, Generation and Implementation. Dissertação (Mestrado) - School of Computer Science of Simon Fraser University, Burnaby, B.C., Canadá., 1997. 
MALLEN, J.; BRAMER, M. Cupid - an iterative knowledge discovery framework. Portsmouth, Reino Unido, 1995. Disponível em: <citeseer.nj.nec.com/92623.html>. Acesso em: 15 out. 2003.

MICHALSKI, R. S. Machine Learning: An Artificial Intelligence Approach. Palo Alto, Califórnia, EUA: Tioga Publishing Company, 1983.

MICHALSKI, R. S. A Theory and Methodology of Inductive Learnin. San Mateo, California, EUA: Morgan Kaufmann, 1993. 323 - 348 p. (Readings in Knowledge Acquisition and Learning).

MICHALSKI, R. S.; KAUFMAN, K. A. Learning patterns in noisy data: The AQ approach. Lecture Notes in Computer Science, v. 2049, p. 22 - 30, 2001. Disponível em: <citeseer.nj.nec.com/michalski01learning.html>.

MICHALSKI, R. S.; KAUFMAN, K. A.; WNEK, J. The AQ family of learning programs: a review of recent developments and an exemplary application. [S.1.], dezembro 1991.

MITCHELL, T. M. Machine Learning. 1. ed. [S.1.]: McGraw-Hill, 1997.

MONARD, M. C. et al. Uma Introdução ao Aprendizado Simbólico de Máquina por Exemplos. outubro 1997. Notas Didáticas do ICMSC.

ONODA, M.; EBECKEN, N. F. Implementação em Java de um algoritmo de Árvore de decisão acoplada a um SGBD relacional. In: Anais do XVI SBBD - Simpósio Brasileiro de Banco de Dados. Rio de Janeiro, RJ, Brasil.: [s.n.], 2001. p. 55-64.

PROVOST, F.; ARONIS, J.; BUCHANAN, B. Rule-space search for knowledge-based discovery. 1999. CIIO Working Paper IS 99-012, Stern School of Business, New York University, NY, NY 10012. Disponível em: <citeseer.nj.nec.com/article/provost99rulespace.html>. Acesso em: 20 ago. 2003.

QUINLAN, J. R. C4.5: Programs for machine learning. 1. ed. [S.1.]: Morgan Kaufmann, 1993.

QUINLAN, J. R.; CAMERON-JONES, R. M. Oversearching and layered search in empirical learning. In: IJCAI. [s.n.], 1995. p. 1019-1024. Disponível em: <http://www.cse.unsw.edu.au/ quinlan/q+cj.ijcai95.ps>. Acesso em: 15 ago. 2003.

RUSSELL, S. J.; NORVIG, P. Artificial Intelligence: A Modern Approach. 2. ed. Englewood Cliffs, NJ. EUA: Prentice Hall, 2002.

TAYLOR, M. G. Finding High Level Discriminant Rules in Parallel. Tese (Doutorado) Faculty of the Graduate School of the University of Maryland, College Park, EUA, 1999.

WANG, M.; IYER, B. Efficient rol-up and drill-down analysis in relational databases. In: 1997 SIGMOD Workshop on Research Issues on Data Mining and Knowledge Discovery. [S.1.: s.n.], 1997. p. 39-43. 